\title{
Verbal Fluency Tests: Normative data for the Latin American Spanish speaking adult population
}

\author{
L. Olabarrieta-Landa ${ }^{\mathrm{a}}$, D. Rivera ${ }^{\mathrm{a}}$, J. Galarza-del-Angel ${ }^{\mathrm{b}}$, M.T. Garza ${ }^{\mathrm{c}}$, C.P. Saracho ${ }^{\mathrm{d}}$, W. Rodríguez ${ }^{\mathrm{e}}$,

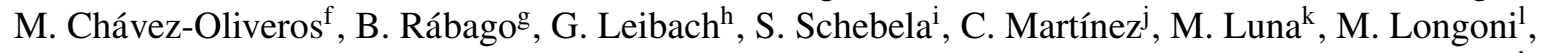

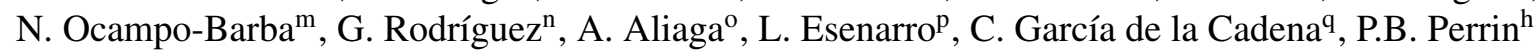 \\ and J.C. Arango-Lasprilla ${ }^{\mathrm{r}, \mathrm{a}, *}$ \\ ${ }^{\mathrm{a}}$ Faculty of Psychology and Education, University of Deusto, Bilbao, Spain \\ ${ }^{\mathrm{b}}$ Universidad Autónoma de Baja California, Mexicali, Mexico \\ ${ }^{\mathrm{c}}$ Facultad de Psicología Universidad Autónoma de Nuevo León, Monterrey, Mexico \\ ${ }^{\mathrm{d}}$ CETYS University, Mexicali, Mexico \\ ${ }^{\mathrm{e}}$ Ponce Health Sciences University, Ponce, Puerto Rico \\ ${ }^{\mathrm{f}}$ Instituto Nacional de Neurología y Neurocirugía MVS, Mexico City, Mexico \\ ${ }^{\mathrm{g}}$ Instituto Vocacional Enrique Díaz de León, Guadalajara, Mexico \\ ${ }^{\mathrm{h}}$ Department of Psychology, Virginia Commonwealth University, Richmond, VA, USA \\ i Instituto de Prevención Social, Asunción, Paraguay \\ ${ }^{\mathrm{j}}$ Departamento de Medicina de Rehabilitación, Universidad Nacional Autónoma de Honduras, \\ Tegucigalpa, Honduras \\ ${ }^{\mathrm{k}}$ Universidad Dr. José Matías Delgado, San Salvador, El Salvador \\ ${ }^{1}$ Clínica de rehabilitación Las Araucarias, Buenos Aires, Argentina \\ ${ }^{\mathrm{m}}$ Fundación Horizontes, Santa Cruz de la Sierra, Bolivia \\ ${ }^{\mathrm{n}}$ Departamento de Psicología, Universidad de Camagüey Ignacio Agramonte Loynaz, Camaguey, Cuba \\ ${ }^{\circ}$ Servicio Médico Legal, Ministerio de Justicia, Santiago, Chile \\ ${ }^{\mathrm{p}}$ Instituto de Neuropsicología y Demencias, Lima, Peru \\ ${ }^{\mathrm{q}}$ Departamento de Psicología, Universidad del Valle de Guatemala, Guatemala City, Guatemala \\ ${ }^{\mathrm{r}}$ IKERBASQUE, Basque Foundation for Science, Bilbao, Spain
}

\begin{abstract}
. adjustments for gender, age, and education, where appropriate.

*Address for correspondence: Juan Carlos Arango-Lasprilla, Ph.D., IKERBASQUE Research Professor, Department of Psychology, University of Deusto, IKERBASQUE, Basque Foundation for Science, Bilbao, Spain. Tel.: +34 804859 4329; E-mail: jcarango@deusto.es.
\end{abstract}

OBJECTIVE: To generate normative data for the Verbal Fluency Tests across 11 countries in Latin America, with country-specific

METHOD: The sample consisted of 3,977 healthy adults who were recruited from Argentina, Bolivia, Chile, Cuba, El Salvador, Guatemala, Honduras, Mexico, Paraguay, Peru, and, Puerto Rico. Each subject was administered the Verbal Fluency Test as part of a larger neuropsychological battery. A standardized five-step statistical procedure was used to generate the norms. 
RESULTS: The final multiple linear regression models for the letter F explained 8-30\% of the variance, 7-32\% for letter A, 8-32\% for the letter S, and 16-43\% for the animal category in Verbal Fluency Test scores. Although $t$-tests showed significant differences between men and women on the Verbal Fluency Test, they did not have an effect size larger than 0.3. As a result, gender-adjusted norms were not generated.

CONCLUSIONS: This is the first normative multicenter study conducted in Latin America aiming to create norms for the Verbal Fluency Test; this study will have important outcomes for the future of neuropsychology in the region.

Keywords: Normative data, semantic verbal fluency test, phonological verbal fluency test, Latin America, executive functions

\section{Introduction}

Verbal fluency tests are used to assess complex cognitive functioning, including executive dysfunction. They are most commonly administered to individuals who have experienced neurological damage, including traumatic brain injury (TBI), brain lesions, multiple sclerosis, schizophrenia, and Parkinson's disease (Henry \& Crawford, 2004a; Strauss, Sherman, \& Spreen, 2006). In healthy individuals, certain areas of the brain are activated when these tasks are attempted, including the left frontal cortex (associated with stimulation of Broca's area), the dorsolateral prefrontal cortex, the premotor cortex, and the right cerebellum (Cabeza \& Nyberg, 2000; Indefrey \& Levelt, 2000; McGraw, Mathews, Wang, \& Phillips, 2001).

Verbal fluency is defined as "the ability to form and express words in accordance with required criteria" and is essential for communication and functioning (Wysokiński et al., 2010, p. 438). Verbal fluency tasks require individuals to be flexible, organize information, provide effort, and exercise inhibition when necessary. An inability to complete these tasks is suggestive of frontal lobe dysfunction, specifically dysfunction in the left frontal cortex (Gouveia, Brucki, Malheiros, \& Bueno, 2007). In phonological fluency tasks, individuals are asked to produce words corresponding with a specific letter of the alphabet (e.g., F), while semantic fluency tasks involve producing words corresponding with a target category of items (e.g., animals; Henry $\&$ Crawford, 2004a). They are often examined concurrently, although some studies have focused solely on one component of verbal fluency (Strauss et al., 2006). Additionally, these tasks can be combined to assess phonological and semantic fluency simultaneously in one operation (e.g., fruit that being with A; Heller \& Dobbs, 1993).

In the phonological verbal fluency task, participants are presented with a letter and asked to produce as many words that begin with that letter as possible. Participants are typically given the letters F, A, and S, one at a time, and then have one minute per letter to complete the task (Strauss et al., 2006). The letters C, F, and L are also occasionally used for this task, and research has shown that these two clusters of letters produce comparable results (Troyer, 2000). In other languages, different combinations of letters are used to assess phonological fluency in more culturally-appropriate ways. For example, one Arabic study tested the use of $\mathrm{W}, \mathrm{R}$, and $\mathrm{G}$, and found that these letters are more appropriate for use within an Arabic population (Khalil, 2010). Similarly, a Greek study used X (Chi), $\Sigma$ (Sigma), and A (Alpha) because these letters followed the same ratios as F, A, and S in the English language and were more relevant to the Greek alphabet and overall culture (Kosmidis, Vlahou, Panagiotaki, $\&$ Kiosseoglou, 2004). The result is the number of words produced for each letter, and sometimes the total summed score of words produced across all phonological fluency tasks (Strauss et al., 2006; Wysokiński et al., 2010).

The semantic verbal fluency task requires participants to produce items that fall within a given category that is provided (e.g., animals), generally within one minute (Strauss et al., 2006). The most common category is "animals," although other studies have used fruits, occupations, items from a grocery store, and furniture (da Silva, Petersson, Faisca, Ingvar, \& Reis, 2005; Gocer March \& Pattison, 2006; Price et al., 2012; Troyer, 2000). The result is the number of words produced for each category, and sometimes the total summed score of words produced across all semantic fluency tasks (Strauss et al., 2006; Wysokiński et al., 2010).

Verbal fluency tests have been administered in a variety of populations, including to patients with various neurological disorders (Strauss et al., 2006). Phonological and semantic fluency have been assessed in individuals with schizophrenia (Costafreda et al., 2011; Henry \& Crawford, 2005), cognitive impairment 
(Price et al., 2012), TBI (Henry \& Crawford, 2004a; Raskin \& Rearick, 1996), brain lesions (Baldo \& Shimamura, 1998), Alzheimer's disease (Gocer March \& Pattison, 2006; Pasquier, Lebert, Grymonprez, \& Petit, 1995; Randolph, Braun, Goldberg, \& Chase, 1993; Ting, Hameed, Earnest, \& Tan, 2012), dementia (Moreno-Martinez \& Montoro, 2010; Pasquier et al., 1995), Parkinson's disease (Henry \& Crawford, 2004b; Randolph et al., 1993), Huntington's disease (Randolph et al., 1993; Weber, Koch, \& Reilmann, 2012), clinically isolated syndrome (Anhoque, Biccas-Neto, Domingues, Teixeira, \& Domingues, 2013; Till et al., 2013), and multiple sclerosis (Brissart et al., 2013; Till et al., 2013).

Previous studies have identified associations between demographic variables and verbal fluency, both phonological and semantic. Age is associated with phonological fluency, such that scores increase substantially between ages five and seven, continue to increase through early adulthood, and subsequently begin to decline in old age (Strauss et al., 2006). Semantic fluency abilities often level off around age 11 or 12 (Sauzeon, Lestage, Raboutet, N'Kaoua, \& Claverie, 2004) and decline around age 20 (Mitrushina, 2005). Education level is related to verbal fluency, such that those with more years of education tend to achieve higher scores on both tasks (Strauss et al., 2006). Moreover, reading level and phonological fluency are moderately correlated, while a smaller correlation has been found between reading level and scores on semantic fluency (Johnson-Selfridge \& Zalewski, 2001). Studies have shown differences in verbal fluency based on ethnicity, language, and geographic region. Specifically, Caucasians and nonHispanics tend to produce more words on phonological and semantic tasks than individuals from other ethnic groups (Strauss et al., 2006). Higher level of intelligence is also related to better phonological and semantic fluency (Diaz-Asper, Schretlen, \& Pearlson, 2004). Gender is another demographic variable that has been examined in the context of performance on phonological and semantic fluency tasks. Data on the impact of gender, however, are inconsistent. Gladsjo et al. (1999) conducted a review of reported verbal fluency norms and found that gender is inconsistently associated with phonological fluency and unrelated to semantic fluency.

To date, verbal fluency norms have been established for adults, specifically for the phonological and semantic tasks (Strauss et al., 2006). Metanorms and individual norms studies have been completed for the phonological verbal fluency task using the cluster of letters F, A, and S, most commonly with English speaking adults in the United States and Canada (Acevedo et al., 2000; Gladsjo et al., 1999; Heaton, 2004; Loonstra, Tarlow, \& Sellers, 2001; Mitrushina, 2005; Tombaugh, Kozak, \& Rees, 1999). Additionally, norms have been established in the United States for phonological fluency using the letters C, F, and L (Ruff, Light, Parker, \& Levin, 1996). Normative data are also available for elderly adults in these regions (Ivnik, Malec, Smith, Tangalos, \& Peterson, 1996; Ravdin, Katzen, Agrawal, \& Relkin, 2003; Steinberg, Bieliauskas, Smith, \& Ivnik, 2005; Stricks, Pittman, Jacobs, Sano, \& Stern, 1998). Stricks et al. (2008) collected normative data in Spanish from Spanish-speakers in the United States. Few norms studies on phonological fluency have been conducted in regions outside of the United States and Canada, including Sweden (Tallberg, Ivachova, Jones Tinghag, \& Österberg, 2008), Saudi Arabia (Khalil, 2010), and the Netherlands (Van der Elst, Van Boxtel, Van Breukelen, \& Jolles, 2006). Semantic fluency norms have also been established for animals, vegetables, fruits, foods, and clothing, primarily from the United States and Canada (Gladsjo et al., 1999; Lucas et al., 1998; Mitrushina, 2005; Tombaugh et al., 1999). Only a select few collected norms for Spanish-speaking individuals, none of which were established in Latin America (Acevedo et al., 2000; Lucas et al., 1998; Stricks et al., 1998).

Normative data are also available for verbal fluency for children and adolescents (Strauss et al., 2006), but they are less frequent. Several studies established norms for F, A, and S on the phonological verbal fluency task (Anderson, Anderson, Northam, Jacobs, \& Catroppa, 2001; Delis, Kaplan, \& Kramer, 2001). In addition, normative data are available for the following clusters of letters: C, F, L and P, R, W, as well as the sound, "sh" (Barr, 2003; Halperin, Healey, Zeitchik, Ludman, \& Weinstein, 1989; Schum, Sivan, \& Benton, 1989). Semantic fluency norms have also been established for children and adolescents (Halperin et al., 1989).

Trends in verbal fluency scores and demographic variables have been identified, as have normative data on the phonological and semantic components of verbal fluency (Strauss et al., 2006). Norms from Latin America, however, are non-existent, and as a result, there is a need to establish normative data on verbal fluency in Latin America given the paucity of research in this diverse region. 


\section{Method}

\subsection{Participants}

The sample consisted of 3,977 healthy individuals who were recruited from Argentina, Bolivia, Chile, Cuba, El Salvador, Guatemala, Honduras, Mexico, Paraguay, Peru, and, Puerto Rico. The participants were selected according to the following criteria: a) were between 18 to 95 years of age, b) were born and currently lived in the country where the protocol was conducted, c) spoke Spanish as their native language, d) had completed at least one year of formal education, e) were able to read and write at the time of evaluation, f) scored $\geq 23$ on the Mini-Mental State Examination (MMSE, Folstein, Folstein, \& McHugh, 1975), g) scored $\leq 4$ on the Patient Health Questionnaire-9 (PHQ-9, Kroenke, Spitzer, \& Williams, 2001), and h) scored $\geq 90$ on the Barthel Index (Mahoney \& Barthel, 1965).

Participants with self-reported neurologic or psychiatric disorders were excluded due to a potential effect on cognitive performance. Participants were volunteers from the community and signed an informed consent. Nine participants were excluded from the analyses, with a final sample of 3,961 participants. Socio-demographic and participant characteristics for each of the countries' samples have been reported in Guàrdia-Olmos, Peró-Cebollero, Rivera \& ArangoLasprilla (2015). The multi-center study was approved by the Ethics Committee of the coordinating site, the University of Deusto, Spain.

\subsection{Instrument administration}

For the present study, phonological and semantic verbal fluency tests were applied. The aim of each test is to create, within 60 seconds, as many words as participants can that begin with certain letter $(\mathrm{F}, \mathrm{A}, \mathrm{S})$ or that belong to a particular category (animals). Participants were told to avoid proper names, augmentatives, and diminutives. At the same time, the examiner provided prompts if the participant gave no responses within 10 seconds during each trial. The total score consisted of the total correct answers for each letter or category.

\subsection{Statistical analyses}

The detailed statistical analyses used to generate the normative data for this test are described in GuàrdiaOlmos et al. (2015). In summary, the data manipulation process for each country-specific dataset involved fivesteps: a) $t$ - tests for independent samples and effect sizes $(r)$ were conducted to determine gender effects. If the effect size was larger than 0.3 , gender was included in the model with gender dummy coded and female as the reference group (male $=1$ and female $=0$ ). b) A multivariable regression model was used to specify the predictive model including gender (if effect size was larger than 0.3 ), age as a continuous variable, and education as a dummy coded variable with 1 if the participants had $>12$ years of education and 0 if participants had 1-12 years of education. If gender, age and/or education were not statistically significant in this multivariate model with an alpha of 0.05 , the non-significant variables were removed and the model was re-run. Then a final regression model was conducted that included age (if statistically significant in the multivariate model), dichotomized education (if statistically significant in the multivariate model), and/or gender (if effect size was greater than 0.3) $\left[\hat{y}_{i}=\beta_{0}+\left(\beta_{\text {Age }} . A g e_{i}\right)+\left(\beta_{E d u c} . E d u c_{i}\right)+\right.$ $\left(\beta_{\text {Gender }}\right.$. Gender $\left.\left.r_{i}\right)\right]$; c) residual scores were calculated based on this final model $\left(e_{i}=y_{i}-\hat{y}_{i}\right)$; d) using the SD (residual) value provided by the regression model, residuals were standardized: $z=e_{i} / S D_{e}$, with $S D_{e}($ residual $)=$ the standard deviation of the residuals in the normative sample; and e) standardized residuals were converted to percentile values (Strauss et al., 2006). Using each country's dataset, these steps were applied to phonological and semantic verbal fluency scores.

\section{Results}

\subsection{Phonological fluency - letter $F$}

Regarding the effect of gender on letter $\mathrm{F}$, the $t$ tests showed significant differences between men and women from Guatemala, however, its effect size was less than 0.3. Table 1 shows the results of the gender analyses by country on letter F. As shown in Table 1, the effect sizes for all countries were less than 0.3 , and therefore gender was not taken into account to generate letter $\mathrm{F}$ normative data for any of the countries in the study.

The final eleven letter $F$ multivariate linear regression models for each country are shown in Table 2 . In all countries, the letter F score increased for those with more than 12 years of education (see Table 2) and, in all countries except Argentina, Guatemala, Honduras, and, Paraguay, letter F score decreased in a linear fashion as 
Table 1

Effect of gender in the Letter $\mathrm{F}$

\begin{tabular}{|c|c|c|c|c|c|c|}
\hline Country & Gender & Mean (SD) & $t$ & $\mathrm{df}$ & Sig. (2-tailed) & $r$ \\
\hline \multirow[t]{2}{*}{ Argentina } & Male & $13.9(4.5)$ & -0.44 & 318 & 0.659 & 0.025 \\
\hline & Female & $14.1(4.6)$ & & & & \\
\hline \multirow[t]{2}{*}{ Bolivia } & Male & $8.7(3.4)$ & 0.81 & 271 & 0.421 & 0.049 \\
\hline & Female & $8.4(3.7)$ & & & & \\
\hline \multirow{2}{*}{ Chile } & Male & $10.6(4.5)$ & 1.13 & 318 & 0.258 & 0.063 \\
\hline & Female & $10.0(4.3)$ & & & & \\
\hline \multirow{2}{*}{ Cuba } & Male & $10.3(4.0)$ & 0.50 & 303 & 0.618 & 0.029 \\
\hline & Female & $10.1(3.8)$ & & & & \\
\hline \multirow[t]{2}{*}{ El Salvador } & Male & $10.0(4.7)$ & 0.66 & 254 & 0.508 & 0.042 \\
\hline & Female & $9.6(5.0)$ & & & & \\
\hline \multirow[t]{2}{*}{ Guatemala } & Male & $10.5(5.0)$ & -2.22 & 211 & $0.027^{*}$ & 0.151 \\
\hline & Female & $12.1(5.3)$ & & & & \\
\hline \multirow[t]{2}{*}{ Honduras } & Male & $10.2(4.7)$ & 1.95 & 181 & 0.053 & 0.143 \\
\hline & Female & $8.8(4.3)$ & & & & \\
\hline \multirow[t]{2}{*}{ Mexico } & Male & $11.8(4.6)$ & -0.20 & 1,297 & 0.839 & 0.006 \\
\hline & Female & $11.8(4.5)$ & & & & \\
\hline \multirow[t]{2}{*}{ Paraguay } & Male & $10.4(2.0)$ & 0.18 & 261 & 0.854 & 0.011 \\
\hline & Female & $10.4(1.7)$ & & & & \\
\hline \multirow[t]{2}{*}{ Peru } & Male & $13.2(4.0)$ & -0.30 & 243 & 0.766 & 0.019 \\
\hline & Female & $13.4(4.6)$ & & & & \\
\hline \multirow{2}{*}{ Puerto Rico } & Male & $10.3(4.0)$ & -0.67 & 289 & 0.504 & 0.039 \\
\hline & Female & $10.6(4.0)$ & & & & \\
\hline
\end{tabular}

${ }^{*} p<0.05$.

Table 2

Final multiple linear regression models for Letter $\mathrm{F}$

\begin{tabular}{|c|c|c|c|c|c|c|c|}
\hline Country & & $\mathrm{B}$ & Std. Error & $t$ & Sig. & $\mathrm{R}^{2}$ & $S D_{e}($ residual $)$ \\
\hline \multirow[t]{2}{*}{ Argentina } & (Constant) & 12.020 & 0.341 & 35.273 & $<0.001$ & 0.171 & 4.139 \\
\hline & Education & 3.770 & 0.465 & 8.112 & $<0.001$ & & \\
\hline \multirow{3}{*}{ Bolivia } & (Constant) & 10.600 & 0.564 & 18.792 & $<0.001$ & 0.179 & 3.248 \\
\hline & Age & -0.046 & 0.009 & -5.038 & $<0.001$ & & \\
\hline & Education & 2.630 & 0.524 & 5.024 & $<0.001$ & & \\
\hline \multirow[t]{3}{*}{ Chile } & (Constant) & 12.793 & 0.685 & 18.686 & $<0.001$ & 0.298 & 3.675 \\
\hline & Age & -0.064 & 0.011 & -5.791 & $<0.001$ & & \\
\hline & Education & 3.968 & 0.500 & 7.942 & $<0.001$ & & \\
\hline \multirow[t]{3}{*}{ Cuba } & (Constant) & 11.827 & 0.634 & 18.661 & $<0.001$ & 0.079 & 3.728 \\
\hline & Age & -0.039 & 0.011 & -3.581 & $<0.001$ & & \\
\hline & Education & 1.702 & 0.505 & 3.366 & $<0.001$ & & \\
\hline \multirow[t]{3}{*}{ El Salvador } & (Constant) & 11.026 & 0.805 & 13.693 & $<0.001$ & 0.229 & 4.321 \\
\hline & Age & -0.042 & 0.013 & -3.184 & 0.002 & & \\
\hline & Education & 5.218 & 0.666 & 7.832 & $<0.001$ & & \\
\hline \multirow[t]{2}{*}{ Guatemala } & (Constant) & 9.750 & 0.416 & 23.451 & $<0.001$ & 0.163 & 4.765 \\
\hline & Education & 4.324 & 0.674 & 6.414 & $<0.001$ & & \\
\hline \multirow[t]{2}{*}{ Honduras } & (Constant) & 8.605 & 0.332 & 24.311 & $<0.001$ & 0.245 & 3.900 \\
\hline & Education & 5.185 & 0.677 & 7.664 & $<0.001$ & & \\
\hline \multirow[t]{3}{*}{ Mexico } & (Constant) & 14.245 & 0.339 & 41.970 & $<0.001$ & 0.149 & 4.195 \\
\hline & Age & -0.058 & 0.006 & -10.075 & $<0.001$ & & \\
\hline & Education & 2.654 & 0.282 & 9.418 & $<0.001$ & & \\
\hline \multirow[t]{2}{*}{ Paraguay } & (Constant) & 9.986 & 0.109 & 91.277 & $<0.001$ & 0.234 & 1.605 \\
\hline & Education & 2.105 & 0.259 & 8.933 & $<0.001$ & & \\
\hline \multirow[t]{3}{*}{ Peru } & (Constant) & 12.195 & 0.742 & 16.437 & $<0.001$ & 0.205 & 3.939 \\
\hline & Age & -0.029 & 0.013 & -2.322 & 0.021 & & \\
\hline & Education & 3.757 & 0.538 & 6.989 & $<0.001$ & & \\
\hline \multirow[t]{3}{*}{ Puerto Rico } & (Constant) & 11.094 & 0.748 & 14.826 & $<0.001$ & 0.121 & 3.739 \\
\hline & Age & -0.032 & 0.012 & -2.545 & 0.011 & & \\
\hline & Education & 2.230 & 0.458 & 4.870 & $<0.001$ & & \\
\hline
\end{tabular}


Table 3

Effect of gender in the Letter A

\begin{tabular}{|c|c|c|c|c|c|c|}
\hline Country & Gender & Mean (SD) & $t$ & $\mathrm{df}$ & Sig. (2-tailed) & $r$ \\
\hline \multirow[t]{2}{*}{ Argentina $^{\mathrm{a}}$} & Male & $13.5(3.8)$ & -0.35 & 202.3 & 0.725 & 0.025 \\
\hline & Female & $13.7(4.3)$ & & & & \\
\hline \multirow{2}{*}{ Bolivia } & Male & $8.4(3.9)$ & -0.23 & 271 & 0.818 & 0.014 \\
\hline & Female & $8.5(3.9)$ & & & & \\
\hline \multirow[t]{2}{*}{ Chile $^{\mathrm{a}}$} & Male & $10.6(4.9)$ & 2.01 & 258.4 & $0.046^{*}$ & 0.124 \\
\hline & Female & $9.5(4.2)$ & & & & \\
\hline \multirow[t]{2}{*}{ Cuba } & Male & $9.6(3.6)$ & -1.11 & 303 & 0.270 & 0.063 \\
\hline & Female & $10.1(3.9)$ & & & & \\
\hline \multirow[t]{2}{*}{ El Salvador } & Male & $9.4(5.1)$ & -0.67 & 254 & 0.506 & 0.042 \\
\hline & Female & $9.8(5.1)$ & & & & \\
\hline \multirow[t]{2}{*}{ Guatemala } & Male & $10.6(5.0)$ & -2.71 & 211 & $0.007^{* *}$ & 0.184 \\
\hline & Female & $12.5(5.5)$ & & & & \\
\hline \multirow[t]{2}{*}{ Honduras } & Male & $10.0(5.2)$ & 1.49 & 181 & 0.139 & 0.110 \\
\hline & Female & $8.9(4.4)$ & & & & \\
\hline \multirow[t]{2}{*}{ Mexico } & Male & $11.7(4.7)$ & 1.29 & 1,297 & 0.198 & 0.036 \\
\hline & Female & $11.3(4.7)$ & & & & \\
\hline \multirow[t]{2}{*}{ Paraguay } & Male & $10.7(2.1)$ & -2.05 & 261 & $0.041^{*}$ & 0.126 \\
\hline & Female & $11.2(1.7)$ & & & & \\
\hline \multirow[t]{2}{*}{ Peru } & Male & $13.1(4.0)$ & -0.90 & 243 & 0.366 & 0.058 \\
\hline & Female & $13.6(4.4)$ & & & & \\
\hline \multirow[t]{2}{*}{ Puerto Rico } & Male & $10.9(3.8)$ & -1.30 & 289 & 0.195 & 0.076 \\
\hline & Female & $11.5(4.1)$ & & & & \\
\hline
\end{tabular}

${ }^{a}$ Value of the $t$-test for independent groups from the different variances with the corresponding correction of Yuen-Welch of degrees of freedom. ${ }^{*} p<0.05,{ }^{* *} p<0.01,{ }^{* * *} p<0.001$.

a function of age. The amount of variance explained in letter $\mathrm{F}$ scores ranged from $8 \%$ (in Cuba) to $30 \%$ (in Chile).

\subsection{Phonological fluency - letter A}

Regarding the effect of gender on letter A, the $t$-tests showed significant differences between men and women in the countries of Chile, Guatemala, and, Paraguay, however, none of these three countries had an effect size larger than 0.3. Table 3 shows the results of the gender analysis by country on letter A. As shown in Table 1, the effect sizes for all countries were less than 0.3 , and therefore gender was not taken into account to generate letter A normative data for any of the countries in the study.

The final eleven letter A multivariate linear regression models for each country are shown in Table 4 . In all countries, the letter A score increased for those with more than 12 years of education (see Table 4) and decreased in a linear fashion as a function of age except in Argentina, Guatemala and, Paraguay. The amount of variance explained in letter A scores ranged from 7\% (in Paraguay) to $32 \%$ (in Chile).

\subsection{Phonological fluency - letter S}

Regarding the effect of gender on letter S, the $t$-tests showed significant differences between men and women from Puerto Rico, however, its effect size was less than 0.3. Table 5 shows the results of the gender analysis by country on letter S. As shown in Table 5, the effect sizes for all countries were less than 0.3 , and therefore gender was not taken into account to generate letter $\mathrm{S}$ normative data for any of the countries in the study.

The final eleven letter $\mathrm{S}$ multivariate linear regression models for each country are shown in Table 6 . In all countries, the letter $\mathrm{S}$ score increased for those with more than 12 years of education (see Table 6) and decreased in linear fashion as a function of age except in Argentina, Guatemala and, Paraguay. The amount of variance explained in letter $\mathrm{S}$ scores ranged from $8 \%$ (in Cuba) to $32 \%$ (in Chile).

\subsection{Semantic fluency - animals}

Regarding the effect of gender on animals, the $t$-tests showed significant differences between men and women in Guatemala, however, its effect size was less than 0.3. Table 7 shows the results of the gender analysis by country on animals. As shown in Table 7, the effect sizes for all countries were less than 0.3 , and therefore gender was not taken into account to generate animals normative data for any of the countries in the study.

The final eleven animals multivariate linear regression models for each country are shown in Table 8 . 
Table 4

Final multiple linear regression models for Letter A

\begin{tabular}{|c|c|c|c|c|c|c|c|}
\hline Country & & $\mathrm{B}$ & Std. Error & $t$ & Sig. & $\mathrm{R}^{2}$ & $S D_{e}$ (residual) \\
\hline \multirow[t]{2}{*}{ Argentina } & (Constant) & 11.696 & 0.308 & 37.953 & $<0.001$ & 0.186 & 3.743 \\
\hline & Education & 3.577 & 0.420 & 8.511 & $<0.001$ & & \\
\hline \multirow{3}{*}{ Bolivia } & (Constant) & 10.651 & 0.598 & 17.823 & $<0.001$ & 0.221 & 3.441 \\
\hline & Age & -0.050 & 0.010 & -5.242 & $<0.001$ & & \\
\hline & Education & 3.435 & 0.555 & 6.193 & $<0.001$ & & \\
\hline \multirow[t]{3}{*}{ Chile } & (Constant) & 13.558 & 0.695 & 19.502 & $<0.001$ & 0.316 & 3.732 \\
\hline & Age & -0.082 & 0.011 & -7.309 & $<0.001$ & & \\
\hline & Education & 3.608 & 0.507 & 7.111 & $<0.001$ & & \\
\hline \multirow[t]{3}{*}{ Cuba } & (Constant) & 11.480 & 0.596 & 19.277 & $<0.001$ & 0.143 & 3.503 \\
\hline & Age & -0.042 & 0.010 & -4.102 & $<0.001$ & & \\
\hline & Education & 2.616 & 0.475 & 5.507 & $<0.001$ & & \\
\hline \multirow{3}{*}{ El Salvador } & (Constant) & 10.776 & 0.815 & 13.227 & $<0.001$ & 0.267 & 4.372 \\
\hline & Age & -0.042 & 0.013 & -3.163 & 0.002 & & \\
\hline & Education & 5.942 & 0.674 & 8.816 & $<0.001$ & & \\
\hline \multirow[t]{2}{*}{ Guatemala } & (Constant) & 9.871 & 0.423 & 23.357 & $<0.001$ & 0.182 & 4.844 \\
\hline & Education & 4.697 & 0.685 & 6.853 & $<0.001$ & & \\
\hline \multirow{3}{*}{ Honduras } & (Constant) & 10.433 & 0.934 & 11.173 & $<0.001$ & 0.222 & 4.167 \\
\hline & Age & -0.045 & 0.017 & -2.643 & 0.009 & & \\
\hline & Education & 4.405 & 0.742 & 5.936 & $<0.001$ & & \\
\hline \multirow[t]{3}{*}{ Mexico } & (Constant) & 14.324 & 0.342 & 41.871 & $<0.001$ & 0.193 & 4.228 \\
\hline & Age & -0.068 & 0.006 & -11.748 & $<0.001$ & & \\
\hline & Education & 3.127 & 0.284 & 11.011 & $<0.001$ & & \\
\hline \multirow[t]{2}{*}{ Paraguay } & (Constant) & 10.810 & 0.122 & 88.656 & $<0.001$ & 0.066 & 1.786 \\
\hline & Education & 1.211 & 0.288 & 4.199 & $<0.001$ & & \\
\hline \multirow[t]{3}{*}{ Peru } & (Constant) & 13.191 & 0.745 & 17.700 & $<0.001$ & 0.152 & 3.957 \\
\hline & Age & -0.036 & 0.013 & -2.869 & 0.004 & & \\
\hline & Education & 2.849 & 0.540 & 5.277 & $<0.001$ & & \\
\hline \multirow[t]{3}{*}{ Puerto Rico } & (Constant) & 13.201 & 0.745 & 17.723 & $<0.001$ & 0.139 & 3.722 \\
\hline & Age & -0.054 & 0.012 & -4.363 & $<0.001$ & & \\
\hline & Education & 1.770 & 0.456 & 3.883 & $<0.001$ & & \\
\hline
\end{tabular}

Table 5

Effect of gender in the Letter $\mathrm{S}$

\begin{tabular}{|c|c|c|c|c|c|c|}
\hline Country & Gender & Mean (SD) & $t$ & df & Sig. (2-tailed) & $r$ \\
\hline \multirow[t]{2}{*}{ Argentina $^{a}$} & Male & $13.4(3.7)$ & -0.81 & 209.8 & 0.419 & 0.056 \\
\hline & Female & $13.8(4.3)$ & & & & \\
\hline \multirow[t]{2}{*}{ Bolivia } & Male & $7.3(3.6)$ & -0.64 & 271 & 0.525 & 0.039 \\
\hline & Female & $7.6(3.9)$ & & & & \\
\hline \multirow[t]{2}{*}{ Chile } & Male & $9.9(4.4)$ & 1.33 & 318 & 0.184 & 0.074 \\
\hline & Female & $9.3(4.2)$ & & & & \\
\hline \multirow[t]{2}{*}{ Cuba } & Male & $9.3(3.7)$ & -1.01 & 303 & 0.315 & 0.058 \\
\hline & Female & 9.7 (3.6) & & & & \\
\hline \multirow[t]{2}{*}{ El Salvador } & Male & $8.9(5.1)$ & 0.48 & 254 & 0.633 & 0.030 \\
\hline & Female & $8.6(4.6)$ & & & & \\
\hline \multirow[t]{2}{*}{ Guatemala } & Male & $10.6(5.2)$ & -1.89 & 211 & 0.060 & 0.129 \\
\hline & Female & $12.0(5.4)$ & & & & \\
\hline \multirow[t]{2}{*}{ Honduras } & Male & $8.7(4.3)$ & 0.77 & 181 & 0.439 & 0.057 \\
\hline & Female & $8.2(4.4)$ & & & & \\
\hline \multirow[t]{2}{*}{ Mexico } & Male & $11.3(4.3)$ & 1.43 & 1,297 & 0.152 & 0.040 \\
\hline & Female & $10.9(4.4)$ & & & & \\
\hline \multirow[t]{2}{*}{ Paraguaya $^{\mathrm{a}}$} & Male & $10.0(2.6)$ & -0.74 & 167.0 & 0.461 & 0.057 \\
\hline & Female & $10.3(1.9)$ & & & & \\
\hline \multirow[t]{2}{*}{ Peru } & Male & $12.4(4.2)$ & -0.61 & 243 & 0.539 & 0.039 \\
\hline & Female & $12.8(4.5)$ & & & & \\
\hline \multirow[t]{2}{*}{ Puerto Rico } & Male & $10.4(4.1)$ & -2.13 & 289 & $0.034^{*}$ & 0.124 \\
\hline & Female & $11.5(4.4)$ & & & & \\
\hline
\end{tabular}

${ }^{a}$ Value of the $t$-test for independent groups from the different variances with the corresponding correction of Yuen-Welch of degrees of freedom. ${ }^{*} p<0.05,{ }^{* *} p<0.01$. 
Table 6

Final multiple linear regression models for Letter $\mathrm{S}$

\begin{tabular}{|c|c|c|c|c|c|c|c|}
\hline Country & & $\mathrm{B}$ & Std. Error & $t$ & Sig. & $\mathrm{R}^{2}$ & $S D_{e}$ (residual) \\
\hline \multirow[t]{2}{*}{ Argentina } & (Constant) & 12.068 & 0.318 & 37.960 & $<0.001$ & 0.128 & 3.860 \\
\hline & Education & 2.950 & 0.434 & 6.803 & $<0.001$ & & \\
\hline \multirow{3}{*}{ Bolivia } & (Constant) & 9.453 & 0.591 & 15.986 & $<0.001$ & 0.210 & 3.405 \\
\hline & Age & -0.046 & 0.010 & -4.854 & $<0.001$ & & \\
\hline & Education & 3.404 & 0.549 & 6.202 & $<0.001$ & & \\
\hline \multirow[t]{3}{*}{ Chile } & (Constant) & 13.110 & 0.661 & 19.842 & $<0.001$ & 0.320 & 3.547 \\
\hline & Age & -0.080 & 0.011 & -7.502 & $<0.001$ & & \\
\hline & Education & 3.384 & 0.482 & 7.018 & $<0.001$ & & \\
\hline \multirow[t]{3}{*}{ Cuba } & (Constant) & 10.705 & 0.595 & 18.001 & $<0.001$ & 0.081 & 3.498 \\
\hline & Age & -0.031 & 0.010 & -3.077 & 0.002 & & \\
\hline & Education & 1.872 & 0.474 & 3.947 & $<0.001$ & & \\
\hline \multirow[t]{3}{*}{ El Salvador } & (Constant) & 9.724 & 0.758 & 12.836 & $<0.001$ & 0.289 & 4.066 \\
\hline & Age & -0.040 & 0.012 & -3.201 & 0.002 & & \\
\hline & Education & 5.881 & 0.627 & 9.382 & $<0.001$ & & \\
\hline \multirow[t]{2}{*}{ Guatemala } & (Constant) & 9.394 & 0.411 & 22.840 & $<0.001$ & 0.219 & 4.714 \\
\hline & Education & 5.137 & 0.667 & 7.702 & $<0.001$ & & \\
\hline \multirow[t]{3}{*}{ Honduras } & (Constant) & 9.020 & 0.881 & 10.240 & $<0.001$ & 0.183 & 3.931 \\
\hline & Age & -0.033 & 0.016 & -2.038 & 0.043 & & \\
\hline & Education & 3.811 & 0.700 & 5.445 & $<0.001$ & & \\
\hline \multirow[t]{3}{*}{ Mexico } & (Constant) & 13.229 & 0.327 & 40.516 & $<0.001$ & 0.144 & 4.035 \\
\hline & Age & -0.053 & 0.006 & -9.574 & $<0.001$ & & \\
\hline & Education & 2.589 & 0.271 & 9.550 & $<0.001$ & & \\
\hline \multirow[t]{2}{*}{ Paraguay } & (Constant) & 9.722 & 0.134 & 72.295 & $<0.001$ & 0.213 & 1.961 \\
\hline & Education & 2.597 & 0.318 & 8.163 & $<0.001$ & & \\
\hline \multirow[t]{3}{*}{ Peru } & (Constant) & 11.256 & 0.731 & 15.397 & $<0.001$ & 0.223 & 3.881 \\
\hline & Age & -0.026 & 0.012 & -2.132 & 0.034 & & \\
\hline & Education & 3.983 & 0.530 & 7.519 & $<0.001$ & & \\
\hline \multirow[t]{3}{*}{ Puerto Rico } & (Constant) & 13.170 & 0.811 & 16.245 & $<0.001$ & 0.111 & 4.051 \\
\hline & Age & -0.056 & 0.013 & -4.154 & $<0.001$ & & \\
\hline & Education & 1.529 & 0.496 & 3.083 & 0.002 & & \\
\hline
\end{tabular}

Table 7

Effect of gender in the Animal category

\begin{tabular}{|c|c|c|c|c|c|c|}
\hline Country & Gender & Mean (SD) & $t$ & $\mathrm{df}$ & Sig. (2-tailed) & $r$ \\
\hline \multirow[t]{2}{*}{ Argentina } & Male & $19.2(4.2)$ & -0.88 & 318 & 0.378 & 0.049 \\
\hline & Female & $19.8(5.0)$ & & & & \\
\hline \multirow[t]{2}{*}{ Bolivia } & Male & $13.2(5.3)$ & 0.02 & 272 & 0.987 & 0.001 \\
\hline & Female & $13.2(5.5)$ & & & & \\
\hline \multirow[t]{2}{*}{ Chile $^{\mathrm{a}}$} & Male & $16.0(5.8)$ & 1.91 & 265.1 & 0.057 & 0.117 \\
\hline & Female & $14.8(5.2)$ & & & & \\
\hline \multirow{2}{*}{ Cuba } & Male & $15.2(4.6)$ & 1.52 & 303 & 0.130 & 0.087 \\
\hline & Female & $14.5(4.1)$ & & & & \\
\hline \multirow[t]{2}{*}{ El Salvador } & Male & $13.9(5.6)$ & 0.58 & 254 & 0.562 & 0.036 \\
\hline & Female & $13.4(5.6)$ & & & & \\
\hline \multirow[t]{2}{*}{ Guatemala } & Male & $17.8(5.8)$ & -2.16 & 212 & $0.032^{*}$ & 0.147 \\
\hline & Female & $19.5(5.3)$ & & & & \\
\hline \multirow[t]{2}{*}{ Honduras } & Male & $16.5(5.1)$ & 1.84 & 182 & 0.067 & 0.135 \\
\hline & Female & $15.1(5.0)$ & & & & \\
\hline \multirow[t]{2}{*}{ Mexico } & Male & $17.7(5.4)$ & 1.21 & 1,298 & 0.225 & 0.034 \\
\hline & Female & $17.3(5.0)$ & & & & \\
\hline \multirow[t]{2}{*}{ Paraguay } & Male & $12.5(3.7)$ & 1.32 & 261 & 0.187 & 0.082 \\
\hline & Female & $11.9(3.3)$ & & & & \\
\hline \multirow[t]{2}{*}{ Peru } & Male & $19.0(5.0)$ & -0.01 & 243 & 0.989 & 0.001 \\
\hline & Female & $19.0(5.3)$ & & & & \\
\hline \multirow[t]{2}{*}{ Puerto Rico } & Male & $15.6(5.4)$ & -1.33 & 288 & 0.185 & 0.078 \\
\hline & Female & $16.4(5.0)$ & & & & \\
\hline
\end{tabular}

${ }^{a}$ Value of the $t$-test for independent groups from the different variances with the corresponding correction of Yuen-Welch of degrees of freedom. ${ }^{*} p<0.05$. 
In all countries, the animals score increased for those with more than 12 years of education (see Table 8) and decreased in a linear fashion as a function of age. The amount of variance explained in animals scores ranged from $16 \%$ (in Cuba) to $43 \%$ (in Paraguay).

\subsection{Normative procedure}

Norms (e.g., a percentile score) for the verbal fluency different scores were established using the five-step procedure described above. To facilitate the understanding of the procedure to obtain the percentile associated with a score on this test, an example will be given. Suppose you need to find the percentile score for a Mexican woman, who is 50 years old and has 8 years of education. She has a score of 20 on animals. The steps to obtain the percentile for this score are: a) Check Table 7 to determine if the effect size of gender in the country of interest (Mexico) on this test and time point (animals) is greater than 0.3 by country. The column labelled $r$ in Table 7 indicates the effect size. In this example, the effect size is 0.034 , which is not greater than 0.3 . For Mexicans on this test, does not influence scores to a sufficient degree to take it into account when determining the percentile. b) Find Mexico in Table 8, which provides the final regression models by country for animals. Use the B weights to create an equation that will allow you to obtain the predicted animals score. The corresponding B weights are multiplied by the actual age and dichotomized education scores and added to a constant in order to calculate the predicted value. In this case, the predicted animals score would be calculated using the equation $\left[\hat{y}_{i}=21.551+\left(-0.087 \cdot\right.\right.$ Age $\left._{i}\right)+$ (2.043 - Dichotomized Educational Level $\left.{ }_{i}\right)$ ] (the values have been rounded for presentation in the formula). The subscript notation $i$ indicate the person of interest. The person's age is 50 , but the education variable is not continuous in the model. Years of education is split into either 1 to 12 years (and assigned a 0 ) or more than 12 years (and assigned a 1) in the model. Since our hypothetical person in the example has 8 years of education, her educational level value is 0 . Thus the predicted value is $\hat{y}_{i}=21.551+(-0.087$. $50)+(2.043 \cdot 0)=21.551-4.350+0=17.201) . c)$ In order to calculate the residual value (indicated with an e in the equation), we subtract the actual value from the predicted value we just calculated $\left(e_{i}=y_{i}-\hat{y}_{i}\right)$. In this case, it would be $e_{i}=20-17.201=2.80 . \mathrm{d}$ ) Next, consult the $S D_{e}$ column in Table 8 to obtain the country-specific $S D_{e}$ (residual) value. For Mexico it is 4.673. Using this value, we can transform the resid- ual value to a standardized $z$ score using the equation $\left(e_{i} / S D_{e}\right)$. In this case, we have $(2.80) / 4.673=0.599$. This is the standardized $z$ score for a Mexican woman aged 50 and 8 years of education and a score of 20 on animals. e) The last step is to look-up the tables in the statistical reference books (e.g. Strauss et al., 2006) or use a trusted online calculator like the one available at http://www.measuringu.com/pcalcz.php. In the online calculator, you would enter the $z$ score and choose a one-sided test and note the percent of area after hitting the submit button. In this case, the probability of 0.599 corresponds to the 72 th percentile. Please remember to use the appropriate tables that correspond to each test (letter vs. animal) when performing these calculations. If the percentile for the others verbal fluency scores is desired, Tables 1-6 must be used.

\subsection{User-friendly normative data}

The five-step normative procedures explained above can provide more individualized norms. However, this method can be prone to human error due to the number of required computations. To enhance user-friendliness, the authors have completed these steps for a range of raw scores based on small age range groupings (see Guàrdia-Olmos et al., 2015) and created tables so that clinicians can more easily use to obtain a percentile range associated with a given raw score on this test. These tables are available by country and type of test in the Appendix. In order to obtain an approximate percentile for the above example (converting a raw score of 20 in animals for a Mexican women who is 50 years old and has 8 years of education using the simplified normative tables provided, the following steps are recommended. (1) First, identify the appropriate table ensuring the specific country and test. In this case, the table for animals scores for Mexico can be found in Table A41. (2) Note if the title of the table indicates that it is only to be used for one specific gender. In this case, gender is not specified. Thus Table A41 is used for both males and females. (3) Next, the table is divided based on educational level ( 1 to 12 vs. $>12$ years of education). Since this woman has 8 years of education, she falls into 1-12 years of education category. These data can be found in the top section of the table. (4) Determine the age range most appropriate for the individual. In this case, 50 falls into the column $48-52$ years of age. (5) Read down the age range column to find the approximate location of the raw score the person obtained on the test. Reading down the $48-52$ column, the score of 
Table 8

Final multiple linear regression models for Animal category

\begin{tabular}{|c|c|c|c|c|c|c|c|}
\hline Country & & $\mathrm{B}$ & Std. Error & $t$ & Sig. & $\mathrm{R}^{2}$ & $S D_{e}$ (residual) \\
\hline \multirow[t]{3}{*}{ Argentina } & (Constant) & 19.442 & 0.707 & 27.508 & $<0.001$ & 0.178 & 4.333 \\
\hline & Age & -0.038 & 0.013 & -3.052 & 0.002 & & \\
\hline & Education & 3.554 & 0.492 & 7.227 & $<0.001$ & & \\
\hline \multirow[t]{3}{*}{ Bolivia } & (Constant) & 18.013 & 0.787 & 22.897 & $<0.001$ & 0.294 & 4.552 \\
\hline & Age & -0.100 & 0.013 & -7.866 & $<0.001$ & & \\
\hline & Education & 4.398 & 0.733 & 5.999 & $<0.001$ & & \\
\hline \multirow[t]{3}{*}{ Chile } & (Constant) & 20.914 & 0.786 & 26.614 & $<0.001$ & 0.407 & 4.218 \\
\hline & Age & -0.122 & 0.013 & -9.640 & $<0.001$ & & \\
\hline & Education & 4.516 & 0.573 & 7.875 & $<0.001$ & & \\
\hline \multirow[t]{3}{*}{ Cuba } & (Constant) & 17.739 & 0.676 & 26.226 & $<0.001$ & 0.157 & 3.979 \\
\hline & Age & -0.066 & 0.012 & -5.650 & $<0.001$ & & \\
\hline & Education & 2.458 & 0.539 & 4.557 & $<0.001$ & & \\
\hline \multirow[t]{3}{*}{ El Salvador } & (Constant) & 17.596 & 0.882 & 19.946 & $<0.001$ & 0.289 & 4.735 \\
\hline & Age & -0.092 & 0.014 & -6.376 & $<0.001$ & & \\
\hline & Education & 5.429 & 0.730 & 7.438 & $<0.001$ & & \\
\hline \multirow[t]{3}{*}{ Guatemala } & (Constant) & 19.598 & 1.079 & 18.161 & $<0.001$ & 0.286 & 4.718 \\
\hline & Age & -0.057 & 0.019 & -3.049 & 0.003 & & \\
\hline & Education & 5.735 & 0.668 & 8.580 & $<0.001$ & & \\
\hline \multirow[t]{3}{*}{ Honduras } & (Constant) & 18.745 & 0.929 & 20.182 & $<0.001$ & 0.324 & 4.184 \\
\hline & Age & -0.088 & 0.017 & -5.214 & $<0.001$ & & \\
\hline & Education & 4.804 & 0.744 & 6.461 & $<0.001$ & & \\
\hline \multirow[t]{3}{*}{ Mexico } & (Constant) & 21.551 & 0.378 & 56.995 & $<0.001$ & 0.169 & 4.673 \\
\hline & Age & -0.087 & 0.006 & -13.638 & $<0.001$ & & \\
\hline & Education & 2.043 & 0.314 & 6.509 & $<0.001$ & & \\
\hline \multirow[t]{3}{*}{ Paraguay } & (Constant) & 14.549 & 0.692 & 21.021 & $<0.001$ & 0.430 & 2.623 \\
\hline & Age & -0.061 & 0.012 & -5.087 & $<0.001$ & & \\
\hline & Education & 4.588 & 0.463 & 9.916 & $<0.001$ & & \\
\hline \multirow[t]{3}{*}{ Peru } & (Constant) & 19.740 & 0.863 & 22.885 & $<0.001$ & 0.228 & 4.580 \\
\hline & Age & -0.071 & 0.015 & -4.862 & $<0.001$ & & \\
\hline & Education & 3.683 & 0.625 & 5.893 & $<0.001$ & & \\
\hline \multirow[t]{3}{*}{ Puerto Rico } & (Constant) & 21.651 & 0.915 & 23.653 & $<0.001$ & 0.226 & 4.571 \\
\hline & Age & -0.122 & 0.015 & -8.019 & $<0.001$ & & \\
\hline & Education & 1.194 & 0.561 & 2.130 & 0.034 & & \\
\hline
\end{tabular}

20 obtained by this Mexican woman corresponds to an approximate percentile of 70 .

The percentile obtained via this user-friendly table method (70th) is slightly different than the more exact one (72th) obtained following the individual conversion steps above because the table method is based on an age range (e.g., individuals aged 48-52) instead of the exact age (individuals aged 50). If the exact score is not listed in the column, you must estimate the percentile value from the listed raw scores.

\section{Discussion}

The purpose of the current study was to generate normative data on the verbal fluency tests across 11 countries in Latin America, with country-specific adjustments for gender, age, and education, where appropriate. The final multiple linear regression models explained between $8-30 \%$ of the variance in letter $\mathrm{F}$ scores, $7-32 \%$ of the variance in letter A scores,
$8-32 \%$ of the variance in letter S scores, and 16-43\% of the variance in animals category scores. There were a number of gender differences across all four verbal fluency test scores in several different countries, but the all effect sizes were small, so gender-adjusted norms were not generated for any country. These findings were in line with the previous literature, which has shown that the impact of gender on phonological fluency and semantic fluency performance is inconsistent or non-existent (Gladsjo et al., 1999). When considering the previous research, the current results suggest that gender-adjustments should not be made when obtaining percentiles for the verbal fluency tests in Latin America.

Verbal fluency test scores increased linearly as a function of education in all countries and tests. This robust pattern is consistent with the previous literature which has found participants with more years of education to score higher on verbal fluency tasks (Strauss et al., 2006). When considering the previous 
research, it is suggested that neuropsychologists in Latin America use education-adjusted norms for each country when administering the verbal fluency tests in that country. As there are likely large differences in education throughout Latin America, this study's education adjustments will be important when administering the verbal fluency tests across many different Latin American countries.

Verbal fluency test scores worsened with increasing age in most countries. However, Argentina, Paraguay, Honduras, and Guatemala did not show an effect of age on letter F scores; Argentina, Paraguay, and Guatemala did not show an effect of age on letter A scores; and Argentina, Paraguay, and Guatemala did not show an effect of age on letter S scores. Previous studies have found that higher age is associated with reduced phonological fluency (Strauss et al., 2006) and semantic fluency (Mitrushina, 2005). In consideration of the previous findings, the current study suggests that verbal fluency test corrections for age in Latin America should be made in all countries and tests except for those that showed no age effect in the current study.

\subsection{Limitations and future directions}

The current study has several limitations and directions for future research. First, participants in this study spoke Spanish as a primary language, and no data were collected on bilingualism. Verbal fluency test performance could likely differ among individuals who speak secondary languages, so future research should examine effects of bilingualism on verbal fluency test performance. Participants were recruited in specific cities and regions of the countries in this study as opposed to nationally. Although the current study is the largest verbal fluency test normative study to date in Latin America, or in any global region, it should be seen as a first step toward larger, nationally representative normative studies. Although many participants in this study had fewer than 12 years of education, illiterate individuals did not participate, and the current norms cannot generalize well to illiterate adults. Similarly, participants with a history of neurological conditions and children were excluded, so future normative research should be conducted with these groups.

Second, neuropsychologists need to exercise caution in using the verbal fluency test norms from this study for people in countries outside of those from which data were collected. Researchers need to create verbal fluency test norms in Latin American countries such as Ecuador, Uruguay, Venezuela, and Panama. Despite this limitation, these verbal fluency test norms may be actually more accurate in Latin American countries not a part of this study than current norms in use, but this generalizability needs to be investigated in future studies.

Third, the verbal fluency tests are common neuropsychological instruments in Latin America, but other measures need to be normed using a similar approach to improve their accuracy in this region. Future research should also examine the psychometrics and ecological validity of the verbal fluency tests, and that of other common assessments in Latin America. Researchers need to create instruments within Latin American cultures with good ecological validity, as the verbal fluency tests were created in a Western culture perhaps very different from the diverse cultures in Latin America. Future research can develop assessments within local cultures, not simply translate and norm tests from other countries.

Despite these limitations, limited studies have produced verbal fluency test norms in Spanish-speakers in the United States (Lucas et al., 1998; Stricks et al., 1998; Acevedo et al., 2000). The current study was the first to generate verbal fluency test norms across 11 countries in Latin America with nearly 4,000 participants. As a result, it was the largest, most comprehensive verbal fluency test normative study to date in any global region, and its norms will influence the standard of neuropsychological assessment with the verbal fluency tests in Latin America unlike any study before it.

\section{References}

Acevedo, A., Loewenstein, D. A., Barker, W. W., Harwood, D. G., Luis, C., Bravo, M., et al. (2000). Category Fluency Test: Normative data for English- and Spanish-speaking elderly. Journal of the International Neuropsychological Society, 6(7), 760-769.

Anderson, V. A., Anderson, P., Northam, E., Jacobs, R., \& Catroppa, C. (2001). Development of executive functions through late childhood and adolescence in an Australian sample. Developmental Neuropsychology, 20(1), 385-406.

Anhoque, C. F., Biccas-Neto, L., Domingues, S. C. A., Teixeira, A. L., \& Domingues, R. B. (2013). Cognitive impairment is correlated with reduced quality of life in patients with clinically isolated syndrome. Arquivos de Neuro-Psiquiatria, 71(2), 74-77.

Baldo, J. V., \& Shimamura, A. P. (1998). Letter and category fluency in patients with frontal lobe lesions. Neuropsychology, 12(2), 259.

Barr, W. B. (2003). Neuropsychological testing of high school athletes: Preliminary norms and test, retest indices. Archives of Clinical Neuropsychology, 18(1), 91-101.

Brissart, H., Leroy, M., Morele, E., Baumann, C., Spitz, E., \& Debouverie, M. (2013). Cognitive rehabilitation in multiple sclerosis. Neurocase, 19(6), 553-565. 
Cabeza, R., \& Nyberg, L. (2000). Imaging cognition II: An empirical review of 275 PET and fMRI studies. Journal of Cognitive Neuroscience, 12(1), 1-47.

Costafreda, S. G., Fu, C. H., Picchioni, M., Toulopoulou, T., McDonald, C., Kravariti, E., McGuire, P. K., et al. (2011). Pattern of neural responses to verbal fluency shows diagnostic specificity for schizophrenia and bipolar disorder. BMC Psychiatry, 11(1), 18

da Silva, C. G., Petersson, K. M., Faísca, L., Ingvar, M., \& Reis, A. (2004). The effects of literacy and education on the quantitative and qualitative aspects of semantic verbal fluency. Journal of Clinical and Experimental Neuropsychology, 26(2), 266-277.

Delis, D. C., Kaplan, E., \& Kramer, J. H. (2001). Delis-Kaplan executive function system (D-KEFS). San Antonio,TX: Psychological Corporation.

Diaz-Asper, C. M., Schretlen, D. J., \& Pearlson, G. D. (2004). How well does IQ predict neuropsychological test performance in normal adults? Journal of the International Neuropsychological Society, 10(01), 82-90.

Folstein, M. F., Folstein, S. E., \& McHugh, P. R. (1975). "Minimental state": A practical method for grading the cognitive state of patients for the clinician. Journal of Psychiatric Research, 12(3), 189-198.

Gladsjo, J. A., Schuman, C. C., Evans, J. D., Peavy, G. M., Miller, S. W., \& Heaton, R. K. (1999). Norms for letter and category fluency: Demographic corrections for age, education, and ethnicity. Assessment, 6(2), 147-178.

Gocer March, E., \& Pattison, P. (2006). Semantic verbal fluency in Alzheimer's disease: Approaches beyond the traditional scoring system. Journal of Clinical and Experimental Neuropsychology, 28(4), 549-566.

Gouveia, P. A., Brucki, S. M., Malheiros, S. M., \& Bueno, O. F. (2007). Disorders in planning and strategy application in frontal lobe lesion patients. Brain and Cognition, 63(3), 240-246.

Guàrdia-Olmos, J., Peró-Cebollero, M., Rivera, D., \& ArangoLasprilla, J.C. (2015). Methodology for the development of normative data for ten Spanish-language neuropsychological tests in eleven Latin American countries. NeuroRehabilitation, 37, 493-499.

Halperin, J. M., Healey, J. M., Zeitchik, E., Ludman, W. L., \& Weinstein, L. (1989). Developmental aspects of linguistic and mnestic abilities in normal children. Journal of Clinical and Experimental Neuropsychology, 11(4), 518-528.

Heaton, R. K. (2004). Revised comprehensive norms for an expanded Halstead-Reitan Battery: Demographically adjusted neuropsychological norms for African American and Caucasian adults, professional manual. Lutz, Fla. Psychological Assessment Resources.

Heller, R. B., \& Dobbs, A. R. (1993). Age differences in word finding in discourse and nondiscourse situations. Psychology and Aging, $8(3), 443$.

Henry, J., \& Crawford, J. (2005). A meta-analytic review of verbal fluency deficits in schizophrenia relative to other neurocognitive deficits. Cognitive Neuropsychiatry, 10(1), 1-33.

Henry, J. D., \& Crawford, J. R. (2004a). A meta-analytic review of verbal fluency performance in patients with traumatic brain injury. Neuropsychology, 18(4), 621-628.

Henry, J. D., \& Crawford, J. R. (2004b). Verbal fluency deficits in Parkinson's disease: A meta-analysis. Journal of the International Neuropsychological Society, 10(4), 608-622.
Indefrey, P., \& Levelt, W. J. M. (2000). The neural correlates of language production. In M. S. Gazzaniga (Ed.), The new cognitive neurosciences; 2nd ed. (pp. 845-865). Cambridge, MA: MIT Press.

Ivnik, R. J., Malec, J. F., Smith, G. E., Tangalos, E. G., \& Petersen, R. C. (1996). Neuropsychological tests' norms above age 55: COWAT, BNT, MAE token, WRAT-R reading, AMNART, STROOP, TMT, and JLO. The Clinical Neuropsychologist, 10(3), 262-278.

Johnson-Selfridge, M., \& Zalewski, C. (2001). Moderator variables of executive functioning in schizophrenia. Schizophrenia Bulletin, 27(2), 305-316.

Khalil, M. S. (2010). Preliminary Arabic normative data of neuropsychological tests: The verbal and design fluency. Journal of Clinical and Experimental Neuropsychology, 32(9), 1028-1035.

Kosmidis, M. H., Vlahou, C. H., Panagiotaki, P., Kiosseoglou, G. (2004). The verbal fluency task in the Greek population: Normative data, and clustering and switching strategies. Journal of the International Neuropsychological Society, 10(2), 164-172.

Kroenke, K., Spitzer, R. L., \& Williams, J. B. (2001). The PHQ-9. Journal of General Internal Medicine, 16(9), 606-613.

Loonstra, A. S., Tarlow, A. R., \& Sellers, A. H. (2001). COWAT metanorms across age, education, and gender. Applied Neuropsychology, 8(3), 161-166.

Lucas, J. A., Ivnik, R. J., Smith, G. E., Bohac, D. L., Tangalos, E. G., Graff-Radford, N. R., \& Petersen, R. C. (1998). Mayo's older Americans normative studies: Category fluency norms. Journal of Clinical and Experimental Neuropsychology, 20(2), 194-200.

Mahoney, F. I., \& Barthel, D. (1965). Functional evaluation: The Barthel Index. Maryland State Medical Journal, 14, 56-61.

McGraw, P., Mathews, V. P., Wang, Y., \& Phillips, M. D. (2001). Approach to functional magnetic resonance imaging of language based on models of language organization. Neuroimaging Clinics of North America, 11(2), 343-53.

Mitrushina, M. (2005). Handbook of normative data for neuropsychological assessment. New York: Oxford University Press.

Moreno-Martinez, F. J., \& Montoro, P. R. (2010). Longitudinal patterns of fluency impairment in dementia: The role of domain and "nuisance variables." Aphasiology, 24(11), 1389-1399.

Pasquier, F., Lebert, F., Grymonprez, L., \& Petit, H. (1995). Verbal fluency in dementia of frontal lobe type and dementia of Alzheimer type. Journal of Neurology, Neurosurgery \& Psychiatry, 58(1), 81-84.

Price, S. E., Ong, B., Mullaly, E., Pangnadasa-Fox, L., Kinsella, G. J., \& Storey, E., et al. (2012). Semantic verbal fluency strategies in amnestic mild cognitive impairment. Neuropsychology, 26(4), 490-497.

Randolph, C., Braun, A. R., Goldberg, T. E., \& Chase, T. N. (1993). Semantic fluency in Alzheimer's, Parkinson's, and Huntington's disease: Dissociation of storage and retrieval failures. Neuropsychology, 7(1), 82.

Raskin, S. A., \& Rearick, E. (1996). Verbal fluency in individuals with mild traumatic brain injury. Neuropsychology, 10(3), 416.

Ravdin, L., Katzen, H., Agrawal, P., \& Relkin, N. (2003). Letter and semantic fluency in older adults: Effects of mild depressive symptoms and age-stratified normative data. The Clinical Neuropsychologist, 17(2), 195-202.

Ruff, R., Light, R., Parker, S., \& Levin, H. (1996). Benton controlled oral word association test: Reliability and updated norms. Archives of Clinical Neuropsychology, 11(4), 329-338. 
Sauzeon, H., Lestage, P., Raboutet, C., N'Kaoua, B., \& Claverie, B. (2004). Verbal fluency output in children aged 7-16 as a function of the production criterion: Qualitative analysis of clustering, switching processes, and semantic network exploitation. Brain and Language, 89(1), 192-202.

Schum, R. L., Sivan, A. B., \& Benton, A. (1989). Multilingual aphasia examination: Norms for children. The Clinical Neuropsychologist, 3(4), 375-383.

Steinberg, B. A., Bieliauskas, L. A., Smith, G. E., \& Ivnik, R. J. (2005). Mayo's Older Americans Normative Studies: Ageand IQ-adjusted norms for the trail-making test, the stroop test, and MAE controlled oral word association test. The Clinical Neuropsychologist, 19(3-4), 329-377.

Strauss, E. H., Sherman, E. M., \& Spreen, O. (2006). A compendium of neuropsychological tests: Administration, norms, and commentary. New York: Oxford University Press.

Stricks, L., Pittman, J., Jacobs, D. M., Sano, M., \& Stern, Y. (1998). Normative data for a brief neuropsychological battery administered to English-and Spanish-speaking community-dwelling elders. Journal of the International Neuropsychological Society, 4(04), 311-318.

Tallberg, I.-M., Ivachova, E., Jones Tinghag, K., \& Östberg, P. (2008). Swedish norms for word fluency tests: FAS, animals and verbs. Scandinavian Journal of Psychology, 49(5), 479-485.

Till, C., Racine, N., Araujo, D., Narayanan, S., Collins, D. L., AubertBroche, B., Banwell, B., et al. (2013). Changes in cognitive performance over a 1-year period in children and adolescents with multiple sclerosis. Neuropsychology, 27(2), 210.

Ting, S. K. S., Hameed, S., Earnest, A., \& Tan, E. K. (2012). Dissociative semantic breakdown in Alzheimer's disease: Evidence from multiple category fluency test. Clinical Neurology and Neurosurgery, 115(7), 1049-1051.
Tombaugh, T. N., Kozak, J., \& Rees, L. (1999). Normative data stratified by age and education for two measures of verbal fluency: FAS and animal naming. Archives of Clinical Neuropsychology, 14(2), 167-177.

Troyer, A. K. (2000). Normative data for clustering and switching on verbal fluency tasks. Journal of Clinical and Experimental Neuropsychology, 22(3), 370-378.

Van Breukelen, G. J. P., \& Vlaeyen, J. W. S. (2005). Norming clinical questionnaires with multiple regression: The Pain Cognition List. Psychological Assessment, 17(3), 336-344.

Van der Elst, W., Van Boxtel, M. P., Van Breukelen, G. J., \& Jolles, J. (2006). Normative data for the animal, profession and letter M naming verbal fluency tests for Dutch speaking participants and the effects of age, education, and sex. Journal of the International Neuropsychological Society, 12(1), 80-89.

Van der Elst, W., Van Boxtel, M. P. J., Van Breukelen, G. J. P., \& Jolles, J. (2007). Assessment of information processing in working memory in applied settings: The paper \& pencil memory scanning test. Psychological Medicine, 37(09), 1335-1344.

Weber, N., Koch, R., \& Reilmann, R. (2012). J04 Measuring cognitive decline in Huntington's disease: A longitudinal analysis of the UHDRS cognitive battery. Journal of Neurology, Neurosurgery \& Psychiatry, 83(Suppl 1), A36-A37.

Wysokiński, A., Zboralski, K., Orzechowska, A., Galecki, P., Florkowski, A., \& Talarowska, M. (2010). Normalization of the verbal fluency test on the basis of results for healthy subjects, patients with schizophrenia, patients with organic lesions of the chronic nervous system and patients with type 1 and 2 diabetes. Archives of Medical Science, 6(3), 438-446. 


\section{Appendix}

Table A1

Normative data for the Letter F stratified by education levels for ARGENTINA

\begin{tabular}{lcc}
\hline Percentile & 1 to 12 years of education & $>12$ years of education \\
\hline 95 & 18.8 & 22.6 \\
90 & 17.3 & 21.1 \\
85 & 16.3 & 20.1 \\
80 & 15.5 & 19.3 \\
70 & 14.2 & 17.9 \\
60 & 13.1 & 16.8 \\
50 & 12.0 & 15.8 \\
40 & 11.0 & 14.8 \\
30 & 9.9 & 13.6 \\
20 & 8.5 & 12.3 \\
15 & 7.7 & 11.5 \\
10 & 6.7 & 10.5 \\
5 & 5.2 & 9.0 \\
\hline
\end{tabular}

Table A2

Normative data for the Letter F stratified by age and education levels for BOLIVIA

\begin{tabular}{|c|c|c|c|c|c|c|c|c|c|c|c|c|c|c|}
\hline & \multirow[b]{2}{*}{ Percentile } & \multicolumn{13}{|c|}{ Age (Years) } \\
\hline & & $18-22$ & $23-27$ & $28-32$ & $33-37$ & $38-42$ & $43-47$ & $48-52$ & $53-57$ & $58-62$ & $63-67$ & $68-72$ & $73-77$ & $>77$ \\
\hline \multirow{13}{*}{ 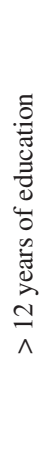 } & 95 & 17.6 & 17.4 & 17.2 & 17.0 & 16.7 & 16.5 & 16.3 & 16.0 & 15.8 & 15.6 & 15.4 & 15.1 & 14.9 \\
\hline & 90 & 16.5 & 16.2 & 16.0 & 15.8 & 15.6 & 15.3 & 15.1 & 14.9 & 14.6 & 14.4 & 14.2 & 14.0 & 13.7 \\
\hline & 85 & 15.7 & 15.5 & 15.2 & 15.0 & 14.8 & 14.5 & 14.3 & 14.1 & 13.9 & 13.6 & 13.4 & 13.2 & 12.9 \\
\hline & 80 & 15.0 & 14.8 & 14.6 & 14.4 & 14.1 & 13.9 & 13.7 & 13.4 & 13.2 & 13.0 & 12.8 & 12.5 & 12.3 \\
\hline & 70 & 14.0 & 13.8 & 13.5 & 13.3 & 13.1 & 12.9 & 12.6 & 12.4 & 12.2 & 11.9 & 11.7 & 11.5 & 11.3 \\
\hline & 60 & 13.1 & 12.9 & 12.7 & 12.4 & 12.2 & 12.0 & 11.8 & 11.5 & 11.3 & 11.1 & 10.8 & 10.6 & 10.4 \\
\hline & 50 & 12.3 & 12.1 & 11.9 & 11.6 & 11.4 & 11.2 & 10.9 & 10.7 & 10.5 & 10.3 & 10.0 & 9.8 & 9.6 \\
\hline & 40 & 11.5 & 11.3 & 11.0 & 10.8 & 10.6 & 10.4 & 10.1 & 9.9 & 9.7 & 9.4 & 9.2 & 9.0 & 8.8 \\
\hline & 30 & 10.6 & 10.4 & 10.2 & 9.9 & 9.7 & 9.5 & 9.3 & 9.0 & 8.8 & 8.6 & 8.3 & 8.1 & 7.9 \\
\hline & 20 & 9.6 & 9.4 & 9.1 & 8.9 & 8.7 & 8.4 & 8.2 & 8.0 & 7.8 & 7.5 & 7.3 & 7.1 & 6.8 \\
\hline & 15 & 8.9 & 8.7 & 8.5 & 8.3 & 8.0 & 7.8 & 7.6 & 7.3 & 7.1 & 6.9 & 6.6 & 6.4 & 6.2 \\
\hline & 10 & 8.2 & 7.9 & 7.7 & 7.5 & 7.2 & 7.0 & 6.8 & 6.6 & 6.3 & 6.1 & 5.9 & 5.6 & 5.4 \\
\hline & 5 & 7.0 & 6.8 & 6.5 & 6.3 & 6.1 & 5.8 & 5.6 & 5.4 & 5.2 & 4.9 & 4.7 & 4.5 & 4.2 \\
\hline \multirow{13}{*}{ 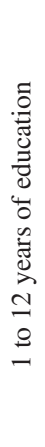 } & 95 & 15.0 & 14.8 & 14.6 & 14.3 & 14.1 & 13.9 & 13.6 & 13.4 & 13.2 & 13.0 & 12.7 & 12.5 & 12.3 \\
\hline & 90 & 13.8 & 13.6 & 13.4 & 13.2 & 12.9 & 12.7 & 12.5 & 12.2 & 12.0 & 11.8 & 11.6 & 11.3 & 11.1 \\
\hline & 85 & 13.1 & 12.8 & 12.6 & 12.4 & 12.1 & 11.9 & 11.7 & 11.5 & 11.2 & 11.0 & 10.8 & 10.5 & 10.3 \\
\hline & 80 & 12.4 & 12.2 & 12.0 & 11.7 & 11.5 & 11.3 & 11.0 & 10.8 & 10.6 & 10.4 & 10.1 & 9.9 & 9.7 \\
\hline & 70 & 11.4 & 11.1 & 10.9 & 10.7 & 10.5 & 10.2 & 10.0 & 9.8 & 9.5 & 9.3 & 9.1 & 8.9 & 8.6 \\
\hline & 60 & 10.5 & 10.3 & 10.0 & 9.8 & 9.6 & 9.4 & 9.1 & 8.9 & 8.7 & 8.4 & 8.2 & 8.0 & 7.8 \\
\hline & 50 & 9.7 & 9.5 & 9.2 & 9.0 & 8.8 & 8.5 & 8.3 & 8.1 & 7.9 & 7.6 & 7.4 & 7.2 & 6.9 \\
\hline & 40 & 8.9 & 8.6 & 8.4 & 8.2 & 8.0 & 7.7 & 7.5 & 7.3 & 7.0 & 6.8 & 6.6 & 6.4 & 6.1 \\
\hline & 30 & 8.0 & 7.8 & 7.5 & 7.3 & 7.1 & 6.9 & 6.6 & 6.4 & 6.2 & 5.9 & 5.7 & 5.5 & 5.3 \\
\hline & 20 & 7.0 & 6.7 & 6.5 & 6.3 & 6.0 & 5.8 & 5.6 & 5.4 & 5.1 & 4.9 & 4.7 & 4.4 & 4.2 \\
\hline & 15 & 6.3 & 6.1 & 5.8 & 5.6 & 5.4 & 5.2 & 4.9 & 4.7 & 4.5 & 4.2 & 4.0 & 3.8 & 3.6 \\
\hline & 10 & 5.5 & 5.3 & 5.1 & 4.8 & 4.6 & 4.4 & 4.2 & 3.9 & 3.7 & 3.5 & 3.2 & 3.0 & 2.8 \\
\hline & 5 & 4.4 & 4.1 & 3.9 & 3.7 & 3.4 & 3.2 & 3.0 & 2.8 & 2.5 & 2.3 & 2.1 & 1.8 & 1.6 \\
\hline
\end{tabular}


Table A3

Normative data for the Letter F stratified by age and education levels for CHILE

\begin{tabular}{|c|c|c|c|c|c|c|c|c|c|c|c|c|c|c|}
\hline & \multirow[b]{2}{*}{ Percentile } & \multicolumn{13}{|c|}{ Age (Years) } \\
\hline & & $18-22$ & $23-27$ & $28-32$ & $33-37$ & $38-42$ & $43-47$ & $48-52$ & $53-57$ & $58-62$ & $63-67$ & $68-72$ & $73-77$ & $>77$ \\
\hline \multirow{13}{*}{ 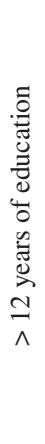 } & 95 & 21.5 & 21.2 & 20.9 & 20.6 & 20.2 & 19.9 & 19.6 & 19.3 & 19.0 & 18.6 & 18.3 & 18.0 & 17.7 \\
\hline & 90 & 20.2 & 19.9 & 19.6 & 19.2 & 18.9 & 18.6 & 18.3 & 18.0 & 17.6 & 17.3 & 17.0 & 16.7 & 16.4 \\
\hline & 85 & 19.3 & 19.0 & 18.7 & 18.4 & 18.0 & 17.7 & 17.4 & 17.1 & 16.8 & 16.4 & 16.1 & 15.8 & 15.5 \\
\hline & 80 & 18.6 & 18.3 & 17.9 & 17.6 & 17.3 & 17.0 & 16.7 & 16.3 & 16.0 & 15.7 & 15.4 & 15.1 & 14.8 \\
\hline & 70 & 17.4 & 17.1 & 16.8 & 16.4 & 16.1 & 15.8 & 15.5 & 15.2 & 14.9 & 14.5 & 14.2 & 13.9 & 13.6 \\
\hline & 60 & 16.4 & 16.1 & 15.8 & 15.5 & 15.1 & 14.8 & 14.5 & 14.2 & 13.9 & 13.5 & 13.2 & 12.9 & 12.6 \\
\hline & 50 & 15.5 & 15.2 & 14.9 & 14.5 & 14.2 & 13.9 & 13.6 & 13.3 & 12.9 & 12.6 & 12.3 & 12.0 & 11.7 \\
\hline & 40 & 14.6 & 14.3 & 13.9 & 13.6 & 13.3 & 13.0 & 12.7 & 12.3 & 12.0 & 11.7 & 11.4 & 11.1 & 10.7 \\
\hline & 30 & 13.6 & 13.3 & 12.9 & 12.6 & 12.3 & 12.0 & 11.7 & 11.3 & 11.0 & 10.7 & 10.4 & 10.1 & 9.8 \\
\hline & 20 & 12.4 & 12.1 & 11.8 & 11.4 & 11.1 & 10.8 & 10.5 & 10.2 & 9.9 & 9.5 & 9.2 & 8.9 & 8.6 \\
\hline & 15 & 11.7 & 11.3 & 11.0 & 10.7 & 10.4 & 10.1 & 9.8 & 9.4 & 9.1 & 8.8 & 8.5 & 8.2 & 7.8 \\
\hline & 10 & 10.8 & 10.5 & 10.1 & 9.8 & 9.5 & 9.2 & 8.9 & 8.6 & 8.2 & 7.9 & 7.6 & 7.3 & 7.0 \\
\hline & 5 & 9.5 & 9.1 & 8.8 & 8.5 & 8.2 & 7.9 & 7.5 & 7.2 & 6.9 & 6.6 & 6.3 & 6.0 & 5.6 \\
\hline \multirow{13}{*}{ 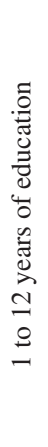 } & 95 & 17.5 & 17.2 & 16.9 & 16.6 & 16.3 & 16.0 & 15.6 & 15.3 & 15.0 & 14.7 & 14.4 & 14.0 & 13.7 \\
\hline & 90 & 16.2 & 15.9 & 15.6 & 15.3 & 15.0 & 14.6 & 14.3 & 14.0 & 13.7 & 13.4 & 13.0 & 12.7 & 12.4 \\
\hline & 85 & 15.3 & 15.0 & 14.7 & 14.4 & 14.1 & 13.7 & 13.4 & 13.1 & 12.8 & 12.5 & 12.2 & 11.8 & 11.5 \\
\hline & 80 & 14.6 & 14.3 & 14.0 & 13.7 & 13.3 & 13.0 & 12.7 & 12.4 & 12.1 & 11.7 & 11.4 & 11.1 & 10.8 \\
\hline & 70 & 13.4 & 13.1 & 12.8 & 12.5 & 12.2 & 11.8 & 11.5 & 11.2 & 10.9 & 10.6 & 10.2 & 9.9 & 9.6 \\
\hline & 60 & 12.4 & 12.1 & 11.8 & 11.5 & 11.2 & 10.8 & 10.5 & 10.2 & 9.9 & 9.6 & 9.3 & 8.9 & 8.6 \\
\hline & 50 & 11.5 & 11.2 & 10.9 & 10.6 & 10.2 & 9.9 & 9.6 & 9.3 & 9.0 & 8.7 & 8.3 & 8.0 & 7.7 \\
\hline & 40 & 10.6 & 10.3 & 10.0 & 9.6 & 9.3 & 9.0 & 8.7 & 8.4 & 8.1 & 7.7 & 7.4 & 7.1 & 6.8 \\
\hline & 30 & 9.6 & 9.3 & 9.0 & 8.7 & 8.3 & 8.0 & 7.7 & 7.4 & 7.1 & 6.7 & 6.4 & 6.1 & 5.8 \\
\hline & 20 & 8.4 & 8.1 & 7.8 & 7.5 & 7.2 & 6.8 & 6.5 & 6.2 & 5.9 & 5.6 & 5.2 & 4.9 & 4.6 \\
\hline & 15 & 7.7 & 7.4 & 7.1 & 6.7 & 6.4 & 6.1 & 5.8 & 5.5 & 5.2 & 4.8 & 4.5 & 4.2 & 3.9 \\
\hline & 10 & 6.8 & 6.5 & 6.2 & 5.9 & 5.5 & 5.2 & 4.9 & 4.6 & 4.3 & 3.9 & 3.6 & 3.3 & 3.0 \\
\hline & 5 & 5.5 & 5.2 & 4.9 & 4.5 & 4.2 & 3.9 & 3.6 & 3.3 & 2.9 & 2.6 & 2.3 & 2.0 & 1.7 \\
\hline
\end{tabular}


Table A4

Normative data for the Letter F stratified by age and education levels for CUBA

\begin{tabular}{|c|c|c|c|c|c|c|c|c|c|c|c|c|c|c|}
\hline & \multirow[b]{2}{*}{ Percentile } & \multicolumn{13}{|c|}{ Age (Years) } \\
\hline & & $18-22$ & $23-27$ & $28-32$ & $33-37$ & $38-42$ & $43-47$ & $48-52$ & $53-57$ & $58-62$ & $63-67$ & $68-72$ & $73-77$ & $>77$ \\
\hline \multirow{13}{*}{ 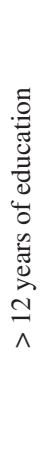 } & 95 & 18.9 & 18.7 & 18.5 & 18.3 & 18.1 & 17.9 & 17.7 & 17.5 & 17.3 & 17.1 & 16.9 & 16.7 & 16.5 \\
\hline & 90 & 17.5 & 17.3 & 17.1 & 16.9 & 16.7 & 16.5 & 16.4 & 16.2 & 16.0 & 15.8 & 15.6 & 15.4 & 15.2 \\
\hline & 85 & 16.6 & 16.4 & 16.2 & 16.0 & 15.8 & 15.7 & 15.5 & 15.3 & 15.1 & 14.9 & 14.7 & 14.5 & 14.3 \\
\hline & 80 & 15.9 & 15.7 & 15.5 & 15.3 & 15.1 & 14.9 & 14.7 & 14.5 & 14.3 & 14.1 & 13.9 & 13.7 & 13.5 \\
\hline & 70 & 14.7 & 14.5 & 14.3 & 14.1 & 13.9 & 13.7 & 13.5 & 13.3 & 13.1 & 12.9 & 12.7 & 12.5 & 12.4 \\
\hline & 60 & 13.7 & 13.5 & 13.3 & 13.1 & 12.9 & 12.7 & 12.5 & 12.3 & 12.1 & 11.9 & 11.7 & 11.5 & 11.3 \\
\hline & 50 & 12.7 & 12.6 & 12.4 & 12.2 & 12.0 & 11.8 & 11.6 & 11.4 & 11.2 & 11.0 & 10.8 & 10.6 & 10.4 \\
\hline & 40 & 11.8 & 11.6 & 11.4 & 11.2 & 11.0 & 10.8 & 10.6 & 10.5 & 10.3 & 10.1 & 9.9 & 9.7 & 9.5 \\
\hline & 30 & 10.8 & 10.6 & 10.4 & 10.2 & 10.0 & 9.8 & 9.6 & 9.4 & 9.3 & 9.1 & 8.9 & 8.7 & 8.5 \\
\hline & 20 & 9.6 & 9.4 & 9.2 & 9.0 & 8.8 & 8.6 & 8.4 & 8.3 & 8.1 & 7.9 & 7.7 & 7.5 & 7.3 \\
\hline & 15 & 8.9 & 8.7 & 8.5 & 8.3 & 8.1 & 7.9 & 7.7 & 7.5 & 7.3 & 7.1 & 6.9 & 6.7 & 6.5 \\
\hline & 10 & 8.0 & 7.8 & 7.6 & 7.4 & 7.2 & 7.0 & 6.8 & 6.6 & 6.4 & 6.2 & 6.0 & 5.8 & 5.6 \\
\hline & 5 & 6.6 & 6.4 & 6.2 & 6.1 & 5.9 & 5.7 & 5.5 & 5.3 & 5.1 & 4.9 & 4.7 & 4.5 & 4.3 \\
\hline \multirow{13}{*}{ 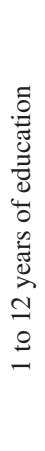 } & 95 & 17.2 & 17.0 & 16.8 & 16.6 & 16.4 & 16.2 & 16.0 & 15.8 & 15.6 & 15.4 & 15.2 & 15.0 & 14.8 \\
\hline & 90 & 15.8 & 15.6 & 15.4 & 15.2 & 15.0 & 14.8 & 14.7 & 14.5 & 14.3 & 14.1 & 13.9 & 13.7 & 13.5 \\
\hline & 85 & 14.9 & 14.7 & 14.5 & 14.3 & 14.1 & 14.0 & 13.8 & 13.6 & 13.4 & 13.2 & 13.0 & 12.8 & 12.6 \\
\hline & 80 & 14.2 & 14.0 & 13.8 & 13.6 & 13.4 & 13.2 & 13.0 & 12.8 & 12.6 & 12.4 & 12.2 & 12.0 & 11.8 \\
\hline & 70 & 13.0 & 12.8 & 12.6 & 12.4 & 12.2 & 12.0 & 11.8 & 11.6 & 11.4 & 11.2 & 11.0 & 10.8 & 10.6 \\
\hline & 60 & 12.0 & 11.8 & 11.6 & 11.4 & 11.2 & 11.0 & 10.8 & 10.6 & 10.4 & 10.2 & 10.0 & 9.8 & 9.6 \\
\hline & 50 & 11.0 & 10.9 & 10.7 & 10.5 & 10.3 & 10.1 & 9.9 & 9.7 & 9.5 & 9.3 & 9.1 & 8.9 & 8.7 \\
\hline & 40 & 10.1 & 9.9 & 9.7 & 9.5 & 9.3 & 9.1 & 8.9 & 8.8 & 8.6 & 8.4 & 8.2 & 8.0 & 7.8 \\
\hline & 30 & 9.1 & 8.9 & 8.7 & 8.5 & 8.3 & 8.1 & 7.9 & 7.7 & 7.6 & 7.4 & 7.2 & 7.0 & 6.8 \\
\hline & 20 & 7.9 & 7.7 & 7.5 & 7.3 & 7.1 & 6.9 & 6.7 & 6.6 & 6.4 & 6.2 & 6.0 & 5.8 & 5.6 \\
\hline & 15 & 7.2 & 7.0 & 6.8 & 6.6 & 6.4 & 6.2 & 6.0 & 5.8 & 5.6 & 5.4 & 5.2 & 5.0 & 4.8 \\
\hline & 10 & 6.3 & 6.1 & 5.9 & 5.7 & 5.5 & 5.3 & 5.1 & 4.9 & 4.7 & 4.5 & 4.3 & 4.1 & 3.9 \\
\hline & 5 & 4.9 & 4.7 & 4.5 & 4.3 & 4.2 & 4.0 & 3.8 & 3.6 & 3.4 & 3.2 & 3.0 & 2.8 & 2.6 \\
\hline
\end{tabular}


Table A5

Normative data for the Letter F stratified by age and education levels for EL SALVADOR

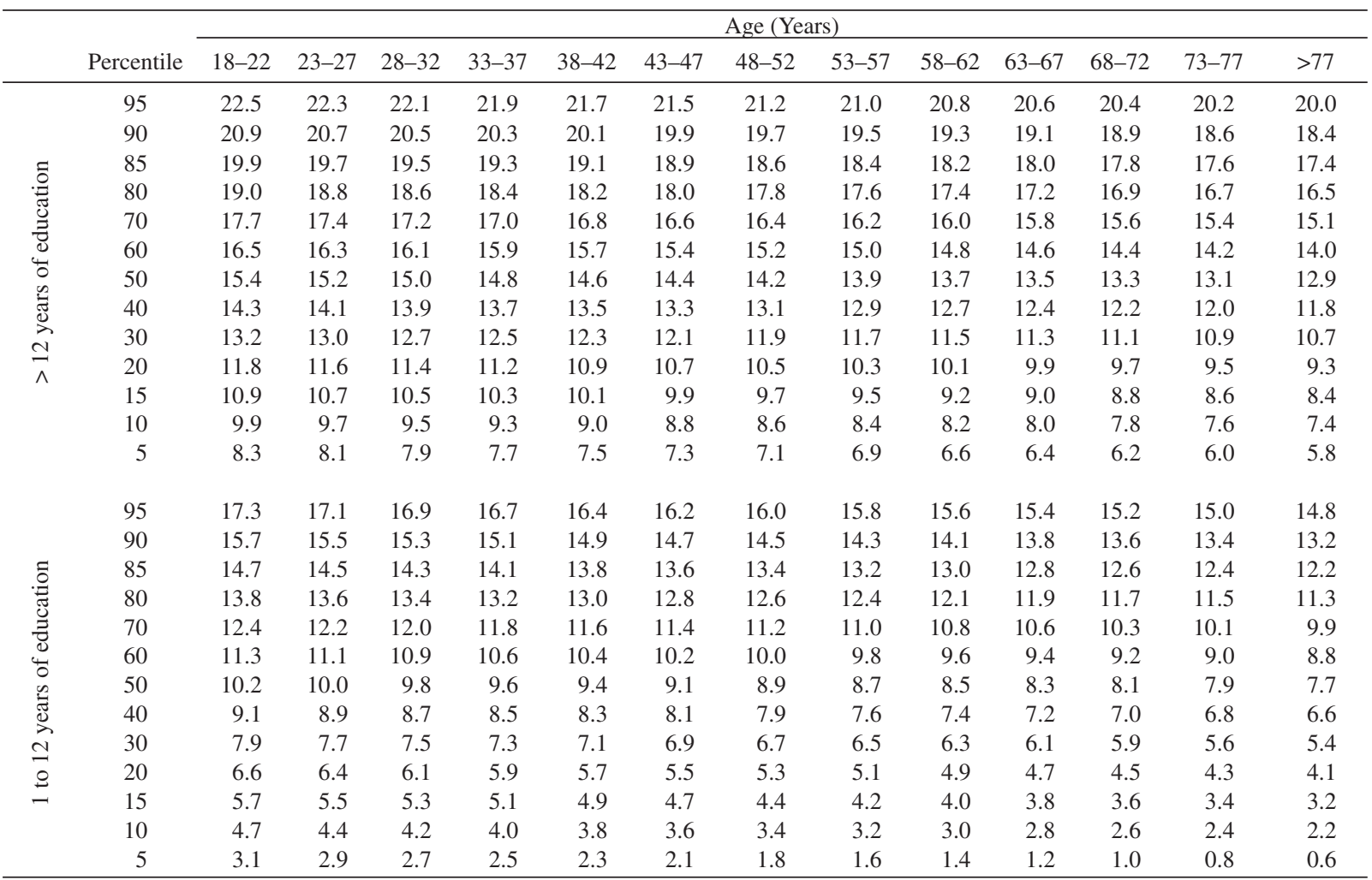

Table A6

Normative data for the Letter F stratified by education levels for GUATEMALA

\begin{tabular}{lcc}
\hline Percentile & 1 to 12 years of education & $>12$ years of education \\
\hline 95 & 17.6 & 21.9 \\
90 & 15.8 & 20.2 \\
85 & 14.7 & 19.0 \\
80 & 13.8 & 18.1 \\
70 & 12.2 & 16.6 \\
60 & 10.9 & 15.3 \\
50 & 9.7 & 14.1 \\
40 & 8.6 & 12.9 \\
30 & 7.3 & 11.6 \\
20 & 5.7 & 10.1 \\
15 & 4.8 & 9.1 \\
10 & 3.7 & 8.0 \\
5 & 1.9 & 6.3 \\
\hline
\end{tabular}


Table A7

Normative data for the Letter F stratified by education levels for HONDURAS

\begin{tabular}{lcc}
\hline Percentile & 1 to 12 years of education & $>$ 12 years of education \\
\hline 95 & 14.5 & 19.6 \\
90 & 13.1 & 18.2 \\
85 & 12.1 & 17.3 \\
80 & 11.3 & 16.5 \\
70 & 10.1 & 15.3 \\
60 & 9.0 & 14.2 \\
50 & 8.1 & 13.3 \\
40 & 7.1 & 12.3 \\
30 & 6.0 & 11.2 \\
20 & 4.8 & 10.0 \\
15 & 4.0 & 9.2 \\
10 & 3.1 & 8.3 \\
5 & 1.7 & 6.9 \\
\hline
\end{tabular}

Table A8

Normative data for the Letter F stratified by age and education levels for MEXICO

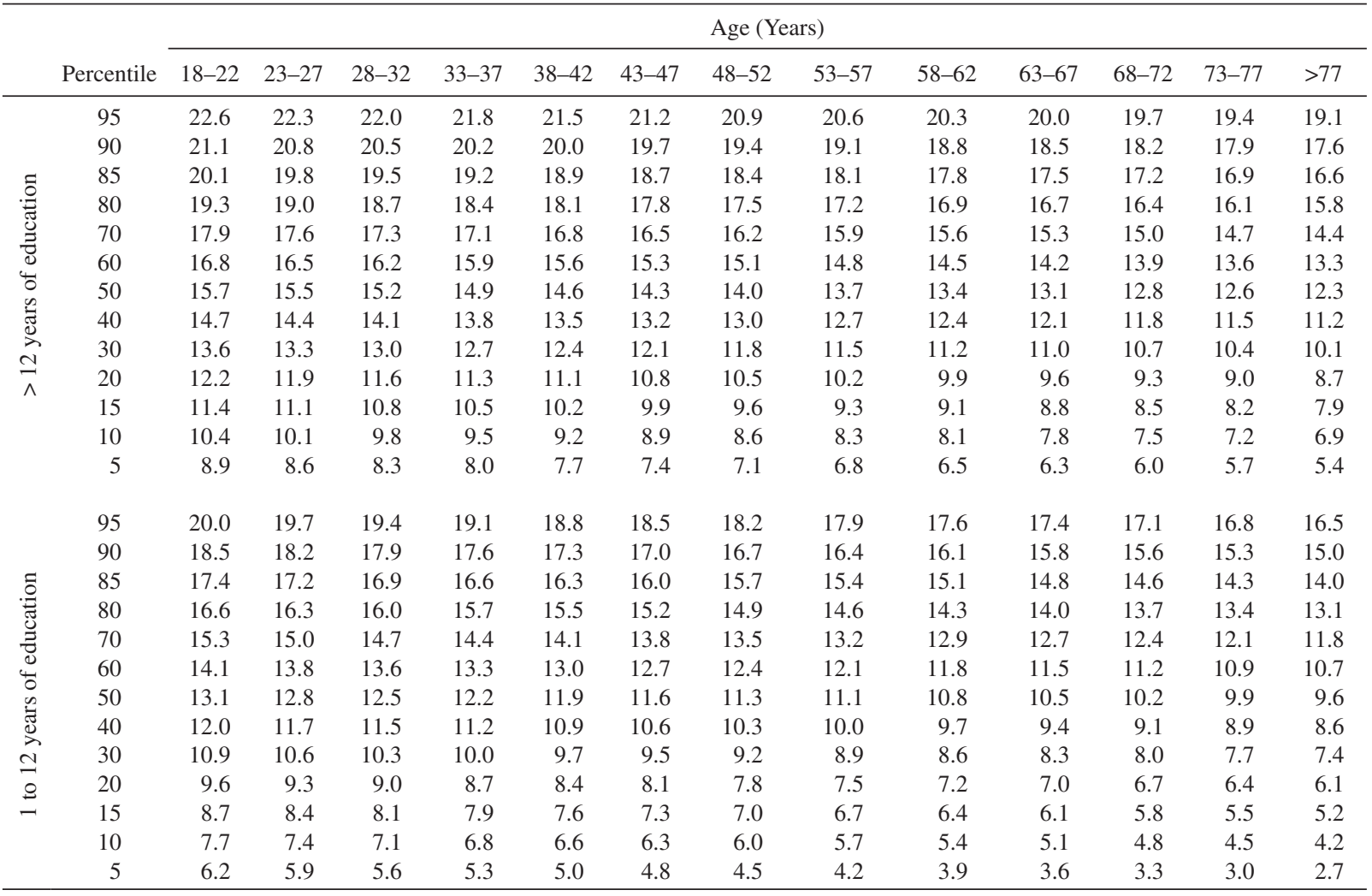


Table A9

Normative data for the Letter F stratified by education levels for PARAGUAY

\begin{tabular}{lcc}
\hline Percentile & 1 to 12 years of education & $>12$ years of education \\
\hline 95 & 12.6 & 14.9 \\
90 & 12.0 & 14.4 \\
85 & 11.7 & 14.0 \\
80 & 11.3 & 13.6 \\
70 & 10.8 & 13.1 \\
60 & 10.4 & 12.7 \\
50 & 10.0 & 12.3 \\
40 & 9.6 & 11.9 \\
30 & 9.2 & 11.5 \\
20 & 8.6 & 10.9 \\
15 & 8.3 & 10.6 \\
10 & 7.9 & 10.2 \\
5 & 7.4 & 9.7 \\
\hline
\end{tabular}

Table A10

Normative data for the Letter F stratified by age and education levels for PERU

\begin{tabular}{|c|c|c|c|c|c|c|c|c|c|c|c|c|c|c|}
\hline & \multirow[b]{2}{*}{ Percentile } & \multicolumn{13}{|c|}{ Age (Years) } \\
\hline & & $18-22$ & $23-27$ & $28-32$ & $33-37$ & $38-42$ & $43-47$ & $48-52$ & $53-57$ & $58-62$ & $63-67$ & $68-72$ & $73-77$ & $>77$ \\
\hline \multirow{13}{*}{ 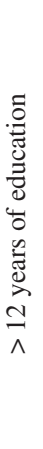 } & 95 & 21.8 & 21.7 & 21.5 & 21.4 & 21.2 & 21.1 & 21.0 & 20.8 & 20.7 & 20.5 & 20.4 & 20.2 & 20.1 \\
\hline & 90 & 20.4 & 20.3 & 20.1 & 20.0 & 19.8 & 19.7 & 19.5 & 19.4 & 19.2 & 19.1 & 19.0 & 18.8 & 18.7 \\
\hline & 85 & 19.5 & 19.3 & 19.2 & 19.0 & 18.9 & 18.7 & 18.6 & 18.4 & 18.3 & 18.2 & 18.0 & 17.9 & 17.7 \\
\hline & 80 & 18.7 & 18.5 & 18.4 & 18.2 & 18.1 & 18.0 & 17.8 & 17.7 & 17.5 & 17.4 & 17.2 & 17.1 & 16.9 \\
\hline & 70 & 17.4 & 17.3 & 17.1 & 17.0 & 16.8 & 16.7 & 16.5 & 16.4 & 16.3 & 16.1 & 16.0 & 15.8 & 15.7 \\
\hline & 60 & 16.4 & 16.2 & 16.1 & 15.9 & 15.8 & 15.6 & 15.5 & 15.3 & 15.2 & 15.0 & 14.9 & 14.8 & 14.6 \\
\hline & 50 & 15.4 & 15.2 & 15.1 & 14.9 & 14.8 & 14.6 & 14.5 & 14.4 & 14.2 & 14.1 & 13.9 & 13.8 & 13.6 \\
\hline & 40 & 14.4 & 14.2 & 14.1 & 13.9 & 13.8 & 13.7 & 13.5 & 13.4 & 13.2 & 13.1 & 12.9 & 12.8 & 12.6 \\
\hline & 30 & 13.3 & 13.2 & 13.0 & 12.9 & 12.7 & 12.6 & 12.4 & 12.3 & 12.2 & 12.0 & 11.9 & 11.7 & 11.6 \\
\hline & 20 & 12.1 & 11.9 & 11.8 & 11.6 & 11.5 & 11.3 & 11.2 & 11.0 & 10.9 & 10.8 & 10.6 & 10.5 & 10.3 \\
\hline & 15 & 11.3 & 11.1 & 11.0 & 10.8 & 10.7 & 10.5 & 10.4 & 10.3 & 10.1 & 10.0 & 9.8 & 9.7 & 9.5 \\
\hline & 10 & 10.3 & 10.2 & 10.0 & 9.9 & 9.7 & 9.6 & 9.5 & 9.3 & 9.2 & 9.0 & 8.9 & 8.7 & 8.6 \\
\hline & 5 & 8.9 & 8.8 & 8.6 & 8.5 & 8.3 & 8.2 & 8.0 & 7.9 & 7.7 & 7.6 & 7.5 & 7.3 & 7.2 \\
\hline \multirow{13}{*}{ 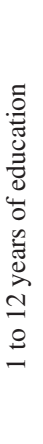 } & 95 & 18.1 & 17.9 & 17.8 & 17.6 & 17.5 & 17.3 & 17.2 & 17.1 & 16.9 & 16.8 & 16.6 & 16.5 & 16.3 \\
\hline & 90 & 16.7 & 16.5 & 16.4 & 16.2 & 16.1 & 15.9 & 15.8 & 15.6 & 15.5 & 15.3 & 15.2 & 15.1 & 14.9 \\
\hline & 85 & 15.7 & 15.6 & 15.4 & 15.3 & 15.1 & 15.0 & 14.8 & 14.7 & 14.5 & 14.4 & 14.3 & 14.1 & 14.0 \\
\hline & 80 & 14.9 & 14.8 & 14.6 & 14.5 & 14.3 & 14.2 & 14.1 & 13.9 & 13.8 & 13.6 & 13.5 & 13.3 & 13.2 \\
\hline & 70 & 13.7 & 13.5 & 13.4 & 13.2 & 13.1 & 12.9 & 12.8 & 12.6 & 12.5 & 12.4 & 12.2 & 12.1 & 11.9 \\
\hline & 60 & 12.6 & 12.5 & 12.3 & 12.2 & 12.0 & 11.9 & 11.7 & 11.6 & 11.4 & 11.3 & 11.1 & 11.0 & 10.9 \\
\hline & 50 & 11.6 & 11.5 & 11.3 & 11.2 & 11.0 & 10.9 & 10.7 & 10.6 & 10.5 & 10.3 & 10.2 & 10.0 & 9.9 \\
\hline & 40 & 10.6 & 10.5 & 10.3 & 10.2 & 10.0 & 9.9 & 9.8 & 9.6 & 9.5 & 9.3 & 9.2 & 9.0 & 8.9 \\
\hline & 30 & 9.6 & 9.4 & 9.3 & 9.1 & 9.0 & 8.8 & 8.7 & 8.5 & 8.4 & 8.3 & 8.1 & 8.0 & 7.8 \\
\hline & 20 & 8.3 & 8.2 & 8.0 & 7.9 & 7.7 & 7.6 & 7.4 & 7.3 & 7.1 & 7.0 & 6.9 & 6.7 & 6.6 \\
\hline & 15 & 7.5 & 7.4 & 7.2 & 7.1 & 6.9 & 6.8 & 6.6 & 6.5 & 6.4 & 6.2 & 6.1 & 5.9 & 5.8 \\
\hline & 10 & 6.6 & 6.4 & 6.3 & 6.1 & 6.0 & 5.8 & 5.7 & 5.6 & 5.4 & 5.3 & 5.1 & 5.0 & 4.8 \\
\hline & 5 & 5.2 & 5.0 & 4.9 & 4.7 & 4.6 & 4.4 & 4.3 & 4.1 & 4.0 & 3.8 & 3.7 & 3.6 & 3.4 \\
\hline
\end{tabular}


Table A11

Normative data for the Letter F stratified by age and education levels for PUERTO RICO

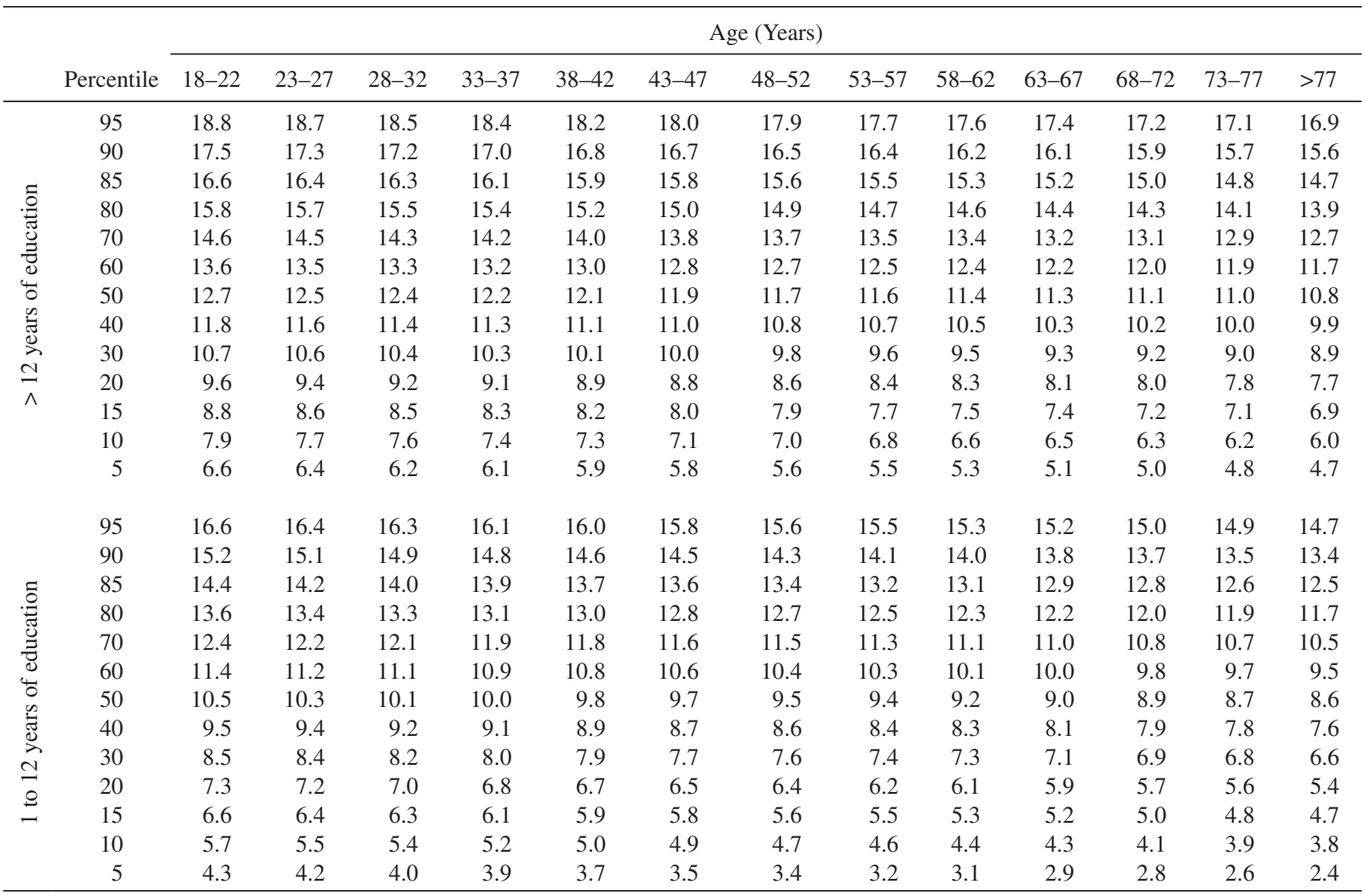

Table A12

Normative data for the Letter A stratified by education levels for ARGENTINA

\begin{tabular}{lcc}
\hline Percentile & 1 to 12 years of education & $>12$ years of education \\
\hline 95 & 17.8 & 21.4 \\
90 & 16.5 & 20.1 \\
85 & 15.6 & 19.2 \\
80 & 14.8 & 18.4 \\
70 & 13.6 & 17.2 \\
60 & 12.6 & 16.2 \\
50 & 11.7 & 15.3 \\
40 & 10.8 & 14.3 \\
30 & 9.7 & 13.3 \\
20 & 8.5 & 12.1 \\
15 & 7.8 & 11.4 \\
10 & 6.9 & 10.5 \\
5 & 5.6 & 9.1 \\
\hline
\end{tabular}


Table A13

Normative data for the Letter A stratified by age and education levels for BOLIVIA

\begin{tabular}{|c|c|c|c|c|c|c|c|c|c|c|c|c|c|c|}
\hline & \multirow[b]{2}{*}{ Percentile } & \multicolumn{13}{|c|}{ Age (Years) } \\
\hline & & $18-22$ & $23-27$ & $28-32$ & $33-37$ & $38-42$ & $43-47$ & $48-52$ & $53-57$ & $58-62$ & $63-67$ & $68-72$ & $73-77$ & $>77$ \\
\hline \multirow{13}{*}{ 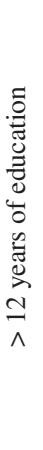 } & 95 & 18.7 & 18.5 & 18.2 & 18.0 & 17.7 & 17.5 & 17.2 & 17.0 & 16.7 & 16.5 & 16.2 & 15.9 & 15.7 \\
\hline & 90 & 17.5 & 17.2 & 17.0 & 16.7 & 16.5 & 16.2 & 16.0 & 15.7 & 15.5 & 15.2 & 15.0 & 14.7 & 14.5 \\
\hline & 85 & 16.7 & 16.4 & 16.2 & 15.9 & 15.6 & 15.4 & 15.1 & 14.9 & 14.6 & 14.4 & 14.1 & 13.9 & 13.6 \\
\hline & 80 & 16.0 & 15.7 & 15.5 & 15.2 & 15.0 & 14.7 & 14.5 & 14.2 & 14.0 & 13.7 & 13.4 & 13.2 & 12.9 \\
\hline & 70 & 14.9 & 14.6 & 14.4 & 14.1 & 13.9 & 13.6 & 13.4 & 13.1 & 12.8 & 12.6 & 12.3 & 12.1 & 11.8 \\
\hline & 60 & 13.9 & 13.7 & 13.4 & 13.2 & 12.9 & 12.7 & 12.4 & 12.2 & 11.9 & 11.7 & 11.4 & 11.2 & 10.9 \\
\hline & 50 & 13.1 & 12.8 & 12.6 & 12.3 & 12.1 & 11.8 & 11.6 & 11.3 & 11.1 & 10.8 & 10.6 & 10.3 & 10.1 \\
\hline & 40 & 12.2 & 12.0 & 11.7 & 11.5 & 11.2 & 11.0 & 10.7 & 10.5 & 10.2 & 9.9 & 9.7 & 9.4 & 9.2 \\
\hline & 30 & 11.3 & 11.0 & 10.8 & 10.5 & 10.3 & 10.0 & 9.8 & 9.5 & 9.3 & 9.0 & 8.8 & 8.5 & 8.3 \\
\hline & 20 & 10.2 & 9.9 & 9.7 & 9.4 & 9.2 & 8.9 & 8.7 & 8.4 & 8.2 & 7.9 & 7.7 & 7.4 & 7.2 \\
\hline & 15 & 9.5 & 9.2 & 9.0 & 8.7 & 8.5 & 8.2 & 8.0 & 7.7 & 7.5 & 7.2 & 7.0 & 6.7 & 6.5 \\
\hline & 10 & 8.7 & 8.4 & 8.2 & 7.9 & 7.7 & 7.4 & 7.2 & 6.9 & 6.7 & 6.4 & 6.2 & 5.9 & 5.6 \\
\hline & 5 & 7.4 & 7.2 & 6.9 & 6.7 & 6.4 & 6.2 & 5.9 & 5.7 & 5.4 & 5.2 & 4.9 & 4.7 & 4.4 \\
\hline \multirow{13}{*}{ 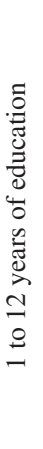 } & 95 & 15.3 & 15.0 & 14.8 & 14.5 & 14.3 & 14.0 & 13.8 & 13.5 & 13.3 & 13.0 & 12.8 & 12.5 & 12.3 \\
\hline & 90 & 14.0 & 13.8 & 13.5 & 13.3 & 13.0 & 12.8 & 12.5 & 12.3 & 12.0 & 11.8 & 11.5 & 11.3 & 11.0 \\
\hline & 85 & 13.2 & 13.0 & 12.7 & 12.5 & 12.2 & 12.0 & 11.7 & 11.5 & 11.2 & 11.0 & 10.7 & 10.4 & 10.2 \\
\hline & 80 & 12.5 & 12.3 & 12.0 & 11.8 & 11.5 & 11.3 & 11.0 & 10.8 & 10.5 & 10.3 & 10.0 & 9.8 & 9.5 \\
\hline & 70 & 11.4 & 11.2 & 10.9 & 10.7 & 10.4 & 10.2 & 9.9 & 9.7 & 9.4 & 9.2 & 8.9 & 8.7 & 8.4 \\
\hline & 60 & 10.5 & 10.3 & 10.0 & 9.7 & 9.5 & 9.2 & 9.0 & 8.7 & 8.5 & 8.2 & 8.0 & 7.7 & 7.5 \\
\hline & 50 & 9.6 & 9.4 & 9.1 & 8.9 & 8.6 & 8.4 & 8.1 & 7.9 & 7.6 & 7.4 & 7.1 & 6.9 & 6.6 \\
\hline & 40 & 8.8 & 8.5 & 8.3 & 8.0 & 7.8 & 7.5 & 7.3 & 7.0 & 6.8 & 6.5 & 6.3 & 6.0 & 5.8 \\
\hline & 30 & 7.9 & 7.6 & 7.3 & 7.1 & 6.8 & 6.6 & 6.3 & 6.1 & 5.8 & 5.6 & 5.3 & 5.1 & 4.8 \\
\hline & 20 & 6.8 & 6.5 & 6.2 & 6.0 & 5.7 & 5.5 & 5.2 & 5.0 & 4.7 & 4.5 & 4.2 & 4.0 & 3.7 \\
\hline & 15 & 6.1 & 5.8 & 5.6 & 5.3 & 5.1 & 4.8 & 4.6 & 4.3 & 4.0 & 3.8 & 3.5 & 3.3 & 3.0 \\
\hline & 10 & 5.2 & 5.0 & 4.7 & 4.5 & 4.2 & 4.0 & 3.7 & 3.5 & 3.2 & 3.0 & 2.7 & 2.5 & 2.2 \\
\hline & 5 & 4.0 & 3.7 & 3.5 & 3.2 & 3.0 & 2.7 & 2.5 & 2.2 & 2.0 & 1.7 & 1.5 & 1.2 & 1.0 \\
\hline
\end{tabular}


Table A14

Normative data for the Letter A stratified by age and education levels for CHILE

\begin{tabular}{|c|c|c|c|c|c|c|c|c|c|c|c|c|c|c|}
\hline & \multirow[b]{2}{*}{ Percentile } & \multicolumn{13}{|c|}{ Age (Years) } \\
\hline & & $18-22$ & $23-27$ & $28-32$ & $33-37$ & $38-42$ & $43-47$ & $48-52$ & $53-57$ & $58-62$ & $63-67$ & $68-72$ & $73-77$ & $>77$ \\
\hline \multirow{13}{*}{ 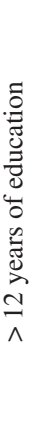 } & 95 & 21.7 & 21.2 & 20.8 & 20.4 & 20.0 & 19.6 & 19.2 & 18.8 & 18.4 & 18.0 & 17.6 & 17.2 & 16.8 \\
\hline & 90 & 20.3 & 19.9 & 19.5 & 19.1 & 18.7 & 18.3 & 17.9 & 17.5 & 17.0 & 16.6 & 16.2 & 15.8 & 15.4 \\
\hline & 85 & 19.4 & 19.0 & 18.6 & 18.2 & 17.8 & 17.4 & 17.0 & 16.6 & 16.2 & 15.7 & 15.3 & 14.9 & 14.5 \\
\hline & 80 & 18.7 & 18.3 & 17.9 & 17.4 & 17.0 & 16.6 & 16.2 & 15.8 & 15.4 & 15.0 & 14.6 & 14.2 & 13.8 \\
\hline & 70 & 17.5 & 17.1 & 16.7 & 16.3 & 15.8 & 15.4 & 15.0 & 14.6 & 14.2 & 13.8 & 13.4 & 13.0 & 12.6 \\
\hline & 60 & 16.5 & 16.1 & 15.7 & 15.2 & 14.8 & 14.4 & 14.0 & 13.6 & 13.2 & 12.8 & 12.4 & 12.0 & 11.6 \\
\hline & 50 & 15.5 & 15.1 & 14.7 & 14.3 & 13.9 & 13.5 & 13.1 & 12.7 & 12.3 & 11.9 & 11.5 & 11.0 & 10.6 \\
\hline & 40 & 14.6 & 14.2 & 13.8 & 13.4 & 13.0 & 12.6 & 12.2 & 11.7 & 11.3 & 10.9 & 10.5 & 10.1 & 9.7 \\
\hline & 30 & 13.6 & 13.2 & 12.8 & 12.4 & 12.0 & 11.6 & 11.1 & 10.7 & 10.3 & 9.9 & 9.5 & 9.1 & 8.7 \\
\hline & 20 & 12.4 & 12.0 & 11.6 & 11.2 & 10.8 & 10.4 & 10.0 & 9.5 & 9.1 & 8.7 & 8.3 & 7.9 & 7.5 \\
\hline & 15 & 11.7 & 11.2 & 10.8 & 10.4 & 10.0 & 9.6 & 9.2 & 8.8 & 8.4 & 8.0 & 7.6 & 7.2 & 6.8 \\
\hline & 10 & 10.8 & 10.3 & 9.9 & 9.5 & 9.1 & 8.7 & 8.3 & 7.9 & 7.5 & 7.1 & 6.7 & 6.3 & 5.9 \\
\hline & 5 & 9.4 & 9.0 & 8.6 & 8.2 & 7.8 & 7.4 & 7.0 & 6.6 & 6.1 & 5.7 & 5.3 & 4.9 & 4.5 \\
\hline \multirow{13}{*}{ 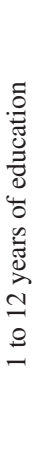 } & 95 & 18.0 & 17.6 & 17.2 & 16.8 & 16.4 & 16.0 & 15.6 & 15.2 & 14.8 & 14.4 & 14.0 & 13.6 & 13.1 \\
\hline & 90 & 16.7 & 16.3 & 15.9 & 15.5 & 15.1 & 14.7 & 14.3 & 13.8 & 13.4 & 13.0 & 12.6 & 12.2 & 11.8 \\
\hline & 85 & 15.8 & 15.4 & 15.0 & 14.6 & 14.2 & 13.8 & 13.4 & 13.0 & 12.5 & 12.1 & 11.7 & 11.3 & 10.9 \\
\hline & 80 & 15.1 & 14.7 & 14.2 & 13.8 & 13.4 & 13.0 & 12.6 & 12.2 & 11.8 & 11.4 & 11.0 & 10.6 & 10.2 \\
\hline & 70 & 13.9 & 13.5 & 13.1 & 12.6 & 12.2 & 11.8 & 11.4 & 11.0 & 10.6 & 10.2 & 9.8 & 9.4 & 9.0 \\
\hline & 60 & 12.9 & 12.5 & 12.0 & 11.6 & 11.2 & 10.8 & 10.4 & 10.0 & 9.6 & 9.2 & 8.8 & 8.4 & 8.0 \\
\hline & 50 & 11.9 & 11.5 & 11.1 & 10.7 & 10.3 & 9.9 & 9.5 & 9.1 & 8.7 & 8.3 & 7.8 & 7.4 & 7.0 \\
\hline & 40 & 11.0 & 10.6 & 10.2 & 9.8 & 9.4 & 9.0 & 8.5 & 8.1 & 7.7 & 7.3 & 6.9 & 6.5 & 6.1 \\
\hline & 30 & 10.0 & 9.6 & 9.2 & 8.8 & 8.4 & 7.9 & 7.5 & 7.1 & 6.7 & 6.3 & 5.9 & 5.5 & 5.1 \\
\hline & 20 & 8.8 & 8.4 & 8.0 & 7.6 & 7.2 & 6.8 & 6.3 & 5.9 & 5.5 & 5.1 & 4.7 & 4.3 & 3.9 \\
\hline & 15 & 8.0 & 7.6 & 7.2 & 6.8 & 6.4 & 6.0 & 5.6 & 5.2 & 4.8 & 4.4 & 4.0 & 3.6 & 3.1 \\
\hline & 10 & 7.1 & 6.7 & 6.3 & 5.9 & 5.5 & 5.1 & 4.7 & 4.3 & 3.9 & 3.5 & 3.1 & 2.7 & 2.3 \\
\hline & 5 & 5.8 & 5.4 & 5.0 & 4.6 & 4.2 & 3.8 & 3.4 & 2.9 & 2.5 & 2.1 & 1.7 & 1.3 & 0.9 \\
\hline
\end{tabular}


Table A15

Normative data for the Letter A stratified by age and education levels for CUBA

\begin{tabular}{|c|c|c|c|c|c|c|c|c|c|c|c|c|c|c|}
\hline & \multirow[b]{2}{*}{ Percentile } & \multicolumn{13}{|c|}{ Age (Years) } \\
\hline & & $18-22$ & $23-27$ & $28-32$ & $33-37$ & $38-42$ & $43-47$ & $48-52$ & $53-57$ & $58-62$ & $63-67$ & $68-72$ & $73-77$ & $>77$ \\
\hline \multirow{13}{*}{ 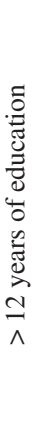 } & 95 & 19.0 & 18.8 & 18.6 & 18.4 & 18.2 & 18.0 & 17.7 & 17.5 & 17.3 & 17.1 & 16.9 & 16.7 & 16.5 \\
\hline & 90 & 17.7 & 17.5 & 17.3 & 17.1 & 16.9 & 16.7 & 16.5 & 16.3 & 16.1 & 15.9 & 15.6 & 15.4 & 15.2 \\
\hline & 85 & 16.9 & 16.7 & 16.5 & 16.3 & 16.1 & 15.9 & 15.6 & 15.4 & 15.2 & 15.0 & 14.8 & 14.6 & 14.4 \\
\hline & 80 & 16.2 & 16.0 & 15.8 & 15.6 & 15.4 & 15.2 & 14.9 & 14.7 & 14.5 & 14.3 & 14.1 & 13.9 & 13.7 \\
\hline & 70 & 15.1 & 14.9 & 14.7 & 14.5 & 14.2 & 14.0 & 13.8 & 13.6 & 13.4 & 13.2 & 13.0 & 12.8 & 12.6 \\
\hline & 60 & 14.1 & 13.9 & 13.7 & 13.5 & 13.3 & 13.1 & 12.9 & 12.7 & 12.5 & 12.2 & 12.0 & 11.8 & 11.6 \\
\hline & 50 & 13.3 & 13.0 & 12.8 & 12.6 & 12.4 & 12.2 & 12.0 & 11.8 & 11.6 & 11.4 & 11.2 & 11.0 & 10.7 \\
\hline & 40 & 12.4 & 12.2 & 12.0 & 11.8 & 11.5 & 11.3 & 11.1 & 10.9 & 10.7 & 10.5 & 10.3 & 10.1 & 9.9 \\
\hline & 30 & 11.4 & 11.2 & 11.0 & 10.8 & 10.6 & 10.4 & 10.2 & 10.0 & 9.8 & 9.5 & 9.3 & 9.1 & 8.9 \\
\hline & 20 & 10.3 & 10.1 & 9.9 & 9.7 & 9.5 & 9.3 & 9.1 & 8.8 & 8.6 & 8.4 & 8.2 & 8.0 & 7.8 \\
\hline & 15 & 9.6 & 9.4 & 9.2 & 9.0 & 8.8 & 8.6 & 8.4 & 8.1 & 7.9 & 7.7 & 7.5 & 7.3 & 7.1 \\
\hline & 10 & 8.8 & 8.6 & 8.4 & 8.1 & 7.9 & 7.7 & 7.5 & 7.3 & 7.1 & 6.9 & 6.7 & 6.5 & 6.3 \\
\hline & 5 & 7.5 & 7.3 & 7.1 & 6.9 & 6.7 & 6.5 & 6.3 & 6.0 & 5.8 & 5.6 & 5.4 & 5.2 & 5.0 \\
\hline \multirow{13}{*}{ 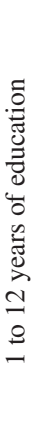 } & 95 & 16.4 & 16.2 & 16.0 & 15.8 & 15.5 & 15.3 & 15.1 & 14.9 & 14.7 & 14.5 & 14.3 & 14.1 & 13.9 \\
\hline & 90 & 15.1 & 14.9 & 14.7 & 14.5 & 14.3 & 14.1 & 13.9 & 13.7 & 13.4 & 13.2 & 13.0 & 12.8 & 12.6 \\
\hline & 85 & 14.3 & 14.1 & 13.9 & 13.7 & 13.4 & 13.2 & 13.0 & 12.8 & 12.6 & 12.4 & 12.2 & 12.0 & 11.8 \\
\hline & 80 & 13.6 & 13.4 & 13.2 & 13.0 & 12.7 & 12.5 & 12.3 & 12.1 & 11.9 & 11.7 & 11.5 & 11.3 & 11.1 \\
\hline & 70 & 12.5 & 12.3 & 12.0 & 11.8 & 11.6 & 11.4 & 11.2 & 11.0 & 10.8 & 10.6 & 10.4 & 10.2 & 9.9 \\
\hline & 60 & 11.5 & 11.3 & 11.1 & 10.9 & 10.7 & 10.5 & 10.3 & 10.1 & 9.8 & 9.6 & 9.4 & 9.2 & 9.0 \\
\hline & 50 & 10.6 & 10.4 & 10.2 & 10.0 & 9.8 & 9.6 & 9.4 & 9.2 & 9.0 & 8.8 & 8.5 & 8.3 & 8.1 \\
\hline & 40 & 9.8 & 9.6 & 9.3 & 9.1 & 8.9 & 8.7 & 8.5 & 8.3 & 8.1 & 7.9 & 7.7 & 7.5 & 7.3 \\
\hline & 30 & 8.8 & 8.6 & 8.4 & 8.2 & 8.0 & 7.8 & 7.6 & 7.4 & 7.1 & 6.9 & 6.7 & 6.5 & 6.3 \\
\hline & 20 & 7.7 & 7.5 & 7.3 & 7.1 & 6.9 & 6.7 & 6.4 & 6.2 & 6.0 & 5.8 & 5.6 & 5.4 & 5.2 \\
\hline & 15 & 7.0 & 6.8 & 6.6 & 6.4 & 6.2 & 6.0 & 5.7 & 5.5 & 5.3 & 5.1 & 4.9 & 4.7 & 4.5 \\
\hline & 10 & 6.2 & 5.9 & 5.7 & 5.5 & 5.3 & 5.1 & 4.9 & 4.7 & 4.5 & 4.3 & 4.1 & 3.9 & 3.6 \\
\hline & 5 & 4.9 & 4.7 & 4.5 & 4.3 & 4.1 & 3.8 & 3.6 & 3.4 & 3.2 & 3.0 & 2.8 & 2.6 & 2.4 \\
\hline
\end{tabular}


Table A16

Normative data for the Letter A stratified by age and education levels for EL SALVADOR

\begin{tabular}{|c|c|c|c|c|c|c|c|c|c|c|c|c|c|c|}
\hline & \multirow[b]{2}{*}{ Percentile } & \multicolumn{13}{|c|}{ Age (Years) } \\
\hline & & $18-22$ & $23-27$ & $28-32$ & $33-37$ & $38-42$ & $43-47$ & $48-52$ & $53-57$ & $58-62$ & $63-67$ & $68-72$ & $73-77$ & $>77$ \\
\hline \multirow{13}{*}{ 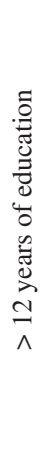 } & 95 & 23.0 & 22.8 & 22.6 & 22.4 & 22.2 & 22.0 & 21.8 & 21.6 & 21.4 & 21.2 & 20.9 & 20.7 & 20.5 \\
\hline & 90 & 21.5 & 21.3 & 21.1 & 20.8 & 20.6 & 20.4 & 20.2 & 20.0 & 19.8 & 19.6 & 19.4 & 19.2 & 19.0 \\
\hline & 85 & 20.4 & 20.2 & 20.0 & 19.8 & 19.6 & 19.4 & 19.2 & 19.0 & 18.7 & 18.5 & 18.3 & 18.1 & 17.9 \\
\hline & 80 & 19.6 & 19.3 & 19.1 & 18.9 & 18.7 & 18.5 & 18.3 & 18.1 & 17.9 & 17.7 & 17.5 & 17.2 & 17.0 \\
\hline & 70 & 18.2 & 17.9 & 17.7 & 17.5 & 17.3 & 17.1 & 16.9 & 16.7 & 16.5 & 16.3 & 16.1 & 15.8 & 15.6 \\
\hline & 60 & 17.0 & 16.8 & 16.6 & 16.3 & 16.1 & 15.9 & 15.7 & 15.5 & 15.3 & 15.1 & 14.9 & 14.7 & 14.5 \\
\hline & 50 & 15.9 & 15.7 & 15.5 & 15.2 & 15.0 & 14.8 & 14.6 & 14.4 & 14.2 & 14.0 & 13.8 & 13.6 & 13.4 \\
\hline & 40 & 14.8 & 14.6 & 14.4 & 14.2 & 13.9 & 13.7 & 13.5 & 13.3 & 13.1 & 12.9 & 12.7 & 12.5 & 12.3 \\
\hline & 30 & 13.6 & 13.4 & 13.2 & 13.0 & 12.8 & 12.6 & 12.3 & 12.1 & 11.9 & 11.7 & 11.5 & 11.3 & 11.1 \\
\hline & 20 & 12.2 & 12.0 & 11.8 & 11.6 & 11.4 & 11.2 & 10.9 & 10.7 & 10.5 & 10.3 & 10.1 & 9.9 & 9.7 \\
\hline & 15 & 11.3 & 11.1 & 10.9 & 10.7 & 10.5 & 10.3 & 10.1 & 9.9 & 9.7 & 9.4 & 9.2 & 9.0 & 8.8 \\
\hline & 10 & 10.3 & 10.1 & 9.9 & 9.7 & 9.4 & 9.2 & 9.0 & 8.8 & 8.6 & 8.4 & 8.2 & 8.0 & 7.8 \\
\hline & 5 & 8.7 & 8.5 & 8.3 & 8.1 & 7.9 & 7.7 & 7.4 & 7.2 & 7.0 & 6.8 & 6.6 & 6.4 & 6.2 \\
\hline \multirow{13}{*}{ 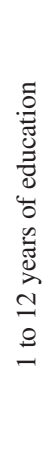 } & 95 & 17.1 & 16.9 & 16.7 & 16.5 & 16.3 & 16.1 & 15.8 & 15.6 & 15.4 & 15.2 & 15.0 & 14.8 & 14.6 \\
\hline & 90 & 15.5 & 15.3 & 15.1 & 14.9 & 14.7 & 14.5 & 14.3 & 14.1 & 13.9 & 13.6 & 13.4 & 13.2 & 13.0 \\
\hline & 85 & 14.5 & 14.3 & 14.1 & 13.9 & 13.6 & 13.4 & 13.2 & 13.0 & 12.8 & 12.6 & 12.4 & 12.2 & 12.0 \\
\hline & 80 & 13.6 & 13.4 & 13.2 & 13.0 & 12.8 & 12.6 & 12.3 & 12.1 & 11.9 & 11.7 & 11.5 & 11.3 & 11.1 \\
\hline & 70 & 12.2 & 12.0 & 11.8 & 11.6 & 11.4 & 11.2 & 10.9 & 10.7 & 10.5 & 10.3 & 10.1 & 9.9 & 9.7 \\
\hline & 60 & 11.0 & 10.8 & 10.6 & 10.4 & 10.2 & 10.0 & 9.8 & 9.6 & 9.3 & 9.1 & 8.9 & 8.7 & 8.5 \\
\hline & 50 & 9.9 & 9.7 & 9.5 & 9.3 & 9.1 & 8.9 & 8.7 & 8.5 & 8.3 & 8.0 & 7.8 & 7.6 & 7.4 \\
\hline & 40 & 8.8 & 8.6 & 8.4 & 8.2 & 8.0 & 7.8 & 7.6 & 7.4 & 7.2 & 7.0 & 6.7 & 6.5 & 6.3 \\
\hline & 30 & 7.7 & 7.5 & 7.2 & 7.0 & 6.8 & 6.6 & 6.4 & 6.2 & 6.0 & 5.8 & 5.6 & 5.4 & 5.1 \\
\hline & 20 & 6.3 & 6.1 & 5.8 & 5.6 & 5.4 & 5.2 & 5.0 & 4.8 & 4.6 & 4.4 & 4.2 & 4.0 & 3.7 \\
\hline & 15 & 5.4 & 5.2 & 5.0 & 4.8 & 4.5 & 4.3 & 4.1 & 3.9 & 3.7 & 3.5 & 3.3 & 3.1 & 2.9 \\
\hline & 10 & 4.3 & 4.1 & 3.9 & 3.7 & 3.5 & 3.3 & 3.1 & 2.9 & 2.7 & 2.4 & 2.2 & 2.0 & 1.8 \\
\hline & 5 & 2.8 & 2.6 & 2.3 & 2.1 & 1.9 & 1.7 & 1.5 & 1.3 & 1.1 & 0.9 & 0.7 & 0.5 & 0.2 \\
\hline
\end{tabular}

Table A17

Normative data for the Letter A stratified by education levels for GUATEMALA

\begin{tabular}{lcc}
\hline Percentile & 1 to 12 years of education & $>$ 12 years of education \\
\hline 95 & 17.8 & 22.5 \\
90 & 16.1 & 20.8 \\
85 & 14.9 & 19.6 \\
80 & 13.9 & 18.6 \\
70 & 12.4 & 17.1 \\
60 & 11.1 & 15.8 \\
50 & 9.9 & 14.6 \\
40 & 8.7 & 13.4 \\
30 & 7.4 & 12.0 \\
20 & 5.8 & 10.5 \\
15 & 4.8 & 9.5 \\
10 & 3.7 & 8.4 \\
5 & 1.9 & 6.6 \\
\hline
\end{tabular}


Table A18

Normative data for the Letter A stratified by age and education levels for HONDURAS

\begin{tabular}{|c|c|c|c|c|c|c|c|c|c|c|c|c|c|c|}
\hline & \multirow[b]{2}{*}{ Percentile } & \multicolumn{13}{|c|}{ Age (Years) } \\
\hline & & $18-22$ & $23-27$ & $28-32$ & $33-37$ & $38-42$ & $43-47$ & $48-52$ & $53-57$ & $58-62$ & $63-67$ & $68-72$ & $73-77$ & $>77$ \\
\hline \multirow{13}{*}{ 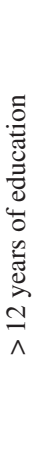 } & 95 & 20.8 & 20.6 & 20.3 & 20.1 & 19.9 & 19.7 & 19.4 & 19.2 & 19.0 & 18.8 & 18.5 & 18.3 & 18.1 \\
\hline & 90 & 19.3 & 19.1 & 18.8 & 18.6 & 18.4 & 18.2 & 17.9 & 17.7 & 17.5 & 17.3 & 17.0 & 16.8 & 16.6 \\
\hline & 85 & 18.3 & 18.1 & 17.8 & 17.6 & 17.4 & 17.2 & 16.9 & 16.7 & 16.5 & 16.3 & 16.0 & 15.8 & 15.6 \\
\hline & 80 & 17.4 & 17.2 & 17.0 & 16.8 & 16.5 & 16.3 & 16.1 & 15.9 & 15.7 & 15.4 & 15.2 & 15.0 & 14.8 \\
\hline & 70 & 16.1 & 15.9 & 15.7 & 15.4 & 15.2 & 15.0 & 14.8 & 14.5 & 14.3 & 14.1 & 13.9 & 13.6 & 13.4 \\
\hline & 60 & 15.0 & 14.8 & 14.5 & 14.3 & 14.1 & 13.9 & 13.6 & 13.4 & 13.2 & 13.0 & 12.7 & 12.5 & 12.3 \\
\hline & 50 & 13.9 & 13.7 & 13.5 & 13.3 & 13.0 & 12.8 & 12.6 & 12.4 & 12.2 & 11.9 & 11.7 & 11.5 & 11.3 \\
\hline & 40 & 12.9 & 12.7 & 12.5 & 12.2 & 12.0 & 11.8 & 11.6 & 11.3 & 11.1 & 10.9 & 10.7 & 10.4 & 10.2 \\
\hline & 30 & 11.8 & 11.6 & 11.3 & 11.1 & 10.9 & 10.7 & 10.4 & 10.2 & 10.0 & 9.8 & 9.5 & 9.3 & 9.1 \\
\hline & 20 & 10.4 & 10.2 & 10.0 & 9.8 & 9.5 & 9.3 & 9.1 & 8.9 & 8.7 & 8.4 & 8.2 & 8.0 & 7.8 \\
\hline & 15 & 9.6 & 9.4 & 9.2 & 8.9 & 8.7 & 8.5 & 8.3 & 8.0 & 7.8 & 7.6 & 7.4 & 7.1 & 6.9 \\
\hline & 10 & 8.6 & 8.4 & 8.2 & 7.9 & 7.7 & 7.5 & 7.3 & 7.0 & 6.8 & 6.6 & 6.4 & 6.1 & 5.9 \\
\hline & 5 & 7.1 & 6.9 & 6.7 & 6.4 & 6.2 & 6.0 & 5.8 & 5.5 & 5.3 & 5.1 & 4.9 & 4.6 & 4.4 \\
\hline \multirow{13}{*}{ 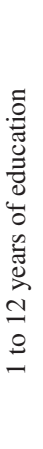 } & 95 & 16.4 & 16.1 & 15.9 & 15.7 & 15.5 & 15.3 & 15.0 & 14.8 & 14.6 & 14.4 & 14.1 & 13.9 & 13.7 \\
\hline & 90 & 14.9 & 14.6 & 14.4 & 14.2 & 14.0 & 13.8 & 13.5 & 13.3 & 13.1 & 12.9 & 12.6 & 12.4 & 12.2 \\
\hline & 85 & 13.9 & 13.6 & 13.4 & 13.2 & 13.0 & 12.8 & 12.5 & 12.3 & 12.1 & 11.9 & 11.6 & 11.4 & 11.2 \\
\hline & 80 & 13.0 & 12.8 & 12.6 & 12.4 & 12.1 & 11.9 & 11.7 & 11.5 & 11.2 & 11.0 & 10.8 & 10.6 & 10.4 \\
\hline & 70 & 11.7 & 11.5 & 11.3 & 11.0 & 10.8 & 10.6 & 10.4 & 10.1 & 9.9 & 9.7 & 9.5 & 9.2 & 9.0 \\
\hline & 60 & 10.6 & 10.4 & 10.1 & 9.9 & 9.7 & 9.5 & 9.2 & 9.0 & 8.8 & 8.6 & 8.3 & 8.1 & 7.9 \\
\hline & 50 & 9.5 & 9.3 & 9.1 & 8.9 & 8.6 & 8.4 & 8.2 & 8.0 & 7.7 & 7.5 & 7.3 & 7.1 & 6.9 \\
\hline & 40 & 8.5 & 8.3 & 8.0 & 7.8 & 7.6 & 7.4 & 7.2 & 6.9 & 6.7 & 6.5 & 6.3 & 6.0 & 5.8 \\
\hline & 30 & 7.4 & 7.1 & 6.9 & 6.7 & 6.5 & 6.3 & 6.0 & 5.8 & 5.6 & 5.4 & 5.1 & 4.9 & 4.7 \\
\hline & 20 & 6.0 & 5.8 & 5.6 & 5.4 & 5.1 & 4.9 & 4.7 & 4.5 & 4.2 & 4.0 & 3.8 & 3.6 & 3.4 \\
\hline & 15 & 5.2 & 5.0 & 4.8 & 4.5 & 4.3 & 4.1 & 3.9 & 3.6 & 3.4 & 3.2 & 3.0 & 2.7 & 2.5 \\
\hline & 10 & 4.2 & 4.0 & 3.8 & 3.5 & 3.3 & 3.1 & 2.9 & 2.6 & 2.4 & 2.2 & 2.0 & 1.7 & 1.5 \\
\hline & 5 & 2.7 & 2.5 & 2.3 & 2.0 & 1.8 & 1.6 & 1.4 & 1.1 & 0.9 & 0.7 & 0.5 & 0.2 & 0.0 \\
\hline
\end{tabular}


Table A19

Normative data for the Letter A stratified by age and education levels for MEXICO

\begin{tabular}{|c|c|c|c|c|c|c|c|c|c|c|c|c|c|c|}
\hline & \multirow[b]{2}{*}{ Percentile } & \multicolumn{13}{|c|}{ Age (Years) } \\
\hline & & $18-22$ & $23-27$ & $28-32$ & $33-37$ & $38-42$ & $43-47$ & $48-52$ & $53-57$ & $58-62$ & $63-67$ & $68-72$ & $73-77$ & $>77$ \\
\hline \multirow{13}{*}{ 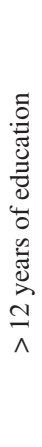 } & 95 & 23.0 & 22.7 & 22.3 & 22.0 & 21.7 & 21.3 & 21.0 & 20.6 & 20.3 & 20.0 & 19.6 & 19.3 & 18.9 \\
\hline & 90 & 21.5 & 21.2 & 20.8 & 20.5 & 20.1 & 19.8 & 19.5 & 19.1 & 18.8 & 18.4 & 18.1 & 17.8 & 17.4 \\
\hline & 85 & 20.5 & 20.1 & 19.8 & 19.5 & 19.1 & 18.8 & 18.4 & 18.1 & 17.8 & 17.4 & 17.1 & 16.7 & 16.4 \\
\hline & 80 & 19.6 & 19.3 & 19.0 & 18.6 & 18.3 & 17.9 & 17.6 & 17.3 & 16.9 & 16.6 & 16.2 & 15.9 & 15.6 \\
\hline & 70 & 18.3 & 17.9 & 17.6 & 17.3 & 16.9 & 16.6 & 16.2 & 15.9 & 15.6 & 15.2 & 14.9 & 14.5 & 14.2 \\
\hline & 60 & 17.1 & 16.8 & 16.5 & 16.1 & 15.8 & 15.4 & 15.1 & 14.8 & 14.4 & 14.1 & 13.7 & 13.4 & 13.1 \\
\hline & 50 & 16.1 & 15.7 & 15.4 & 15.1 & 14.7 & 14.4 & 14.0 & 13.7 & 13.4 & 13.0 & 12.7 & 12.3 & 12.0 \\
\hline & 40 & 15.0 & 14.7 & 14.4 & 14.0 & 13.7 & 13.3 & 13.0 & 12.6 & 12.3 & 12.0 & 11.6 & 11.3 & 10.9 \\
\hline & 30 & 13.9 & 13.5 & 13.2 & 12.9 & 12.5 & 12.2 & 11.8 & 11.5 & 11.2 & 10.8 & 10.5 & 10.1 & 9.8 \\
\hline & 20 & 12.5 & 12.2 & 11.9 & 11.5 & 11.2 & 10.8 & 10.5 & 10.2 & 9.8 & 9.5 & 9.1 & 8.8 & 8.5 \\
\hline & 15 & 11.7 & 11.4 & 11.0 & 10.7 & 10.3 & 10.0 & 9.6 & 9.3 & 9.0 & 8.6 & 8.3 & 7.9 & 7.6 \\
\hline & 10 & 10.7 & 10.3 & 10.0 & 9.7 & 9.3 & 9.0 & 8.6 & 8.3 & 8.0 & 7.6 & 7.3 & 6.9 & 6.6 \\
\hline & 5 & 9.2 & 8.8 & 8.5 & 8.1 & 7.8 & 7.5 & 7.1 & 6.8 & 6.4 & 6.1 & 5.8 & 5.4 & 5.1 \\
\hline \multirow{13}{*}{ 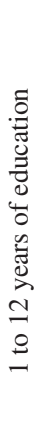 } & 95 & 19.9 & 19.6 & 19.2 & 18.9 & 18.5 & 18.2 & 17.9 & 17.5 & 17.2 & 16.8 & 16.5 & 16.2 & 15.8 \\
\hline & 90 & 18.4 & 18.0 & 17.7 & 17.4 & 17.0 & 16.7 & 16.3 & 16.0 & 15.6 & 15.3 & 15.0 & 14.6 & 14.3 \\
\hline & 85 & 17.4 & 17.0 & 16.7 & 16.3 & 16.0 & 15.7 & 15.3 & 15.0 & 14.6 & 14.3 & 14.0 & 13.6 & 13.3 \\
\hline & 80 & 16.5 & 16.2 & 15.8 & 15.5 & 15.2 & 14.8 & 14.5 & 14.1 & 13.8 & 13.4 & 13.1 & 12.8 & 12.4 \\
\hline & 70 & 15.2 & 14.8 & 14.5 & 14.1 & 13.8 & 13.5 & 13.1 & 12.8 & 12.4 & 12.1 & 11.8 & 11.4 & 11.1 \\
\hline & 60 & 14.0 & 13.7 & 13.3 & 13.0 & 12.7 & 12.3 & 12.0 & 11.6 & 11.3 & 11.0 & 10.6 & 10.3 & 9.9 \\
\hline & 50 & 13.0 & 12.6 & 12.3 & 11.9 & 11.6 & 11.3 & 10.9 & 10.6 & 10.2 & 9.9 & 9.6 & 9.2 & 8.9 \\
\hline & 40 & 11.9 & 11.6 & 11.2 & 10.9 & 10.5 & 10.2 & 9.9 & 9.5 & 9.2 & 8.8 & 8.5 & 8.2 & 7.8 \\
\hline & 30 & 10.8 & 10.4 & 10.1 & 9.7 & 9.4 & 9.1 & 8.7 & 8.4 & 8.0 & 7.7 & 7.4 & 7.0 & 6.7 \\
\hline & 20 & 9.4 & 9.1 & 8.7 & 8.4 & 8.0 & 7.7 & 7.4 & 7.0 & 6.7 & 6.3 & 6.0 & 5.7 & 5.3 \\
\hline & 15 & 8.6 & 8.2 & 7.9 & 7.5 & 7.2 & 6.9 & 6.5 & 6.2 & 5.8 & 5.5 & 5.2 & 4.8 & 4.5 \\
\hline & 10 & 7.6 & 7.2 & 6.9 & 6.5 & 6.2 & 5.8 & 5.5 & 5.2 & 4.8 & 4.5 & 4.1 & 3.8 & 3.5 \\
\hline & 5 & 6.0 & 5.7 & 5.3 & 5.0 & 4.7 & 4.3 & 4.0 & 3.6 & 3.3 & 3.0 & 2.6 & 2.3 & 1.9 \\
\hline
\end{tabular}

Table A20

Normative data for the Letter A stratified by education levels for PARAGUAY

\begin{tabular}{lcc}
\hline Percentile & 1 to 12 years of education & $>$ 12 years of education \\
\hline 95 & 13.7 & 15.0 \\
90 & 13.1 & 14.3 \\
85 & 12.7 & 13.9 \\
80 & 12.3 & 13.5 \\
70 & 11.7 & 13.0 \\
60 & 11.3 & 12.5 \\
50 & 10.8 & 12.0 \\
40 & 10.4 & 11.6 \\
30 & 9.9 & 11.1 \\
20 & 9.3 & 10.5 \\
15 & 9.0 & 10.2 \\
10 & 8.5 & 9.7 \\
5 & 7.9 & 9.1 \\
\hline
\end{tabular}


Table A21

Normative data for the Letter A stratified by age and education levels for PERU

\begin{tabular}{|c|c|c|c|c|c|c|c|c|c|c|c|c|c|c|}
\hline & \multirow[b]{2}{*}{ Percentile } & \multicolumn{13}{|c|}{ Age (Years) } \\
\hline & & $18-22$ & $23-27$ & $28-32$ & $33-37$ & $38-42$ & $43-47$ & $48-52$ & $53-57$ & $58-62$ & $63-67$ & $68-72$ & $73-77$ & $>77$ \\
\hline \multirow{13}{*}{ 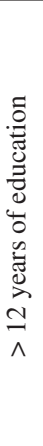 } & 95 & 21.8 & 21.6 & 21.4 & 21.3 & 21.1 & 20.9 & 20.7 & 20.5 & 20.4 & 20.2 & 20.0 & 19.8 & 19.6 \\
\hline & 90 & 20.4 & 20.2 & 20.0 & 19.8 & 19.7 & 19.5 & 19.3 & 19.1 & 18.9 & 18.8 & 18.6 & 18.4 & 18.2 \\
\hline & 85 & 19.4 & 19.3 & 19.1 & 18.9 & 18.7 & 18.5 & 18.4 & 18.2 & 18.0 & 17.8 & 17.6 & 17.4 & 17.3 \\
\hline & 80 & 18.6 & 18.5 & 18.3 & 18.1 & 17.9 & 17.7 & 17.6 & 17.4 & 17.2 & 17.0 & 16.8 & 16.7 & 16.5 \\
\hline & 70 & 17.4 & 17.2 & 17.0 & 16.8 & 16.7 & 16.5 & 16.3 & 16.1 & 15.9 & 15.8 & 15.6 & 15.4 & 15.2 \\
\hline & 60 & 16.3 & 16.1 & 15.9 & 15.8 & 15.6 & 15.4 & 15.2 & 15.0 & 14.9 & 14.7 & 14.5 & 14.3 & 14.1 \\
\hline & 50 & 15.3 & 15.1 & 15.0 & 14.8 & 14.6 & 14.4 & 14.2 & 14.1 & 13.9 & 13.7 & 13.5 & 13.3 & 13.2 \\
\hline & 40 & 14.3 & 14.1 & 14.0 & 13.8 & 13.6 & 13.4 & 13.2 & 13.1 & 12.9 & 12.7 & 12.5 & 12.3 & 12.2 \\
\hline & 30 & 13.3 & 13.1 & 12.9 & 12.7 & 12.5 & 12.4 & 12.2 & 12.0 & 11.8 & 11.6 & 11.5 & 11.3 & 11.1 \\
\hline & 20 & 12.0 & 11.8 & 11.6 & 11.5 & 11.3 & 11.1 & 10.9 & 10.7 & 10.6 & 10.4 & 10.2 & 10.0 & 9.8 \\
\hline & 15 & 11.2 & 11.0 & 10.8 & 10.7 & 10.5 & 10.3 & 10.1 & 9.9 & 9.8 & 9.6 & 9.4 & 9.2 & 9.0 \\
\hline & 10 & 10.3 & 10.1 & 9.9 & 9.7 & 9.5 & 9.4 & 9.2 & 9.0 & 8.8 & 8.6 & 8.4 & 8.3 & 8.1 \\
\hline & 5 & 8.8 & 8.6 & 8.5 & 8.3 & 8.1 & 7.9 & 7.7 & 7.6 & 7.4 & 7.2 & 7.0 & 6.8 & 6.7 \\
\hline \multirow{13}{*}{ 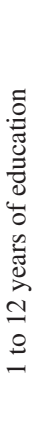 } & 95 & 19.0 & 18.8 & 18.6 & 18.4 & 18.2 & 18.1 & 17.9 & 17.7 & 17.5 & 17.3 & 17.2 & 17.0 & 16.8 \\
\hline & 90 & 17.5 & 17.4 & 17.2 & 17.0 & 16.8 & 16.6 & 16.5 & 16.3 & 16.1 & 15.9 & 15.7 & 15.5 & 15.4 \\
\hline & 85 & 16.6 & 16.4 & 16.2 & 16.0 & 15.9 & 15.7 & 15.5 & 15.3 & 15.1 & 15.0 & 14.8 & 14.6 & 14.4 \\
\hline & 80 & 15.8 & 15.6 & 15.4 & 15.3 & 15.1 & 14.9 & 14.7 & 14.5 & 14.3 & 14.2 & 14.0 & 13.8 & 13.6 \\
\hline & 70 & 14.5 & 14.3 & 14.2 & 14.0 & 13.8 & 13.6 & 13.4 & 13.3 & 13.1 & 12.9 & 12.7 & 12.5 & 12.4 \\
\hline & 60 & 13.5 & 13.3 & 13.1 & 12.9 & 12.7 & 12.6 & 12.4 & 12.2 & 12.0 & 11.8 & 11.7 & 11.5 & 11.3 \\
\hline & 50 & 12.5 & 12.3 & 12.1 & 11.9 & 11.7 & 11.6 & 11.4 & 11.2 & 11.0 & 10.8 & 10.7 & 10.5 & 10.3 \\
\hline & 40 & 11.5 & 11.3 & 11.1 & 10.9 & 10.8 & 10.6 & 10.4 & 10.2 & 10.0 & 9.9 & 9.7 & 9.5 & 9.3 \\
\hline & 30 & 10.4 & 10.2 & 10.1 & 9.9 & 9.7 & 9.5 & 9.3 & 9.1 & 9.0 & 8.8 & 8.6 & 8.4 & 8.2 \\
\hline & 20 & 9.1 & 9.0 & 8.8 & 8.6 & 8.4 & 8.2 & 8.1 & 7.9 & 7.7 & 7.5 & 7.3 & 7.2 & 7.0 \\
\hline & 15 & 8.4 & 8.2 & 8.0 & 7.8 & 7.6 & 7.5 & 7.3 & 7.1 & 6.9 & 6.7 & 6.5 & 6.4 & 6.2 \\
\hline & 10 & 7.4 & 7.2 & 7.0 & 6.9 & 6.7 & 6.5 & 6.3 & 6.1 & 6.0 & 5.8 & 5.6 & 5.4 & 5.2 \\
\hline & 5 & 6.0 & 5.8 & 5.6 & 5.4 & 5.3 & 5.1 & 4.9 & 4.7 & 4.5 & 4.4 & 4.2 & 4.0 & 3.8 \\
\hline
\end{tabular}


Table A22

Normative data for the Letter A stratified by age and education levels for PUERTO RICO

\begin{tabular}{|c|c|c|c|c|c|c|c|c|c|c|c|c|c|c|}
\hline & \multirow[b]{2}{*}{ Percentile } & \multicolumn{13}{|c|}{ Age (Years) } \\
\hline & & $18-22$ & $23-27$ & $28-32$ & $33-37$ & $38-42$ & $43-47$ & $48-52$ & $53-57$ & $58-62$ & $63-67$ & $68-72$ & $73-77$ & $>77$ \\
\hline \multirow{13}{*}{ 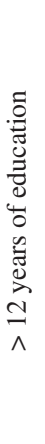 } & 95 & 20.0 & 19.7 & 19.5 & 19.2 & 18.9 & 18.6 & 18.4 & 18.1 & 17.8 & 17.6 & 17.3 & 17.0 & 16.8 \\
\hline & 90 & 18.7 & 18.4 & 18.1 & 17.8 & 17.6 & 17.3 & 17.0 & 16.8 & 16.5 & 16.2 & 16.0 & 15.7 & 15.4 \\
\hline & 85 & 17.8 & 17.5 & 17.2 & 17.0 & 16.7 & 16.4 & 16.1 & 15.9 & 15.6 & 15.3 & 15.1 & 14.8 & 14.5 \\
\hline & 80 & 17.0 & 16.8 & 16.5 & 16.2 & 15.9 & 15.7 & 15.4 & 15.1 & 14.9 & 14.6 & 14.3 & 14.1 & 13.8 \\
\hline & 70 & 15.8 & 15.6 & 15.3 & 15.0 & 14.8 & 14.5 & 14.2 & 13.9 & 13.7 & 13.4 & 13.1 & 12.9 & 12.6 \\
\hline & 60 & 14.8 & 14.6 & 14.3 & 14.0 & 13.7 & 13.5 & 13.2 & 12.9 & 12.7 & 12.4 & 12.1 & 11.9 & 11.6 \\
\hline & 50 & 13.9 & 13.6 & 13.4 & 13.1 & 12.8 & 12.5 & 12.3 & 12.0 & 11.7 & 11.5 & 11.2 & 10.9 & 10.7 \\
\hline & 40 & 13.0 & 12.7 & 12.4 & 12.2 & 11.9 & 11.6 & 11.3 & 11.1 & 10.8 & 10.5 & 10.3 & 10.0 & 9.7 \\
\hline & 30 & 12.0 & 11.7 & 11.4 & 11.1 & 10.9 & 10.6 & 10.3 & 10.1 & 9.8 & 9.5 & 9.3 & 9.0 & 8.7 \\
\hline & 20 & 10.8 & 10.5 & 10.2 & 10.0 & 9.7 & 9.4 & 9.2 & 8.9 & 8.6 & 8.3 & 8.1 & 7.8 & 7.5 \\
\hline & 15 & 10.0 & 9.8 & 9.5 & 9.2 & 8.9 & 8.7 & 8.4 & 8.1 & 7.9 & 7.6 & 7.3 & 7.1 & 6.8 \\
\hline & 10 & 9.1 & 8.9 & 8.6 & 8.3 & 8.1 & 7.8 & 7.5 & 7.2 & 7.0 & 6.7 & 6.4 & 6.2 & 5.9 \\
\hline & 5 & 7.8 & 7.5 & 7.3 & 7.0 & 6.7 & 6.4 & 6.2 & 5.9 & 5.6 & 5.4 & 5.1 & 4.8 & 4.6 \\
\hline \multirow{13}{*}{ 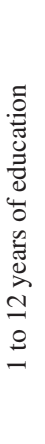 } & 95 & 18.2 & 18.0 & 17.7 & 17.4 & 17.1 & 16.9 & 16.6 & 16.3 & 16.1 & 15.8 & 15.5 & 15.3 & 15.0 \\
\hline & 90 & 16.9 & 16.6 & 16.3 & 16.1 & 15.8 & 15.5 & 15.3 & 15.0 & 14.7 & 14.5 & 14.2 & 13.9 & 13.7 \\
\hline & 85 & 16.0 & 15.7 & 15.5 & 15.2 & 14.9 & 14.6 & 14.4 & 14.1 & 13.8 & 13.6 & 13.3 & 13.0 & 12.8 \\
\hline & 80 & 15.2 & 15.0 & 14.7 & 14.4 & 14.2 & 13.9 & 13.6 & 13.4 & 13.1 & 12.8 & 12.6 & 12.3 & 12.0 \\
\hline & 70 & 14.1 & 13.8 & 13.5 & 13.3 & 13.0 & 12.7 & 12.4 & 12.2 & 11.9 & 11.6 & 11.4 & 11.1 & 10.8 \\
\hline & 60 & 13.1 & 12.8 & 12.5 & 12.2 & 12.0 & 11.7 & 11.4 & 11.2 & 10.9 & 10.6 & 10.4 & 10.1 & 9.8 \\
\hline & 50 & 12.1 & 11.9 & 11.6 & 11.3 & 11.0 & 10.8 & 10.5 & 10.2 & 10.0 & 9.7 & 9.4 & 9.2 & 8.9 \\
\hline & 40 & 11.2 & 10.9 & 10.7 & 10.4 & 10.1 & 9.8 & 9.6 & 9.3 & 9.0 & 8.8 & 8.5 & 8.2 & 8.0 \\
\hline & 30 & 10.2 & 9.9 & 9.6 & 9.4 & 9.1 & 8.8 & 8.6 & 8.3 & 8.0 & 7.8 & 7.5 & 7.2 & 7.0 \\
\hline & 20 & 9.0 & 8.7 & 8.5 & 8.2 & 7.9 & 7.6 & 7.4 & 7.1 & 6.8 & 6.6 & 6.3 & 6.0 & 5.8 \\
\hline & 15 & 8.3 & 8.0 & 7.7 & 7.4 & 7.2 & 6.9 & 6.6 & 6.4 & 6.1 & 5.8 & 5.6 & 5.3 & 5.0 \\
\hline & 10 & 7.4 & 7.1 & 6.8 & 6.6 & 6.3 & 6.0 & 5.7 & 5.5 & 5.2 & 4.9 & 4.7 & 4.4 & 4.1 \\
\hline & 5 & 6.0 & 5.8 & 5.5 & 5.2 & 4.9 & 4.7 & 4.4 & 4.1 & 3.9 & 3.6 & 3.3 & 3.1 & 2.8 \\
\hline
\end{tabular}

Table A23

Normative data for the Letter S stratified by education levels for ARGENTINA

\begin{tabular}{lcc}
\hline Percentile & 1 to 12 years of education & $>12$ years of education \\
\hline 95 & 18.4 & 21.4 \\
90 & 17.0 & 20.0 \\
85 & 16.1 & 19.0 \\
80 & 15.3 & 18.3 \\
70 & 14.1 & 17.0 \\
60 & 13.0 & 16.0 \\
50 & 12.1 & 15.0 \\
40 & 11.1 & 14.1 \\
30 & 10.1 & 13.0 \\
20 & 8.8 & 11.8 \\
15 & 8.1 & 11.0 \\
10 & 7.1 & 10.1 \\
5 & 5.7 & 8.7 \\
\hline
\end{tabular}


Table A24

Normative data for the Letter $\mathrm{S}$ stratified by age and education levels for BOLIVIA

\begin{tabular}{|c|c|c|c|c|c|c|c|c|c|c|c|c|c|c|}
\hline & \multirow[b]{2}{*}{ Percentile } & \multicolumn{13}{|c|}{ Age (Years) } \\
\hline & & $18-22$ & $23-27$ & $28-32$ & $33-37$ & $38-42$ & $43-47$ & $48-52$ & $53-57$ & $58-62$ & $63-67$ & $68-72$ & $73-77$ & $>77$ \\
\hline \multirow{13}{*}{ 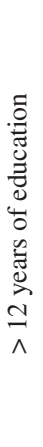 } & 95 & 17.5 & 17.3 & 17.1 & 16.8 & 16.6 & 16.4 & 16.1 & 15.9 & 15.7 & 15.4 & 15.2 & 15.0 & 14.7 \\
\hline & 90 & 16.3 & 16.1 & 15.8 & 15.6 & 15.4 & 15.1 & 14.9 & 14.7 & 14.4 & 14.2 & 14.0 & 13.8 & 13.5 \\
\hline & 85 & 15.5 & 15.2 & 15.0 & 14.8 & 14.6 & 14.3 & 14.1 & 13.9 & 13.6 & 13.4 & 13.2 & 12.9 & 12.7 \\
\hline & 80 & 14.8 & 14.6 & 14.3 & 14.1 & 13.9 & 13.6 & 13.4 & 13.2 & 12.9 & 12.7 & 12.5 & 12.3 & 12.0 \\
\hline & 70 & 13.7 & 13.5 & 13.2 & 13.0 & 12.8 & 12.5 & 12.3 & 12.1 & 11.9 & 11.6 & 11.4 & 11.2 & 10.9 \\
\hline & 60 & 12.8 & 12.6 & 12.3 & 12.1 & 11.9 & 11.6 & 11.4 & 11.2 & 10.9 & 10.7 & 10.5 & 10.2 & 10.0 \\
\hline & 50 & 11.9 & 11.7 & 11.5 & 11.2 & 11.0 & 10.8 & 10.5 & 10.3 & 10.1 & 9.9 & 9.6 & 9.4 & 9.2 \\
\hline & 40 & 11.1 & 10.9 & 10.6 & 10.4 & 10.2 & 9.9 & 9.7 & 9.5 & 9.2 & 9.0 & 8.8 & 8.5 & 8.3 \\
\hline & 30 & 10.2 & 9.9 & 9.7 & 9.5 & 9.2 & 9.0 & 8.8 & 8.5 & 8.3 & 8.1 & 7.9 & 7.6 & 7.4 \\
\hline & 20 & 9.1 & 8.8 & 8.6 & 8.4 & 8.1 & 7.9 & 7.7 & 7.5 & 7.2 & 7.0 & 6.8 & 6.5 & 6.3 \\
\hline & 15 & 8.4 & 8.2 & 7.9 & 7.7 & 7.5 & 7.2 & 7.0 & 6.8 & 6.5 & 6.3 & 6.1 & 5.9 & 5.6 \\
\hline & 10 & 7.6 & 7.3 & 7.1 & 6.9 & 6.7 & 6.4 & 6.2 & 6.0 & 5.7 & 5.5 & 5.3 & 5.0 & 4.8 \\
\hline & 5 & 6.3 & 6.1 & 5.9 & 5.7 & 5.4 & 5.2 & 5.0 & 4.7 & 4.5 & 4.3 & 4.0 & 3.8 & 3.6 \\
\hline \multirow{13}{*}{ 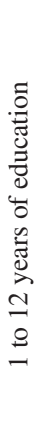 } & 95 & 14.1 & 13.9 & 13.7 & 13.4 & 13.2 & 13.0 & 12.7 & 12.5 & 12.3 & 12.0 & 11.8 & 11.6 & 11.3 \\
\hline & 90 & 12.9 & 12.7 & 12.4 & 12.2 & 12.0 & 11.7 & 11.5 & 11.3 & 11.0 & 10.8 & 10.6 & 10.3 & 10.1 \\
\hline & 85 & 12.1 & 11.8 & 11.6 & 11.4 & 11.1 & 10.9 & 10.7 & 10.5 & 10.2 & 10.0 & 9.8 & 9.5 & 9.3 \\
\hline & 80 & 11.4 & 11.2 & 10.9 & 10.7 & 10.5 & 10.2 & 10.0 & 9.8 & 9.5 & 9.3 & 9.1 & 8.8 & 8.6 \\
\hline & 70 & 10.3 & 10.1 & 9.8 & 9.6 & 9.4 & 9.1 & 8.9 & 8.7 & 8.5 & 8.2 & 8.0 & 7.8 & 7.5 \\
\hline & 60 & 9.4 & 9.1 & 8.9 & 8.7 & 8.5 & 8.2 & 8.0 & 7.8 & 7.5 & 7.3 & 7.1 & 6.8 & 6.6 \\
\hline & 50 & 8.5 & 8.3 & 8.1 & 7.8 & 7.6 & 7.4 & 7.1 & 6.9 & 6.7 & 6.4 & 6.2 & 6.0 & 5.8 \\
\hline & 40 & 7.7 & 7.4 & 7.2 & 7.0 & 6.8 & 6.5 & 6.3 & 6.1 & 5.8 & 5.6 & 5.4 & 5.1 & 4.9 \\
\hline & 30 & 6.8 & 6.5 & 6.3 & 6.1 & 5.8 & 5.6 & 5.4 & 5.1 & 4.9 & 4.7 & 4.4 & 4.2 & 4.0 \\
\hline & 20 & 5.7 & 5.4 & 5.2 & 5.0 & 4.7 & 4.5 & 4.3 & 4.1 & 3.8 & 3.6 & 3.4 & 3.1 & 2.9 \\
\hline & 15 & 5.0 & 4.8 & 4.5 & 4.3 & 4.1 & 3.8 & 3.6 & 3.4 & 3.1 & 2.9 & 2.7 & 2.4 & 2.2 \\
\hline & 10 & 4.2 & 3.9 & 3.7 & 3.5 & 3.2 & 3.0 & 2.8 & 2.6 & 2.3 & 2.1 & 1.9 & 1.6 & 1.4 \\
\hline & 5 & 2.9 & 2.7 & 2.5 & 2.3 & 2.0 & 1.8 & 1.6 & 1.3 & 1.1 & 0.9 & 0.6 & 0.4 & 0.2 \\
\hline
\end{tabular}


Table A25

Normative data for the Letter S stratified by age and education levels for CHILE

\begin{tabular}{|c|c|c|c|c|c|c|c|c|c|c|c|c|c|c|}
\hline & \multirow[b]{2}{*}{ Percentile } & \multicolumn{13}{|c|}{ Age (Years) } \\
\hline & & $18-22$ & $23-27$ & $28-32$ & $33-37$ & $38-42$ & $43-47$ & $48-52$ & $53-57$ & $58-62$ & $63-67$ & $68-72$ & $73-77$ & $>77$ \\
\hline \multirow{13}{*}{ 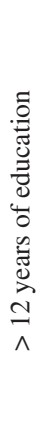 } & 95 & 20.7 & 20.3 & 19.9 & 19.5 & 19.1 & 18.7 & 18.3 & 17.9 & 17.5 & 17.1 & 16.7 & 16.3 & 15.9 \\
\hline & 90 & 19.4 & 19.0 & 18.6 & 18.2 & 17.8 & 17.5 & 17.1 & 16.7 & 16.3 & 15.9 & 15.5 & 15.1 & 14.7 \\
\hline & 85 & 18.6 & 18.2 & 17.8 & 17.4 & 17.0 & 16.6 & 16.2 & 15.8 & 15.4 & 15.0 & 14.6 & 14.2 & 13.8 \\
\hline & 80 & 17.9 & 17.5 & 17.1 & 16.7 & 16.3 & 15.9 & 15.5 & 15.1 & 14.7 & 14.3 & 13.9 & 13.5 & 13.1 \\
\hline & 70 & 16.7 & 16.3 & 15.9 & 15.6 & 15.2 & 14.8 & 14.4 & 14.0 & 13.6 & 13.2 & 12.8 & 12.4 & 12.0 \\
\hline & 60 & 15.8 & 15.4 & 15.0 & 14.6 & 14.2 & 13.8 & 13.4 & 13.0 & 12.6 & 12.2 & 11.8 & 11.4 & 11.0 \\
\hline & 50 & 14.9 & 14.5 & 14.1 & 13.7 & 13.3 & 12.9 & 12.5 & 12.1 & 11.7 & 11.3 & 10.9 & 10.5 & 10.1 \\
\hline & 40 & 14.0 & 13.6 & 13.2 & 12.8 & 12.4 & 12.0 & 11.6 & 11.2 & 10.8 & 10.4 & 10.0 & 9.6 & 9.2 \\
\hline & 30 & 13.1 & 12.7 & 12.3 & 11.9 & 11.5 & 11.1 & 10.7 & 10.3 & 9.9 & 9.5 & 9.1 & 8.7 & 8.3 \\
\hline & 20 & 11.9 & 11.5 & 11.1 & 10.7 & 10.3 & 9.9 & 9.5 & 9.1 & 8.7 & 8.3 & 7.9 & 7.5 & 7.1 \\
\hline & 15 & 11.2 & 10.8 & 10.4 & 10.0 & 9.6 & 9.2 & 8.8 & 8.4 & 8.0 & 7.6 & 7.2 & 6.8 & 6.4 \\
\hline & 10 & 10.4 & 10.0 & 9.6 & 9.2 & 8.8 & 8.4 & 8.0 & 7.6 & 7.2 & 6.8 & 6.4 & 6.0 & 5.6 \\
\hline & 5 & 9.1 & 8.7 & 8.3 & 7.9 & 7.5 & 7.1 & 6.7 & 6.3 & 5.9 & 5.5 & 5.1 & 4.7 & 4.3 \\
\hline \multirow{13}{*}{ 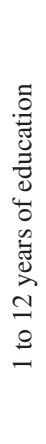 } & 95 & 17.3 & 16.9 & 16.5 & 16.1 & 15.7 & 15.3 & 14.9 & 14.5 & 14.1 & 13.8 & 13.4 & 13.0 & 12.6 \\
\hline & 90 & 16.1 & 15.7 & 15.3 & 14.9 & 14.5 & 14.1 & 13.7 & 13.3 & 12.9 & 12.5 & 12.1 & 11.7 & 11.3 \\
\hline & 85 & 15.2 & 14.8 & 14.4 & 14.0 & 13.6 & 13.2 & 12.8 & 12.4 & 12.0 & 11.6 & 11.2 & 10.8 & 10.4 \\
\hline & 80 & 14.5 & 14.1 & 13.7 & 13.3 & 12.9 & 12.5 & 12.1 & 11.7 & 11.3 & 10.9 & 10.5 & 10.1 & 9.7 \\
\hline & 70 & 13.4 & 13.0 & 12.6 & 12.2 & 11.8 & 11.4 & 11.0 & 10.6 & 10.2 & 9.8 & 9.4 & 9.0 & 8.6 \\
\hline & 60 & 12.4 & 12.0 & 11.6 & 11.2 & 10.8 & 10.4 & 10.0 & 9.6 & 9.2 & 8.8 & 8.4 & 8.0 & 7.6 \\
\hline & 50 & 11.5 & 11.1 & 10.7 & 10.3 & 9.9 & 9.5 & 9.1 & 8.7 & 8.3 & 7.9 & 7.5 & 7.1 & 6.7 \\
\hline & 40 & 10.6 & 10.2 & 9.8 & 9.4 & 9.0 & 8.6 & 8.2 & 7.8 & 7.4 & 7.0 & 6.6 & 6.3 & 5.9 \\
\hline & 30 & 9.7 & 9.3 & 8.9 & 8.5 & 8.1 & 7.7 & 7.3 & 6.9 & 6.5 & 6.1 & 5.7 & 5.3 & 4.9 \\
\hline & 20 & 8.5 & 8.1 & 7.7 & 7.3 & 6.9 & 6.5 & 6.1 & 5.8 & 5.4 & 5.0 & 4.6 & 4.2 & 3.8 \\
\hline & 15 & 7.8 & 7.4 & 7.0 & 6.6 & 6.2 & 5.8 & 5.4 & 5.0 & 4.6 & 4.2 & 3.8 & 3.4 & 3.1 \\
\hline & 10 & 7.0 & 6.6 & 6.2 & 5.8 & 5.4 & 5.0 & 4.6 & 4.2 & 3.8 & 3.4 & 3.0 & 2.6 & 2.2 \\
\hline & 5 & 5.7 & 5.3 & 4.9 & 4.5 & 4.1 & 3.7 & 3.3 & 2.9 & 2.5 & 2.1 & 1.7 & 1.3 & 0.9 \\
\hline
\end{tabular}


Table A26

Normative data for the Letter S stratified by age and education levels for CUBA

\begin{tabular}{|c|c|c|c|c|c|c|c|c|c|c|c|c|c|c|}
\hline & \multirow[b]{2}{*}{ Percentile } & \multicolumn{13}{|c|}{ Age (Years) } \\
\hline & & $18-22$ & $23-27$ & $28-32$ & $33-37$ & $38-42$ & $43-47$ & $48-52$ & $53-57$ & $58-62$ & $63-67$ & $68-72$ & $73-77$ & $>77$ \\
\hline \multirow{13}{*}{ 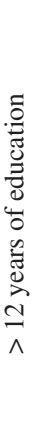 } & 95 & 17.7 & 17.5 & 17.4 & 17.2 & 17.1 & 16.9 & 16.7 & 16.6 & 16.4 & 16.3 & 16.1 & 16.0 & 15.8 \\
\hline & 90 & 16.4 & 16.3 & 16.1 & 16.0 & 15.8 & 15.6 & 15.5 & 15.3 & 15.2 & 15.0 & 14.9 & 14.7 & 14.5 \\
\hline & 85 & 15.6 & 15.4 & 15.3 & 15.1 & 15.0 & 14.8 & 14.6 & 14.5 & 14.3 & 14.2 & 14.0 & 13.9 & 13.7 \\
\hline & 80 & 14.9 & 14.7 & 14.6 & 14.4 & 14.3 & 14.1 & 13.9 & 13.8 & 13.6 & 13.5 & 13.3 & 13.2 & 13.0 \\
\hline & 70 & 13.8 & 13.6 & 13.5 & 13.3 & 13.1 & 13.0 & 12.8 & 12.7 & 12.5 & 12.4 & 12.2 & 12.0 & 11.9 \\
\hline & 60 & 12.8 & 12.7 & 12.5 & 12.4 & 12.2 & 12.0 & 11.9 & 11.7 & 11.6 & 11.4 & 11.3 & 11.1 & 10.9 \\
\hline & 50 & 11.9 & 11.8 & 11.6 & 11.5 & 11.3 & 11.2 & 11.0 & 10.8 & 10.7 & 10.5 & 10.4 & 10.2 & 10.1 \\
\hline & 40 & 11.1 & 10.9 & 10.8 & 10.6 & 10.4 & 10.3 & 10.1 & 10.0 & 9.8 & 9.7 & 9.5 & 9.3 & 9.2 \\
\hline & 30 & 10.1 & 10.0 & 9.8 & 9.7 & 9.5 & 9.3 & 9.2 & 9.0 & 8.9 & 8.7 & 8.6 & 8.4 & 8.2 \\
\hline & 20 & 9.0 & 8.9 & 8.7 & 8.5 & 8.4 & 8.2 & 8.1 & 7.9 & 7.8 & 7.6 & 7.4 & 7.3 & 7.1 \\
\hline & 15 & 8.3 & 8.2 & 8.0 & 7.8 & 7.7 & 7.5 & 7.4 & 7.2 & 7.1 & 6.9 & 6.7 & 6.6 & 6.4 \\
\hline & 10 & 7.5 & 7.3 & 7.2 & 7.0 & 6.8 & 6.7 & 6.5 & 6.4 & 6.2 & 6.1 & 5.9 & 5.7 & 5.6 \\
\hline & 5 & 6.2 & 6.1 & 5.9 & 5.7 & 5.6 & 5.4 & 5.3 & 5.1 & 5.0 & 4.8 & 4.6 & 4.5 & 4.3 \\
\hline \multirow{13}{*}{ 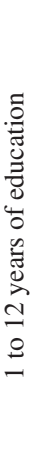 } & 95 & 15.8 & 15.7 & 15.5 & 15.3 & 15.2 & 15.0 & 14.9 & 14.7 & 14.6 & 14.4 & 14.2 & 14.1 & 13.9 \\
\hline & 90 & 14.6 & 14.4 & 14.2 & 14.1 & 13.9 & 13.8 & 13.6 & 13.5 & 13.3 & 13.1 & 13.0 & 12.8 & 12.7 \\
\hline & 85 & 13.7 & 13.6 & 13.4 & 13.2 & 13.1 & 12.9 & 12.8 & 12.6 & 12.5 & 12.3 & 12.1 & 12.0 & 11.8 \\
\hline & 80 & 13.0 & 12.9 & 12.7 & 12.5 & 12.4 & 12.2 & 12.1 & 11.9 & 11.8 & 11.6 & 11.4 & 11.3 & 11.1 \\
\hline & 70 & 11.9 & 11.7 & 11.6 & 11.4 & 11.3 & 11.1 & 11.0 & 10.8 & 10.6 & 10.5 & 10.3 & 10.2 & 10.0 \\
\hline & 60 & 11.0 & 10.8 & 10.6 & 10.5 & 10.3 & 10.2 & 10.0 & 9.9 & 9.7 & 9.5 & 9.4 & 9.2 & 9.1 \\
\hline & 50 & 10.1 & 9.9 & 9.8 & 9.6 & 9.4 & 9.3 & 9.1 & 9.0 & 8.8 & 8.7 & 8.5 & 8.3 & 8.2 \\
\hline & 40 & 9.2 & 9.0 & 8.9 & 8.7 & 8.6 & 8.4 & 8.3 & 8.1 & 7.9 & 7.8 & 7.6 & 7.5 & 7.3 \\
\hline & 30 & 8.3 & 8.1 & 7.9 & 7.8 & 7.6 & 7.5 & 7.3 & 7.2 & 7.0 & 6.8 & 6.7 & 6.5 & 6.4 \\
\hline & 20 & 7.1 & 7.0 & 6.8 & 6.7 & 6.5 & 6.4 & 6.2 & 6.0 & 5.9 & 5.7 & 5.6 & 5.4 & 5.3 \\
\hline & 15 & 6.4 & 6.3 & 6.1 & 6.0 & 5.8 & 5.7 & 5.5 & 5.3 & 5.2 & 5.0 & 4.9 & 4.7 & 4.6 \\
\hline & 10 & 5.6 & 5.4 & 5.3 & 5.1 & 5.0 & 4.8 & 4.7 & 4.5 & 4.3 & 4.2 & 4.0 & 3.9 & 3.7 \\
\hline & 5 & 4.3 & 4.2 & 4.0 & 3.9 & 3.7 & 3.6 & 3.4 & 3.2 & 3.1 & 2.9 & 2.8 & 2.6 & 2.5 \\
\hline
\end{tabular}


Table A27

Normative data for the Letter S stratified by age and education levels for EL SALVADOR

\begin{tabular}{|c|c|c|c|c|c|c|c|c|c|c|c|c|c|c|}
\hline & \multirow[b]{2}{*}{ Percentile } & \multicolumn{13}{|c|}{ Age (Years) } \\
\hline & & $18-22$ & $23-27$ & $28-32$ & $33-37$ & $38-42$ & $43-47$ & $48-52$ & $53-57$ & $58-62$ & $63-67$ & $68-72$ & $73-77$ & $>77$ \\
\hline \multirow{13}{*}{ 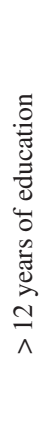 } & 95 & 21.5 & 21.3 & 21.1 & 20.9 & 20.7 & 20.5 & 20.3 & 20.1 & 19.9 & 19.7 & 19.5 & 19.3 & 19.1 \\
\hline & 90 & 20.0 & 19.8 & 19.6 & 19.4 & 19.2 & 19.0 & 18.8 & 18.6 & 18.4 & 18.2 & 18.0 & 17.8 & 17.6 \\
\hline & 85 & 19.0 & 18.8 & 18.6 & 18.5 & 18.3 & 18.1 & 17.9 & 17.7 & 17.5 & 17.3 & 17.1 & 16.9 & 16.7 \\
\hline & 80 & 18.2 & 18.0 & 17.8 & 17.6 & 17.4 & 17.2 & 17.0 & 16.8 & 16.6 & 16.5 & 16.3 & 16.1 & 15.9 \\
\hline & 70 & 16.9 & 16.7 & 16.5 & 16.3 & 16.1 & 15.9 & 15.7 & 15.5 & 15.3 & 15.2 & 15.0 & 14.8 & 14.6 \\
\hline & 60 & 15.8 & 15.6 & 15.4 & 15.2 & 15.0 & 14.8 & 14.6 & 14.4 & 14.3 & 14.1 & 13.9 & 13.7 & 13.5 \\
\hline & 50 & 14.8 & 14.6 & 14.4 & 14.2 & 14.0 & 13.8 & 13.6 & 13.4 & 13.2 & 13.0 & 12.8 & 12.6 & 12.4 \\
\hline & 40 & 13.8 & 13.6 & 13.4 & 13.2 & 13.0 & 12.8 & 12.6 & 12.4 & 12.2 & 12.0 & 11.8 & 11.6 & 11.4 \\
\hline & 30 & 12.7 & 12.5 & 12.3 & 12.1 & 11.9 & 11.7 & 11.5 & 11.3 & 11.1 & 10.9 & 10.7 & 10.5 & 10.3 \\
\hline & 20 & 11.4 & 11.2 & 11.0 & 10.8 & 10.6 & 10.4 & 10.2 & 10.0 & 9.8 & 9.6 & 9.4 & 9.2 & 9.0 \\
\hline & 15 & 10.6 & 10.4 & 10.2 & 10.0 & 9.8 & 9.6 & 9.4 & 9.2 & 9.0 & 8.8 & 8.6 & 8.4 & 8.2 \\
\hline & 10 & 9.6 & 9.4 & 9.2 & 9.0 & 8.8 & 8.6 & 8.4 & 8.2 & 8.0 & 7.8 & 7.6 & 7.4 & 7.2 \\
\hline & 5 & 8.1 & 7.9 & 7.8 & 7.6 & 7.4 & 7.2 & 7.0 & 6.8 & 6.6 & 6.4 & 6.2 & 6.0 & 5.8 \\
\hline \multirow{13}{*}{ 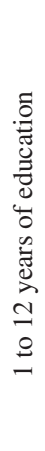 } & 95 & 15.6 & 15.4 & 15.2 & 15.0 & 14.8 & 14.6 & 14.4 & 14.2 & 14.0 & 13.8 & 13.6 & 13.4 & 13.2 \\
\hline & 90 & 14.1 & 13.9 & 13.7 & 13.5 & 13.3 & 13.1 & 13.0 & 12.8 & 12.6 & 12.4 & 12.2 & 12.0 & 11.8 \\
\hline & 85 & 13.2 & 13.0 & 12.8 & 12.6 & 12.4 & 12.2 & 12.0 & 11.8 & 11.6 & 11.4 & 11.2 & 11.0 & 10.8 \\
\hline & 80 & 12.3 & 12.2 & 12.0 & 11.8 & 11.6 & 11.4 & 11.2 & 11.0 & 10.8 & 10.6 & 10.4 & 10.2 & 10.0 \\
\hline & 70 & 11.0 & 10.9 & 10.7 & 10.5 & 10.3 & 10.1 & 9.9 & 9.7 & 9.5 & 9.3 & 9.1 & 8.9 & 8.7 \\
\hline & 60 & 10.0 & 9.8 & 9.6 & 9.4 & 9.2 & 9.0 & 8.8 & 8.6 & 8.4 & 8.2 & 8.0 & 7.8 & 7.6 \\
\hline & 50 & 8.9 & 8.7 & 8.5 & 8.3 & 8.1 & 7.9 & 7.7 & 7.6 & 7.4 & 7.2 & 7.0 & 6.8 & 6.6 \\
\hline & 40 & 7.9 & 7.7 & 7.5 & 7.3 & 7.1 & 6.9 & 6.7 & 6.5 & 6.3 & 6.1 & 5.9 & 5.7 & 5.5 \\
\hline & 30 & 6.8 & 6.6 & 6.4 & 6.2 & 6.0 & 5.8 & 5.6 & 5.4 & 5.2 & 5.0 & 4.8 & 4.6 & 4.4 \\
\hline & 20 & 5.5 & 5.3 & 5.1 & 4.9 & 4.7 & 4.5 & 4.3 & 4.1 & 3.9 & 3.7 & 3.5 & 3.3 & 3.1 \\
\hline & 15 & 4.7 & 4.5 & 4.3 & 4.1 & 3.9 & 3.7 & 3.5 & 3.3 & 3.1 & 2.9 & 2.7 & 2.5 & 2.3 \\
\hline & 10 & 3.7 & 3.5 & 3.3 & 3.1 & 2.9 & 2.7 & 2.5 & 2.3 & 2.1 & 2.0 & 1.8 & 1.6 & 1.4 \\
\hline & 5 & 2.3 & 2.1 & 1.9 & 1.7 & 1.5 & 1.3 & 1.1 & 0.9 & 0.7 & 0.5 & 0.3 & 0.1 & 0.0 \\
\hline
\end{tabular}

Table A28

Normative data for the Letter $\mathrm{S}$ stratified by education levels for GUATEMALA

\begin{tabular}{lcc}
\hline Percentile & 1 to 12 years of education & $>12$ years of education \\
\hline 95 & 17.1 & 22.3 \\
90 & 15.4 & 20.6 \\
85 & 14.3 & 19.4 \\
80 & 13.4 & 18.5 \\
70 & 11.8 & 17.0 \\
60 & 10.6 & 15.7 \\
50 & 9.4 & 14.5 \\
40 & 8.2 & 13.4 \\
30 & 6.9 & 12.1 \\
20 & 5.4 & 10.6 \\
15 & 4.5 & 9.6 \\
10 & 3.4 & 8.5 \\
5 & 1.7 & 6.8 \\
\hline
\end{tabular}


Table A29

Normative data for the Letter S stratified by age and education levels for HONDURAS

\begin{tabular}{|c|c|c|c|c|c|c|c|c|c|c|c|c|c|c|}
\hline & \multirow[b]{2}{*}{ Percentile } & \multicolumn{13}{|c|}{ Age (Years) } \\
\hline & & $18-22$ & $23-27$ & $28-32$ & $33-37$ & $38-42$ & $43-47$ & $48-52$ & $53-57$ & $58-62$ & $63-67$ & $68-72$ & $73-77$ & $>77$ \\
\hline \multirow{13}{*}{ 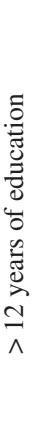 } & 95 & 18.6 & 18.5 & 18.3 & 18.1 & 18.0 & 17.8 & 17.7 & 17.5 & 17.3 & 17.2 & 17.0 & 16.8 & 16.7 \\
\hline & 90 & 17.2 & 17.0 & 16.9 & 16.7 & 16.6 & 16.4 & 16.2 & 16.1 & 15.9 & 15.7 & 15.6 & 15.4 & 15.3 \\
\hline & 85 & 16.3 & 16.1 & 15.9 & 15.8 & 15.6 & 15.5 & 15.3 & 15.1 & 15.0 & 14.8 & 14.6 & 14.5 & 14.3 \\
\hline & 80 & 15.5 & 15.3 & 15.2 & 15.0 & 14.8 & 14.7 & 14.5 & 14.3 & 14.2 & 14.0 & 13.9 & 13.7 & 13.5 \\
\hline & 70 & 14.2 & 14.1 & 13.9 & 13.7 & 13.6 & 13.4 & 13.2 & 13.1 & 12.9 & 12.8 & 12.6 & 12.4 & 12.3 \\
\hline & 60 & 13.2 & 13.0 & 12.8 & 12.7 & 12.5 & 12.3 & 12.2 & 12.0 & 11.9 & 11.7 & 11.5 & 11.4 & 11.2 \\
\hline & 50 & 12.2 & 12.0 & 11.9 & 11.7 & 11.5 & 11.4 & 11.2 & 11.0 & 10.9 & 10.7 & 10.6 & 10.4 & 10.2 \\
\hline & 40 & 11.2 & 11.0 & 10.9 & 10.7 & 10.5 & 10.4 & 10.2 & 10.1 & 9.9 & 9.7 & 9.6 & 9.4 & 9.2 \\
\hline & 30 & 10.1 & 10.0 & 9.8 & 9.6 & 9.5 & 9.3 & 9.2 & 9.0 & 8.8 & 8.7 & 8.5 & 8.3 & 8.2 \\
\hline & 20 & 8.9 & 8.7 & 8.6 & 8.4 & 8.2 & 8.1 & 7.9 & 7.7 & 7.6 & 7.4 & 7.3 & 7.1 & 6.9 \\
\hline & 15 & 8.1 & 7.9 & 7.8 & 7.6 & 7.4 & 7.3 & 7.1 & 7.0 & 6.8 & 6.6 & 6.5 & 6.3 & 6.1 \\
\hline & 10 & 7.1 & 7.0 & 6.8 & 6.7 & 6.5 & 6.3 & 6.2 & 6.0 & 5.8 & 5.7 & 5.5 & 5.4 & 5.2 \\
\hline & 5 & 5.7 & 5.6 & 5.4 & 5.2 & 5.1 & 4.9 & 4.8 & 4.6 & 4.4 & 4.3 & 4.1 & 3.9 & 3.8 \\
\hline \multirow{13}{*}{ 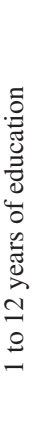 } & 95 & 14.8 & 14.7 & 14.5 & 14.3 & 14.2 & 14.0 & 13.8 & 13.7 & 13.5 & 13.4 & 13.2 & 13.0 & 12.9 \\
\hline & 90 & 13.4 & 13.2 & 13.1 & 12.9 & 12.7 & 12.6 & 12.4 & 12.3 & 12.1 & 11.9 & 11.8 & 11.6 & 11.4 \\
\hline & 85 & 12.5 & 12.3 & 12.1 & 12.0 & 11.8 & 11.6 & 11.5 & 11.3 & 11.2 & 11.0 & 10.8 & 10.7 & 10.5 \\
\hline & 80 & 11.7 & 11.5 & 11.3 & 11.2 & 11.0 & 10.9 & 10.7 & 10.5 & 10.4 & 10.2 & 10.0 & 9.9 & 9.7 \\
\hline & 70 & 10.4 & 10.2 & 10.1 & 9.9 & 9.8 & 9.6 & 9.4 & 9.3 & 9.1 & 8.9 & 8.8 & 8.6 & 8.5 \\
\hline & 60 & 9.4 & 9.2 & 9.0 & 8.9 & 8.7 & 8.5 & 8.4 & 8.2 & 8.0 & 7.9 & 7.7 & 7.6 & 7.4 \\
\hline & 50 & 8.4 & 8.2 & 8.0 & 7.9 & 7.7 & 7.6 & 7.4 & 7.2 & 7.1 & 6.9 & 6.7 & 6.6 & 6.4 \\
\hline & 40 & 7.4 & 7.2 & 7.1 & 6.9 & 6.7 & 6.6 & 6.4 & 6.2 & 6.1 & 5.9 & 5.8 & 5.6 & 5.4 \\
\hline & 30 & 6.3 & 6.2 & 6.0 & 5.8 & 5.7 & 5.5 & 5.3 & 5.2 & 5.0 & 4.9 & 4.7 & 4.5 & 4.4 \\
\hline & 20 & 5.1 & 4.9 & 4.7 & 4.6 & 4.4 & 4.3 & 4.1 & 3.9 & 3.8 & 3.6 & 3.4 & 3.3 & 3.1 \\
\hline & 15 & 4.3 & 4.1 & 4.0 & 3.8 & 3.6 & 3.5 & 3.3 & 3.1 & 3.0 & 2.8 & 2.7 & 2.5 & 2.3 \\
\hline & 10 & 3.3 & 3.2 & 3.0 & 2.8 & 2.7 & 2.5 & 2.4 & 2.2 & 2.0 & 1.9 & 1.7 & 1.5 & 1.4 \\
\hline & 5 & 1.9 & 1.8 & 1.6 & 1.4 & 1.3 & 1.1 & 0.9 & 0.8 & 0.6 & 0.5 & 0.3 & 0.1 & 0.0 \\
\hline
\end{tabular}


Table A30

Normative data for the Letter S stratified by age and education levels for MEXICO

\begin{tabular}{|c|c|c|c|c|c|c|c|c|c|c|c|c|c|c|}
\hline & \multirow[b]{2}{*}{ Percentile } & \multicolumn{13}{|c|}{ Age (Years) } \\
\hline & & $18-22$ & $23-27$ & $28-32$ & $33-37$ & $38-42$ & $43-47$ & $48-52$ & $53-57$ & $58-62$ & $63-67$ & $68-72$ & $73-77$ & $>77$ \\
\hline \multirow{13}{*}{ 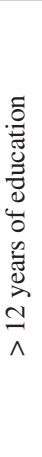 } & 95 & 21.4 & 21.1 & 20.8 & 20.6 & 20.3 & 20.1 & 19.8 & 19.5 & 19.3 & 19.0 & 18.7 & 18.5 & 18.2 \\
\hline & 90 & 19.9 & 19.7 & 19.4 & 19.1 & 18.9 & 18.6 & 18.3 & 18.1 & 17.8 & 17.5 & 17.3 & 17.0 & 16.7 \\
\hline & 85 & 19.0 & 18.7 & 18.4 & 18.2 & 17.9 & 17.6 & 17.4 & 17.1 & 16.8 & 16.6 & 16.3 & 16.0 & 15.8 \\
\hline & 80 & 18.1 & 17.9 & 17.6 & 17.4 & 17.1 & 16.8 & 16.6 & 16.3 & 16.0 & 15.8 & 15.5 & 15.2 & 15.0 \\
\hline & 70 & 16.9 & 16.6 & 16.3 & 16.1 & 15.8 & 15.5 & 15.3 & 15.0 & 14.7 & 14.5 & 14.2 & 13.9 & 13.7 \\
\hline & 60 & 15.8 & 15.5 & 15.2 & 15.0 & 14.7 & 14.4 & 14.2 & 13.9 & 13.6 & 13.4 & 13.1 & 12.9 & 12.6 \\
\hline & 50 & 14.8 & 14.5 & 14.2 & 14.0 & 13.7 & 13.4 & 13.2 & 12.9 & 12.6 & 12.4 & 12.1 & 11.8 & 11.6 \\
\hline & 40 & 13.7 & 13.5 & 13.2 & 13.0 & 12.7 & 12.4 & 12.2 & 11.9 & 11.6 & 11.4 & 11.1 & 10.8 & 10.6 \\
\hline & 30 & 12.7 & 12.4 & 12.1 & 11.9 & 11.6 & 11.3 & 11.1 & 10.8 & 10.5 & 10.3 & 10.0 & 9.7 & 9.5 \\
\hline & 20 & 11.4 & 11.1 & 10.8 & 10.6 & 10.3 & 10.0 & 9.8 & 9.5 & 9.2 & 9.0 & 8.7 & 8.5 & 8.2 \\
\hline & 15 & 10.6 & 10.3 & 10.0 & 9.8 & 9.5 & 9.2 & 9.0 & 8.7 & 8.4 & 8.2 & 7.9 & 7.6 & 7.4 \\
\hline & 10 & 9.6 & 9.3 & 9.1 & 8.8 & 8.5 & 8.3 & 8.0 & 7.7 & 7.5 & 7.2 & 6.9 & 6.7 & 6.4 \\
\hline & 5 & 8.1 & 7.9 & 7.6 & 7.3 & 7.1 & 6.8 & 6.6 & 6.3 & 6.0 & 5.8 & 5.5 & 5.2 & 5.0 \\
\hline \multirow{13}{*}{ 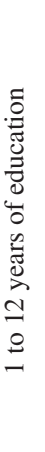 } & 95 & 18.8 & 18.5 & 18.3 & 18.0 & 17.7 & 17.5 & 17.2 & 16.9 & 16.7 & 16.4 & 16.1 & 15.9 & 15.6 \\
\hline & 90 & 17.3 & 17.1 & 16.8 & 16.5 & 16.3 & 16.0 & 15.7 & 15.5 & 15.2 & 15.0 & 14.7 & 14.4 & 14.2 \\
\hline & 85 & 16.4 & 16.1 & 15.8 & 15.6 & 15.3 & 15.0 & 14.8 & 14.5 & 14.2 & 14.0 & 13.7 & 13.5 & 13.2 \\
\hline & 80 & 15.6 & 15.3 & 15.0 & 14.8 & 14.5 & 14.2 & 14.0 & 13.7 & 13.4 & 13.2 & 12.9 & 12.6 & 12.4 \\
\hline & 70 & 14.3 & 14.0 & 13.7 & 13.5 & 13.2 & 12.9 & 12.7 & 12.4 & 12.1 & 11.9 & 11.6 & 11.4 & 11.1 \\
\hline & 60 & 13.2 & 12.9 & 12.6 & 12.4 & 12.1 & 11.9 & 11.6 & 11.3 & 11.1 & 10.8 & 10.5 & 10.3 & 10.0 \\
\hline & 50 & 12.2 & 11.9 & 11.6 & 11.4 & 11.1 & 10.8 & 10.6 & 10.3 & 10.1 & 9.8 & 9.5 & 9.3 & 9.0 \\
\hline & 40 & 11.2 & 10.9 & 10.6 & 10.4 & 10.1 & 9.8 & 9.6 & 9.3 & 9.0 & 8.8 & 8.5 & 8.2 & 8.0 \\
\hline & 30 & 10.1 & 9.8 & 9.5 & 9.3 & 9.0 & 8.7 & 8.5 & 8.2 & 8.0 & 7.7 & 7.4 & 7.2 & 6.9 \\
\hline & 20 & 8.8 & 8.5 & 8.3 & 8.0 & 7.7 & 7.5 & 7.2 & 6.9 & 6.7 & 6.4 & 6.1 & 5.9 & 5.6 \\
\hline & 15 & 8.0 & 7.7 & 7.4 & 7.2 & 6.9 & 6.6 & 6.4 & 6.1 & 5.9 & 5.6 & 5.3 & 5.1 & 4.8 \\
\hline & 10 & 7.0 & 6.7 & 6.5 & 6.2 & 5.9 & 5.7 & 5.4 & 5.2 & 4.9 & 4.6 & 4.4 & 4.1 & 3.8 \\
\hline & 5 & 5.6 & 5.3 & 5.0 & 4.8 & 4.5 & 4.2 & 4.0 & 3.7 & 3.4 & 3.2 & 2.9 & 2.6 & 2.4 \\
\hline
\end{tabular}

Table A31

Normative data for the Letter $\mathrm{S}$ stratified by education levels for PARAGUAY

\begin{tabular}{lcc}
\hline Percentile & 1 to 12 years of education & $>12$ years of education \\
\hline 95 & 13.0 & 15.6 \\
90 & 12.2 & 14.8 \\
85 & 11.8 & 14.4 \\
80 & 11.4 & 14.0 \\
70 & 10.7 & 13.3 \\
60 & 10.2 & 12.8 \\
50 & 9.7 & 12.3 \\
40 & 9.2 & 11.8 \\
30 & 8.7 & 11.3 \\
20 & 8.1 & 10.7 \\
15 & 7.7 & 10.3 \\
10 & 7.2 & 9.8 \\
5 & 6.5 & 9.1 \\
\hline
\end{tabular}


Table A32

Normative data for the Letter S stratified by age and education levels for PERU

\begin{tabular}{|c|c|c|c|c|c|c|c|c|c|c|c|c|c|c|}
\hline & \multirow[b]{2}{*}{ Percentile } & \multicolumn{13}{|c|}{ Age (Years) } \\
\hline & & $18-22$ & $23-27$ & $28-32$ & $33-37$ & $38-42$ & $43-47$ & $48-52$ & $53-57$ & $58-62$ & $63-67$ & $68-72$ & $73-77$ & $>77$ \\
\hline \multirow{13}{*}{ 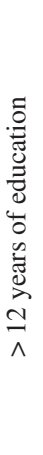 } & 95 & 21.1 & 20.9 & 20.8 & 20.7 & 20.6 & 20.4 & 20.3 & 20.2 & 20.0 & 19.9 & 19.8 & 19.6 & 19.5 \\
\hline & 90 & 19.7 & 19.5 & 19.4 & 19.3 & 19.2 & 19.0 & 18.9 & 18.8 & 18.6 & 18.5 & 18.4 & 18.2 & 18.1 \\
\hline & 85 & 18.7 & 18.6 & 18.5 & 18.4 & 18.2 & 18.1 & 18.0 & 17.8 & 17.7 & 17.6 & 17.4 & 17.3 & 17.2 \\
\hline & 80 & 18.0 & 17.8 & 17.7 & 17.6 & 17.4 & 17.3 & 17.2 & 17.1 & 16.9 & 16.8 & 16.7 & 16.5 & 16.4 \\
\hline & 70 & 16.7 & 16.6 & 16.5 & 16.3 & 16.2 & 16.1 & 15.9 & 15.8 & 15.7 & 15.5 & 15.4 & 15.3 & 15.2 \\
\hline & 60 & 15.7 & 15.6 & 15.4 & 15.3 & 15.2 & 15.0 & 14.9 & 14.8 & 14.6 & 14.5 & 14.4 & 14.2 & 14.1 \\
\hline & 50 & 14.7 & 14.6 & 14.4 & 14.3 & 14.2 & 14.1 & 13.9 & 13.8 & 13.7 & 13.5 & 13.4 & 13.3 & 13.1 \\
\hline & 40 & 13.7 & 13.6 & 13.5 & 13.3 & 13.2 & 13.1 & 13.0 & 12.8 & 12.7 & 12.6 & 12.4 & 12.3 & 12.2 \\
\hline & 30 & 12.7 & 12.6 & 12.4 & 12.3 & 12.2 & 12.0 & 11.9 & 11.8 & 11.6 & 11.5 & 11.4 & 11.2 & 11.1 \\
\hline & 20 & 11.5 & 11.3 & 11.2 & 11.1 & 10.9 & 10.8 & 10.7 & 10.5 & 10.4 & 10.3 & 10.1 & 10.0 & 9.9 \\
\hline & 15 & 10.7 & 10.5 & 10.4 & 10.3 & 10.1 & 10.0 & 9.9 & 9.8 & 9.6 & 9.5 & 9.4 & 9.2 & 9.1 \\
\hline & 10 & 9.7 & 9.6 & 9.5 & 9.3 & 9.2 & 9.1 & 9.0 & 8.8 & 8.7 & 8.6 & 8.4 & 8.3 & 8.2 \\
\hline & 5 & 8.3 & 8.2 & 8.1 & 8.0 & 7.8 & 7.7 & 7.6 & 7.4 & 7.3 & 7.2 & 7.0 & 6.9 & 6.8 \\
\hline \multirow{13}{*}{ 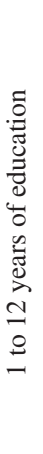 } & 95 & 17.1 & 17.0 & 16.8 & 16.7 & 16.6 & 16.4 & 16.3 & 16.2 & 16.0 & 15.9 & 15.8 & 15.6 & 15.5 \\
\hline & 90 & 15.7 & 15.6 & 15.4 & 15.3 & 15.2 & 15.0 & 14.9 & 14.8 & 14.6 & 14.5 & 14.4 & 14.3 & 14.1 \\
\hline & 85 & 14.8 & 14.6 & 14.5 & 14.4 & 14.2 & 14.1 & 14.0 & 13.8 & 13.7 & 13.6 & 13.5 & 13.3 & 13.2 \\
\hline & 80 & 14.0 & 13.9 & 13.7 & 13.6 & 13.5 & 13.3 & 13.2 & 13.1 & 12.9 & 12.8 & 12.7 & 12.5 & 12.4 \\
\hline & 70 & 12.7 & 12.6 & 12.5 & 12.4 & 12.2 & 12.1 & 12.0 & 11.8 & 11.7 & 11.6 & 11.4 & 11.3 & 11.2 \\
\hline & 60 & 11.7 & 11.6 & 11.4 & 11.3 & 11.2 & 11.0 & 10.9 & 10.8 & 10.6 & 10.5 & 10.4 & 10.3 & 10.1 \\
\hline & 50 & 10.7 & 10.6 & 10.5 & 10.3 & 10.2 & 10.1 & 9.9 & 9.8 & 9.7 & 9.5 & 9.4 & 9.3 & 9.2 \\
\hline & 40 & 9.8 & 9.6 & 9.5 & 9.4 & 9.2 & 9.1 & 9.0 & 8.8 & 8.7 & 8.6 & 8.4 & 8.3 & 8.2 \\
\hline & 30 & 8.7 & 8.6 & 8.4 & 8.3 & 8.2 & 8.1 & 7.9 & 7.8 & 7.7 & 7.5 & 7.4 & 7.3 & 7.1 \\
\hline & 20 & 7.5 & 7.3 & 7.2 & 7.1 & 6.9 & 6.8 & 6.7 & 6.5 & 6.4 & 6.3 & 6.2 & 6.0 & 5.9 \\
\hline & 15 & 6.7 & 6.6 & 6.4 & 6.3 & 6.2 & 6.0 & 5.9 & 5.8 & 5.6 & 5.5 & 5.4 & 5.2 & 5.1 \\
\hline & 10 & 5.8 & 5.6 & 5.5 & 5.4 & 5.2 & 5.1 & 5.0 & 4.8 & 4.7 & 4.6 & 4.4 & 4.3 & 4.2 \\
\hline & 5 & 4.4 & 4.2 & 4.1 & 4.0 & 3.8 & 3.7 & 3.6 & 3.4 & 3.3 & 3.2 & 3.0 & 2.9 & 2.8 \\
\hline
\end{tabular}


Table A33

Normative data for the Letter S stratified by age and education levels for PUERTO RICO

\begin{tabular}{|c|c|c|c|c|c|c|c|c|c|c|c|c|c|c|}
\hline & \multirow[b]{2}{*}{ Percentile } & \multicolumn{13}{|c|}{ Age (Years) } \\
\hline & & $18-22$ & $23-27$ & $28-32$ & $33-37$ & $38-42$ & $43-47$ & $48-52$ & $53-57$ & $58-62$ & $63-67$ & $68-72$ & $73-77$ & $>77$ \\
\hline \multirow{13}{*}{ 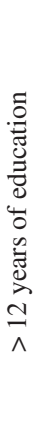 } & 95 & 20.2 & 19.9 & 19.7 & 19.4 & 19.1 & 18.8 & 18.6 & 18.3 & 18.0 & 17.7 & 17.4 & 17.2 & 16.9 \\
\hline & 90 & 18.8 & 18.5 & 18.2 & 17.9 & 17.7 & 17.4 & 17.1 & 16.8 & 16.5 & 16.3 & 16.0 & 15.7 & 15.4 \\
\hline & 85 & 17.8 & 17.5 & 17.2 & 17.0 & 16.7 & 16.4 & 16.1 & 15.8 & 15.6 & 15.3 & 15.0 & 14.7 & 14.4 \\
\hline & 80 & 17.0 & 16.7 & 16.4 & 16.1 & 15.9 & 15.6 & 15.3 & 15.0 & 14.8 & 14.5 & 14.2 & 13.9 & 13.6 \\
\hline & 70 & 15.7 & 15.4 & 15.1 & 14.9 & 14.6 & 14.3 & 14.0 & 13.7 & 13.5 & 13.2 & 12.9 & 12.6 & 12.3 \\
\hline & 60 & 14.6 & 14.3 & 14.0 & 13.8 & 13.5 & 13.2 & 12.9 & 12.6 & 12.4 & 12.1 & 11.8 & 11.5 & 11.2 \\
\hline & 50 & 13.6 & 13.3 & 13.0 & 12.7 & 12.5 & 12.2 & 11.9 & 11.6 & 11.3 & 11.1 & 10.8 & 10.5 & 10.2 \\
\hline & 40 & 12.6 & 12.3 & 12.0 & 11.7 & 11.5 & 11.2 & 10.9 & 10.6 & 10.3 & 10.1 & 9.8 & 9.5 & 9.2 \\
\hline & 30 & 11.5 & 11.2 & 10.9 & 10.6 & 10.4 & 10.1 & 9.8 & 9.5 & 9.2 & 9.0 & 8.7 & 8.4 & 8.1 \\
\hline & 20 & 10.2 & 9.9 & 9.6 & 9.3 & 9.1 & 8.8 & 8.5 & 8.2 & 7.9 & 7.7 & 7.4 & 7.1 & 6.8 \\
\hline & 15 & 9.4 & 9.1 & 8.8 & 8.5 & 8.3 & 8.0 & 7.7 & 7.4 & 7.1 & 6.9 & 6.6 & 6.3 & 6.0 \\
\hline & 10 & 8.4 & 8.1 & 7.8 & 7.6 & 7.3 & 7.0 & 6.7 & 6.4 & 6.2 & 5.9 & 5.6 & 5.3 & 5.0 \\
\hline & 5 & 6.9 & 6.7 & 6.4 & 6.1 & 5.8 & 5.5 & 5.3 & 5.0 & 4.7 & 4.4 & 4.1 & 3.9 & 3.6 \\
\hline \multirow{13}{*}{ 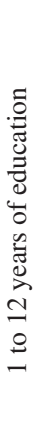 } & 95 & 18.7 & 18.4 & 18.1 & 17.9 & 17.6 & 17.3 & 17.0 & 16.7 & 16.5 & 16.2 & 15.9 & 15.6 & 15.3 \\
\hline & 90 & 17.2 & 17.0 & 16.7 & 16.4 & 16.1 & 15.8 & 15.6 & 15.3 & 15.0 & 14.7 & 14.4 & 14.2 & 13.9 \\
\hline & 85 & 16.3 & 16.0 & 15.7 & 15.4 & 15.1 & 14.9 & 14.6 & 14.3 & 14.0 & 13.8 & 13.5 & 13.2 & 12.9 \\
\hline & 80 & 15.5 & 15.2 & 14.9 & 14.6 & 14.3 & 14.1 & 13.8 & 13.5 & 13.2 & 12.9 & 12.7 & 12.4 & 12.1 \\
\hline & 70 & 14.2 & 13.9 & 13.6 & 13.3 & 13.0 & 12.8 & 12.5 & 12.2 & 11.9 & 11.6 & 11.4 & 11.1 & 10.8 \\
\hline & 60 & 13.1 & 12.8 & 12.5 & 12.2 & 11.9 & 11.7 & 11.4 & 11.1 & 10.8 & 10.6 & 10.3 & 10.0 & 9.7 \\
\hline & 50 & 12.1 & 11.8 & 11.5 & 11.2 & 10.9 & 10.7 & 10.4 & 10.1 & 9.8 & 9.5 & 9.3 & 9.0 & 8.7 \\
\hline & 40 & 11.0 & 10.8 & 10.5 & 10.2 & 9.9 & 9.6 & 9.4 & 9.1 & 8.8 & 8.5 & 8.2 & 8.0 & 7.7 \\
\hline & 30 & 9.9 & 9.7 & 9.4 & 9.1 & 8.8 & 8.6 & 8.3 & 8.0 & 7.7 & 7.4 & 7.2 & 6.9 & 6.6 \\
\hline & 20 & 8.7 & 8.4 & 8.1 & 7.8 & 7.5 & 7.3 & 7.0 & 6.7 & 6.4 & 6.1 & 5.9 & 5.6 & 5.3 \\
\hline & 15 & 7.8 & 7.6 & 7.3 & 7.0 & 6.7 & 6.4 & 6.2 & 5.9 & 5.6 & 5.3 & 5.0 & 4.8 & 4.5 \\
\hline & 10 & 6.9 & 6.6 & 6.3 & 6.0 & 5.8 & 5.5 & 5.2 & 4.9 & 4.6 & 4.4 & 4.1 & 3.8 & 3.5 \\
\hline & 5 & 5.4 & 5.1 & 4.9 & 4.6 & 4.3 & 4.0 & 3.7 & 3.5 & 3.2 & 2.9 & 2.6 & 2.3 & 2.1 \\
\hline
\end{tabular}


Table A34

Normative data for the Animals category stratified by age and education levels for ARGENTINA

\begin{tabular}{|c|c|c|c|c|c|c|c|c|c|c|c|c|c|c|}
\hline & \multirow[b]{2}{*}{ Percentile } & \multicolumn{13}{|c|}{ Age (Years) } \\
\hline & & $18-22$ & $23-27$ & $28-32$ & $33-37$ & $38-42$ & $43-47$ & $48-52$ & $53-57$ & $58-62$ & $63-67$ & $68-72$ & $73-77$ & $>77$ \\
\hline \multirow{13}{*}{ 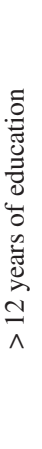 } & 95 & 29.3 & 29.1 & 29.0 & 28.8 & 28.6 & 28.4 & 28.2 & 28.0 & 27.8 & 27.6 & 27.4 & 27.2 & 27.0 \\
\hline & 90 & 27.8 & 27.6 & 27.4 & 27.2 & 27.0 & 26.8 & 26.6 & 26.4 & 26.2 & 26.0 & 25.9 & 25.7 & 25.5 \\
\hline & 85 & 26.7 & 26.5 & 26.4 & 26.2 & 26.0 & 25.8 & 25.6 & 25.4 & 25.2 & 25.0 & 24.8 & 24.6 & 24.4 \\
\hline & 80 & 25.9 & 25.7 & 25.5 & 25.3 & 25.1 & 24.9 & 24.7 & 24.5 & 24.3 & 24.1 & 23.9 & 23.8 & 23.6 \\
\hline & 70 & 24.5 & 24.3 & 24.1 & 23.9 & 23.7 & 23.5 & 23.3 & 23.1 & 22.9 & 22.8 & 22.6 & 22.4 & 22.2 \\
\hline & 60 & 23.3 & 23.1 & 22.9 & 22.7 & 22.5 & 22.4 & 22.2 & 22.0 & 21.8 & 21.6 & 21.4 & 21.2 & 21.0 \\
\hline & 50 & 22.2 & 22.0 & 21.8 & 21.7 & 21.5 & 21.3 & 21.1 & 20.9 & 20.7 & 20.5 & 20.3 & 20.1 & 19.9 \\
\hline & 40 & 21.1 & 21.0 & 20.8 & 20.6 & 20.4 & 20.2 & 20.0 & 19.8 & 19.6 & 19.4 & 19.2 & 19.0 & 18.8 \\
\hline & 30 & 20.0 & 19.8 & 19.6 & 19.4 & 19.2 & 19.0 & 18.8 & 18.6 & 18.4 & 18.2 & 18.1 & 17.9 & 17.7 \\
\hline & 20 & 18.6 & 18.4 & 18.2 & 18.0 & 17.8 & 17.6 & 17.4 & 17.2 & 17.1 & 16.9 & 16.7 & 16.5 & 16.3 \\
\hline & 15 & 17.7 & 17.5 & 17.3 & 17.1 & 17.0 & 16.8 & 16.6 & 16.4 & 16.2 & 16.0 & 15.8 & 15.6 & 15.4 \\
\hline & 10 & 16.7 & 16.5 & 16.3 & 16.1 & 15.9 & 15.7 & 15.5 & 15.3 & 15.1 & 15.0 & 14.8 & 14.6 & 14.4 \\
\hline & 5 & 15.1 & 14.9 & 14.7 & 14.5 & 14.4 & 14.2 & 14.0 & 13.8 & 13.6 & 13.4 & 13.2 & 13.0 & 12.8 \\
\hline \multirow{13}{*}{ 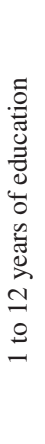 } & 95 & 25.8 & 25.6 & 25.4 & 25.2 & 25.0 & 24.8 & 24.6 & 24.4 & 24.2 & 24.1 & 23.9 & 23.7 & 23.5 \\
\hline & 90 & 24.2 & 24.0 & 23.8 & 23.6 & 23.5 & 23.3 & 23.1 & 22.9 & 22.7 & 22.5 & 22.3 & 22.1 & 21.9 \\
\hline & 85 & 23.2 & 23.0 & 22.8 & 22.6 & 22.4 & 22.2 & 22.0 & 21.8 & 21.6 & 21.5 & 21.3 & 21.1 & 20.9 \\
\hline & 80 & 22.3 & 22.1 & 21.9 & 21.7 & 21.5 & 21.4 & 21.2 & 21.0 & 20.8 & 20.6 & 20.4 & 20.2 & 20.0 \\
\hline & 70 & 20.9 & 20.7 & 20.5 & 20.4 & 20.2 & 20.0 & 19.8 & 19.6 & 19.4 & 19.2 & 19.0 & 18.8 & 18.6 \\
\hline & 60 & 19.8 & 19.6 & 19.4 & 19.2 & 19.0 & 18.8 & 18.6 & 18.4 & 18.2 & 18.0 & 17.8 & 17.6 & 17.5 \\
\hline & 50 & 18.7 & 18.5 & 18.3 & 18.1 & 17.9 & 17.7 & 17.5 & 17.3 & 17.1 & 16.9 & 16.8 & 16.6 & 16.4 \\
\hline & 40 & 17.6 & 17.4 & 17.2 & 17.0 & 16.8 & 16.6 & 16.4 & 16.2 & 16.1 & 15.9 & 15.7 & 15.5 & 15.3 \\
\hline & 30 & 16.4 & 16.2 & 16.0 & 15.8 & 15.7 & 15.5 & 15.3 & 15.1 & 14.9 & 14.7 & 14.5 & 14.3 & 14.1 \\
\hline & 20 & 15.0 & 14.8 & 14.7 & 14.5 & 14.3 & 14.1 & 13.9 & 13.7 & 13.5 & 13.3 & 13.1 & 12.9 & 12.7 \\
\hline & 15 & 14.2 & 14.0 & 13.8 & 13.6 & 13.4 & 13.2 & 13.0 & 12.8 & 12.6 & 12.4 & 12.2 & 12.1 & 11.9 \\
\hline & 10 & 13.1 & 12.9 & 12.7 & 12.6 & 12.4 & 12.2 & 12.0 & 11.8 & 11.6 & 11.4 & 11.2 & 11.0 & 10.8 \\
\hline & 5 & 11.6 & 11.4 & 11.2 & 11.0 & 10.8 & 10.6 & 10.4 & 10.2 & 10.0 & 9.8 & 9.6 & 9.5 & 9.3 \\
\hline
\end{tabular}


Table A35

Normative data for the Animals category stratified by age and education levels for BOLIVIA

\begin{tabular}{|c|c|c|c|c|c|c|c|c|c|c|c|c|c|c|}
\hline & \multirow[b]{2}{*}{ Percentile } & \multicolumn{13}{|c|}{ Age (Years) } \\
\hline & & $18-22$ & $23-27$ & $28-32$ & $33-37$ & $38-42$ & $43-47$ & $48-52$ & $53-57$ & $58-62$ & $63-67$ & $68-72$ & $73-77$ & $>77$ \\
\hline \multirow{13}{*}{ 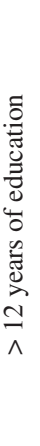 } & 95 & 27.9 & 27.4 & 26.9 & 26.4 & 25.9 & 25.4 & 24.9 & 24.4 & 23.9 & 23.4 & 22.9 & 22.4 & 21.9 \\
\hline & 90 & 26.2 & 25.7 & 25.2 & 24.7 & 24.2 & 23.7 & 23.2 & 22.7 & 22.2 & 21.8 & 21.3 & 20.8 & 20.3 \\
\hline & 85 & 25.1 & 24.6 & 24.2 & 23.7 & 23.2 & 22.7 & 22.2 & 21.7 & 21.2 & 20.7 & 20.2 & 19.7 & 19.2 \\
\hline & 80 & 24.2 & 23.7 & 23.2 & 22.7 & 22.2 & 21.7 & 21.2 & 20.7 & 20.2 & 19.7 & 19.2 & 18.7 & 18.3 \\
\hline & 70 & 22.8 & 22.3 & 21.8 & 21.3 & 20.8 & 20.3 & 19.8 & 19.3 & 18.8 & 18.3 & 17.8 & 17.3 & 16.8 \\
\hline & 60 & 21.6 & 21.1 & 20.6 & 20.1 & 19.6 & 19.1 & 18.6 & 18.1 & 17.6 & 17.1 & 16.6 & 16.1 & 15.6 \\
\hline & 50 & 20.4 & 19.9 & 19.4 & 18.9 & 18.4 & 17.9 & 17.4 & 16.9 & 16.4 & 15.9 & 15.4 & 14.9 & 14.4 \\
\hline & 40 & 19.3 & 18.8 & 18.3 & 17.8 & 17.3 & 16.8 & 16.3 & 15.8 & 15.3 & 14.8 & 14.3 & 13.8 & 13.3 \\
\hline & 30 & 18.0 & 17.5 & 17.0 & 16.6 & 16.1 & 15.6 & 15.1 & 14.6 & 14.1 & 13.6 & 13.1 & 12.6 & 12.1 \\
\hline & 20 & 16.6 & 16.1 & 15.6 & 15.1 & 14.6 & 14.1 & 13.6 & 13.1 & 12.6 & 12.1 & 11.6 & 11.1 & 10.6 \\
\hline & 15 & 15.7 & 15.2 & 14.7 & 14.2 & 13.7 & 13.2 & 12.7 & 12.2 & 11.7 & 11.2 & 10.7 & 10.2 & 9.7 \\
\hline & 10 & 14.6 & 14.1 & 13.6 & 13.1 & 12.6 & 12.1 & 11.6 & 11.1 & 10.6 & 10.1 & 9.6 & 9.1 & 8.6 \\
\hline & 5 & 12.9 & 12.5 & 12.0 & 11.5 & 11.0 & 10.5 & 10.0 & 9.5 & 9.0 & 8.5 & 8.0 & 7.5 & 7.0 \\
\hline \multirow{13}{*}{ 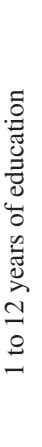 } & 95 & 23.5 & 23.0 & 22.5 & 22.0 & 21.5 & 21.0 & 20.5 & 20.0 & 19.5 & 19.0 & 18.5 & 18.0 & 17.5 \\
\hline & 90 & 21.8 & 21.3 & 20.8 & 20.3 & 19.8 & 19.3 & 18.8 & 18.4 & 17.9 & 17.4 & 16.9 & 16.4 & 15.9 \\
\hline & 85 & 20.8 & 20.3 & 19.8 & 19.3 & 18.8 & 18.3 & 17.8 & 17.3 & 16.8 & 16.3 & 15.8 & 15.3 & 14.8 \\
\hline & 80 & 19.8 & 19.3 & 18.8 & 18.3 & 17.8 & 17.3 & 16.8 & 16.3 & 15.8 & 15.4 & 14.9 & 14.4 & 13.9 \\
\hline & 70 & 18.4 & 17.9 & 17.4 & 16.9 & 16.4 & 15.9 & 15.4 & 14.9 & 14.4 & 13.9 & 13.4 & 12.9 & 12.4 \\
\hline & 60 & 17.2 & 16.7 & 16.2 & 15.7 & 15.2 & 14.7 & 14.2 & 13.7 & 13.2 & 12.7 & 12.2 & 11.7 & 11.2 \\
\hline & 50 & 16.0 & 15.5 & 15.0 & 14.5 & 14.0 & 13.5 & 13.0 & 12.5 & 12.0 & 11.5 & 11.0 & 10.5 & 10.0 \\
\hline & 40 & 14.9 & 14.4 & 13.9 & 13.4 & 12.9 & 12.4 & 11.9 & 11.4 & 10.9 & 10.4 & 9.9 & 9.4 & 8.9 \\
\hline & 30 & 13.6 & 13.2 & 12.7 & 12.2 & 11.7 & 11.2 & 10.7 & 10.2 & 9.7 & 9.2 & 8.7 & 8.2 & 7.7 \\
\hline & 20 & 12.2 & 11.7 & 11.2 & 10.7 & 10.2 & 9.7 & 9.2 & 8.7 & 8.2 & 7.7 & 7.2 & 6.7 & 6.2 \\
\hline & 15 & 11.3 & 10.8 & 10.3 & 9.8 & 9.3 & 8.8 & 8.3 & 7.8 & 7.3 & 6.8 & 6.3 & 5.8 & 5.3 \\
\hline & 10 & 10.2 & 9.7 & 9.2 & 8.7 & 8.2 & 7.7 & 7.2 & 6.7 & 6.2 & 5.7 & 5.2 & 4.7 & 4.2 \\
\hline & 5 & 8.6 & 8.1 & 7.6 & 7.1 & 6.6 & 6.1 & 5.6 & 5.1 & 4.6 & 4.1 & 3.6 & 3.1 & 2.6 \\
\hline
\end{tabular}


Table A36

Normative data for the Animals category stratified by age and education levels for CHILE

\begin{tabular}{|c|c|c|c|c|c|c|c|c|c|c|c|c|c|c|}
\hline & \multirow[b]{2}{*}{ Percentile } & \multicolumn{13}{|c|}{ Age (Years) } \\
\hline & & $18-22$ & $23-27$ & $28-32$ & $33-37$ & $38-42$ & $43-47$ & $48-52$ & $53-57$ & $58-62$ & $63-67$ & $68-72$ & $73-77$ & $>77$ \\
\hline \multirow{13}{*}{ 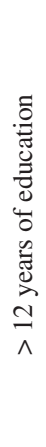 } & 95 & 29.9 & 29.3 & 28.7 & 28.1 & 27.5 & 26.9 & 26.3 & 25.7 & 25.0 & 24.4 & 23.8 & 23.2 & 22.6 \\
\hline & 90 & 28.4 & 27.8 & 27.2 & 26.6 & 26.0 & 25.4 & 24.7 & 24.1 & 23.5 & 22.9 & 22.3 & 21.7 & 21.1 \\
\hline & 85 & 27.4 & 26.8 & 26.2 & 25.6 & 25.0 & 24.3 & 23.7 & 23.1 & 22.5 & 21.9 & 21.3 & 20.7 & 20.1 \\
\hline & 80 & 26.5 & 25.9 & 25.3 & 24.7 & 24.1 & 23.5 & 22.9 & 22.3 & 21.7 & 21.1 & 20.5 & 19.8 & 19.2 \\
\hline & 70 & 25.2 & 24.6 & 24.0 & 23.4 & 22.8 & 22.1 & 21.5 & 20.9 & 20.3 & 19.7 & 19.1 & 18.5 & 17.9 \\
\hline & 60 & 24.1 & 23.4 & 22.8 & 22.2 & 21.6 & 21.0 & 20.4 & 19.8 & 19.2 & 18.6 & 18.0 & 17.4 & 16.8 \\
\hline & 50 & 23.0 & 22.4 & 21.8 & 21.2 & 20.6 & 20.0 & 19.3 & 18.7 & 18.1 & 17.5 & 16.9 & 16.3 & 15.7 \\
\hline & 40 & 21.9 & 21.3 & 20.7 & 20.1 & 19.5 & 18.9 & 18.3 & 17.7 & 17.1 & 16.5 & 15.9 & 15.3 & 14.6 \\
\hline & 30 & 20.8 & 20.2 & 19.6 & 19.0 & 18.4 & 17.8 & 17.2 & 16.5 & 15.9 & 15.3 & 14.7 & 14.1 & 13.5 \\
\hline & 20 & 19.5 & 18.8 & 18.2 & 17.6 & 17.0 & 16.4 & 15.8 & 15.2 & 14.6 & 14.0 & 13.4 & 12.8 & 12.2 \\
\hline & 15 & 18.6 & 18.0 & 17.4 & 16.8 & 16.2 & 15.6 & 15.0 & 14.4 & 13.7 & 13.1 & 12.5 & 11.9 & 11.3 \\
\hline & 10 & 17.6 & 17.0 & 16.4 & 15.8 & 15.2 & 14.6 & 13.9 & 13.3 & 12.7 & 12.1 & 11.5 & 10.9 & 10.3 \\
\hline & 5 & 16.1 & 15.5 & 14.9 & 14.3 & 13.6 & 13.0 & 12.4 & 11.8 & 11.2 & 10.6 & 10.0 & 9.4 & 8.8 \\
\hline \multirow{13}{*}{ 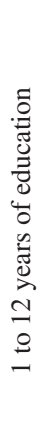 } & 95 & 25.4 & 24.8 & 24.2 & 23.6 & 23.0 & 22.4 & 21.7 & 21.1 & 20.5 & 19.9 & 19.3 & 18.7 & 18.1 \\
\hline & 90 & 23.9 & 23.3 & 22.7 & 22.1 & 21.4 & 20.8 & 20.2 & 19.6 & 19.0 & 18.4 & 17.8 & 17.2 & 16.6 \\
\hline & 85 & 22.9 & 22.3 & 21.7 & 21.0 & 20.4 & 19.8 & 19.2 & 18.6 & 18.0 & 17.4 & 16.8 & 16.2 & 15.6 \\
\hline & 80 & 22.0 & 21.4 & 20.8 & 20.2 & 19.6 & 19.0 & 18.4 & 17.8 & 17.2 & 16.5 & 15.9 & 15.3 & 14.7 \\
\hline & 70 & 20.7 & 20.1 & 19.5 & 18.8 & 18.2 & 17.6 & 17.0 & 16.4 & 15.8 & 15.2 & 14.6 & 14.0 & 13.4 \\
\hline & 60 & 19.5 & 18.9 & 18.3 & 17.7 & 17.1 & 16.5 & 15.9 & 15.3 & 14.7 & 14.1 & 13.5 & 12.8 & 12.2 \\
\hline & 50 & 18.5 & 17.9 & 17.3 & 16.7 & 16.0 & 15.4 & 14.8 & 14.2 & 13.6 & 13.0 & 12.4 & 11.8 & 11.2 \\
\hline & 40 & 17.4 & 16.8 & 16.2 & 15.6 & 15.0 & 14.4 & 13.8 & 13.2 & 12.6 & 12.0 & 11.3 & 10.7 & 10.1 \\
\hline & 30 & 16.3 & 15.7 & 15.1 & 14.5 & 13.9 & 13.2 & 12.6 & 12.0 & 11.4 & 10.8 & 10.2 & 9.6 & 9.0 \\
\hline & 20 & 14.9 & 14.3 & 13.7 & 13.1 & 12.5 & 11.9 & 11.3 & 10.7 & 10.1 & 9.5 & 8.9 & 8.2 & 7.6 \\
\hline & 15 & 14.1 & 13.5 & 12.9 & 12.3 & 11.7 & 11.1 & 10.4 & 9.8 & 9.2 & 8.6 & 8.0 & 7.4 & 6.8 \\
\hline & 10 & 13.1 & 12.5 & 11.9 & 11.3 & 10.6 & 10.0 & 9.4 & 8.8 & 8.2 & 7.6 & 7.0 & 6.4 & 5.8 \\
\hline & 5 & 11.6 & 11.0 & 10.3 & 9.7 & 9.1 & 8.5 & 7.9 & 7.3 & 6.7 & 6.1 & 5.5 & 4.9 & 4.3 \\
\hline
\end{tabular}


Table A37

Normative data for the Animals category stratified by age and education levels for CUBA

\begin{tabular}{|c|c|c|c|c|c|c|c|c|c|c|c|c|c|c|}
\hline & \multirow[b]{2}{*}{ Percentile } & \multicolumn{13}{|c|}{ Age (Years) } \\
\hline & & $18-22$ & $23-27$ & $28-32$ & $33-37$ & $38-42$ & $43-47$ & $48-52$ & $53-57$ & $58-62$ & $63-67$ & $68-72$ & $73-77$ & $>77$ \\
\hline \multirow{13}{*}{ 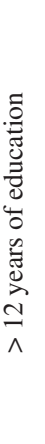 } & 95 & 25.4 & 25.1 & 24.8 & 24.4 & 24.1 & 23.8 & 23.4 & 23.1 & 22.8 & 22.5 & 22.1 & 21.8 & 21.5 \\
\hline & 90 & 24.0 & 23.7 & 23.3 & 23.0 & 22.7 & 22.3 & 22.0 & 21.7 & 21.4 & 21.0 & 20.7 & 20.4 & 20.0 \\
\hline & 85 & 23.0 & 22.7 & 22.4 & 22.0 & 21.7 & 21.4 & 21.1 & 20.7 & 20.4 & 20.1 & 19.7 & 19.4 & 19.1 \\
\hline & 80 & 22.2 & 21.9 & 21.6 & 21.2 & 20.9 & 20.6 & 20.3 & 19.9 & 19.6 & 19.3 & 18.9 & 18.6 & 18.3 \\
\hline & 70 & 21.0 & 20.6 & 20.3 & 20.0 & 19.6 & 19.3 & 19.0 & 18.7 & 18.3 & 18.0 & 17.7 & 17.3 & 17.0 \\
\hline & 60 & 19.9 & 19.6 & 19.2 & 18.9 & 18.6 & 18.2 & 17.9 & 17.6 & 17.3 & 16.9 & 16.6 & 16.3 & 15.9 \\
\hline & 50 & 18.9 & 18.6 & 18.2 & 17.9 & 17.6 & 17.2 & 16.9 & 16.6 & 16.3 & 15.9 & 15.6 & 15.3 & 15.0 \\
\hline & 40 & 17.9 & 17.6 & 17.2 & 16.9 & 16.6 & 16.3 & 15.9 & 15.6 & 15.3 & 14.9 & 14.6 & 14.3 & 14.0 \\
\hline & 30 & 16.8 & 16.5 & 16.2 & 15.8 & 15.5 & 15.2 & 14.8 & 14.5 & 14.2 & 13.9 & 13.5 & 13.2 & 12.9 \\
\hline & 20 & 15.5 & 15.2 & 14.9 & 14.6 & 14.2 & 13.9 & 13.6 & 13.2 & 12.9 & 12.6 & 12.3 & 11.9 & 11.6 \\
\hline & 15 & 14.7 & 14.4 & 14.1 & 13.8 & 13.4 & 13.1 & 12.8 & 12.5 & 12.1 & 11.8 & 11.5 & 11.1 & 10.8 \\
\hline & 10 & 13.8 & 13.5 & 13.1 & 12.8 & 12.5 & 12.2 & 11.8 & 11.5 & 11.2 & 10.8 & 10.5 & 10.2 & 9.9 \\
\hline & 5 & 12.4 & 12.0 & 11.7 & 11.4 & 11.0 & 10.7 & 10.4 & 10.1 & 9.7 & 9.4 & 9.1 & 8.8 & 8.4 \\
\hline \multirow{13}{*}{ 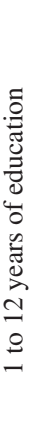 } & 95 & 23.0 & 22.6 & 22.3 & 22.0 & 21.6 & 21.3 & 21.0 & 20.7 & 20.3 & 20.0 & 19.7 & 19.3 & 19.0 \\
\hline & 90 & 21.5 & 21.2 & 20.9 & 20.5 & 20.2 & 19.9 & 19.6 & 19.2 & 18.9 & 18.6 & 18.2 & 17.9 & 17.6 \\
\hline & 85 & 20.6 & 20.2 & 19.9 & 19.6 & 19.3 & 18.9 & 18.6 & 18.3 & 17.9 & 17.6 & 17.3 & 17.0 & 16.6 \\
\hline & 80 & 19.8 & 19.4 & 19.1 & 18.8 & 18.5 & 18.1 & 17.8 & 17.5 & 17.1 & 16.8 & 16.5 & 16.2 & 15.8 \\
\hline & 70 & 18.5 & 18.2 & 17.8 & 17.5 & 17.2 & 16.9 & 16.5 & 16.2 & 15.9 & 15.5 & 15.2 & 14.9 & 14.6 \\
\hline & 60 & 17.4 & 17.1 & 16.8 & 16.4 & 16.1 & 15.8 & 15.5 & 15.1 & 14.8 & 14.5 & 14.1 & 13.8 & 13.5 \\
\hline & 50 & 16.4 & 16.1 & 15.8 & 15.4 & 15.1 & 14.8 & 14.5 & 14.1 & 13.8 & 13.5 & 13.1 & 12.8 & 12.5 \\
\hline & 40 & 15.4 & 15.1 & 14.8 & 14.4 & 14.1 & 13.8 & 13.5 & 13.1 & 12.8 & 12.5 & 12.2 & 11.8 & 11.5 \\
\hline & 30 & 14.4 & 14.0 & 13.7 & 13.4 & 13.0 & 12.7 & 12.4 & 12.1 & 11.7 & 11.4 & 11.1 & 10.8 & 10.4 \\
\hline & 20 & 13.1 & 12.8 & 12.4 & 12.1 & 11.8 & 11.4 & 11.1 & 10.8 & 10.5 & 10.1 & 9.8 & 9.5 & 9.1 \\
\hline & 15 & 12.3 & 12.0 & 11.6 & 11.3 & 11.0 & 10.6 & 10.3 & 10.0 & 9.7 & 9.3 & 9.0 & 8.7 & 8.4 \\
\hline & 10 & 11.3 & 11.0 & 10.7 & 10.4 & 10.0 & 9.7 & 9.4 & 9.0 & 8.7 & 8.4 & 8.1 & 7.7 & 7.4 \\
\hline & 5 & 9.9 & 9.6 & 9.2 & 8.9 & 8.6 & 8.3 & 7.9 & 7.6 & 7.3 & 7.0 & 6.6 & 6.3 & 6.0 \\
\hline
\end{tabular}


Table A38

Normative data for the Animals category stratified by age and education levels for EL SALVADOR

\begin{tabular}{|c|c|c|c|c|c|c|c|c|c|c|c|c|c|c|}
\hline & \multirow[b]{2}{*}{ Percentile } & \multicolumn{13}{|c|}{ Age (Years) } \\
\hline & & $18-22$ & $23-27$ & $28-32$ & $33-37$ & $38-42$ & $43-47$ & $48-52$ & $53-57$ & $58-62$ & $63-67$ & $68-72$ & $73-77$ & $>77$ \\
\hline \multirow{13}{*}{ 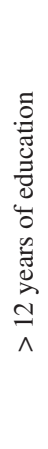 } & 95 & 29.0 & 28.5 & 28.0 & 27.6 & 27.1 & 26.7 & 26.2 & 25.7 & 25.3 & 24.8 & 24.4 & 23.9 & 23.4 \\
\hline & 90 & 27.2 & 26.8 & 26.3 & 25.9 & 25.4 & 24.9 & 24.5 & 24.0 & 23.6 & 23.1 & 22.7 & 22.2 & 21.7 \\
\hline & 85 & 26.1 & 25.7 & 25.2 & 24.7 & 24.3 & 23.8 & 23.4 & 22.9 & 22.4 & 22.0 & 21.5 & 21.1 & 20.6 \\
\hline & 80 & 25.2 & 24.7 & 24.2 & 23.8 & 23.3 & 22.9 & 22.4 & 21.9 & 21.5 & 21.0 & 20.6 & 20.1 & 19.6 \\
\hline & 70 & 23.6 & 23.2 & 22.7 & 22.3 & 21.8 & 21.4 & 20.9 & 20.4 & 20.0 & 19.5 & 19.1 & 18.6 & 18.1 \\
\hline & 60 & 22.4 & 21.9 & 21.5 & 21.0 & 20.5 & 20.1 & 19.6 & 19.2 & 18.7 & 18.2 & 17.8 & 17.3 & 16.9 \\
\hline & 50 & 21.2 & 20.7 & 20.3 & 19.8 & 19.3 & 18.9 & 18.4 & 18.0 & 17.5 & 17.1 & 16.6 & 16.1 & 15.7 \\
\hline & 40 & 20.0 & 19.5 & 19.1 & 18.6 & 18.2 & 17.7 & 17.2 & 16.8 & 16.3 & 15.9 & 15.4 & 14.9 & 14.5 \\
\hline & 30 & 18.7 & 18.3 & 17.8 & 17.3 & 16.9 & 16.4 & 16.0 & 15.5 & 15.0 & 14.6 & 14.1 & 13.7 & 13.2 \\
\hline & 20 & 17.2 & 16.7 & 16.3 & 15.8 & 15.4 & 14.9 & 14.5 & 14.0 & 13.5 & 13.1 & 12.6 & 12.2 & 11.7 \\
\hline & 15 & 16.3 & 15.8 & 15.3 & 14.9 & 14.4 & 14.0 & 13.5 & 13.0 & 12.6 & 12.1 & 11.7 & 11.2 & 10.7 \\
\hline & 10 & 15.1 & 14.7 & 14.2 & 13.7 & 13.3 & 12.8 & 12.4 & 11.9 & 11.4 & 11.0 & 10.5 & 10.1 & 9.6 \\
\hline & 5 & 13.4 & 13.0 & 12.5 & 12.0 & 11.6 & 11.1 & 10.7 & 10.2 & 9.7 & 9.3 & 8.8 & 8.4 & 7.9 \\
\hline \multirow{13}{*}{ 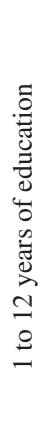 } & 95 & 23.5 & 23.1 & 22.6 & 22.1 & 21.7 & 21.2 & 20.8 & 20.3 & 19.8 & 19.4 & 18.9 & 18.5 & 18.0 \\
\hline & 90 & 21.8 & 21.4 & 20.9 & 20.4 & 20.0 & 19.5 & 19.1 & 18.6 & 18.1 & 17.7 & 17.2 & 16.8 & 16.3 \\
\hline & 85 & 20.7 & 20.2 & 19.8 & 19.3 & 18.8 & 18.4 & 17.9 & 17.5 & 17.0 & 16.5 & 16.1 & 15.6 & 15.2 \\
\hline & 80 & 19.7 & 19.3 & 18.8 & 18.4 & 17.9 & 17.4 & 17.0 & 16.5 & 16.1 & 15.6 & 15.1 & 14.7 & 14.2 \\
\hline & 70 & 18.2 & 17.8 & 17.3 & 16.8 & 16.4 & 15.9 & 15.5 & 15.0 & 14.5 & 14.1 & 13.6 & 13.2 & 12.7 \\
\hline & 60 & 16.9 & 16.5 & 16.0 & 15.6 & 15.1 & 14.6 & 14.2 & 13.7 & 13.3 & 12.8 & 12.3 & 11.9 & 11.4 \\
\hline & 50 & 15.8 & 15.3 & 14.8 & 14.4 & 13.9 & 13.5 & 13.0 & 12.5 & 12.1 & 11.6 & 11.2 & 10.7 & 10.2 \\
\hline & 40 & 14.6 & 14.1 & 13.7 & 13.2 & 12.7 & 12.3 & 11.8 & 11.4 & 10.9 & 10.4 & 10.0 & 9.5 & 9.1 \\
\hline & 30 & 13.3 & 12.8 & 12.4 & 11.9 & 11.5 & 11.0 & 10.5 & 10.1 & 9.6 & 9.2 & 8.7 & 8.2 & 7.8 \\
\hline & 20 & 11.8 & 11.3 & 10.9 & 10.4 & 9.9 & 9.5 & 9.0 & 8.6 & 8.1 & 7.6 & 7.2 & 6.7 & 6.3 \\
\hline & 15 & 10.8 & 10.4 & 9.9 & 9.5 & 9.0 & 8.5 & 8.1 & 7.6 & 7.2 & 6.7 & 6.2 & 5.8 & 5.3 \\
\hline & 10 & 9.7 & 9.2 & 8.8 & 8.3 & 7.9 & 7.4 & 6.9 & 6.5 & 6.0 & 5.6 & 5.1 & 4.6 & 4.2 \\
\hline & 5 & 8.0 & 7.5 & 7.1 & 6.6 & 6.2 & 5.7 & 5.2 & 4.8 & 4.3 & 3.9 & 3.4 & 2.9 & 2.5 \\
\hline
\end{tabular}


Table A39

Normative data for the Animals category stratified by age and education levels for GUATEMALA

\begin{tabular}{|c|c|c|c|c|c|c|c|c|c|c|c|c|c|c|}
\hline & \multirow[b]{2}{*}{ Percentile } & \multicolumn{13}{|c|}{ Age (Years) } \\
\hline & & $18-22$ & $23-27$ & $28-32$ & $33-37$ & $38-42$ & $43-47$ & $48-52$ & $53-57$ & $58-62$ & $63-67$ & $68-72$ & $73-77$ & $>77$ \\
\hline \multirow{13}{*}{ 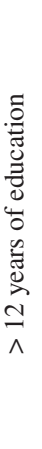 } & 95 & 31.9 & 31.7 & 31.4 & 31.1 & 30.8 & 30.5 & 30.2 & 29.9 & 29.7 & 29.4 & 29.1 & 28.8 & 28.5 \\
\hline & 90 & 30.2 & 30.0 & 29.7 & 29.4 & 29.1 & 28.8 & 28.5 & 28.2 & 28.0 & 27.7 & 27.4 & 27.1 & 26.8 \\
\hline & 85 & 29.1 & 28.8 & 28.5 & 28.3 & 28.0 & 27.7 & 27.4 & 27.1 & 26.8 & 26.5 & 26.3 & 26.0 & 25.7 \\
\hline & 80 & 28.2 & 27.9 & 27.6 & 27.3 & 27.0 & 26.7 & 26.5 & 26.2 & 25.9 & 25.6 & 25.3 & 25.0 & 24.7 \\
\hline & 70 & 26.7 & 26.4 & 26.1 & 25.8 & 25.5 & 25.2 & 24.9 & 24.7 & 24.4 & 24.1 & 23.8 & 23.5 & 23.2 \\
\hline & 60 & 25.4 & 25.1 & 24.8 & 24.5 & 24.2 & 24.0 & 23.7 & 23.4 & 23.1 & 22.8 & 22.5 & 22.3 & 22.0 \\
\hline & 50 & 24.2 & 23.9 & 23.6 & 23.3 & 23.1 & 22.8 & 22.5 & 22.2 & 21.9 & 21.6 & 21.4 & 21.1 & 20.8 \\
\hline & 40 & 23.0 & 22.7 & 22.4 & 22.2 & 21.9 & 21.6 & 21.3 & 21.0 & 20.7 & 20.5 & 20.2 & 19.9 & 19.6 \\
\hline & 30 & 21.7 & 21.5 & 21.2 & 20.9 & 20.6 & 20.3 & 20.0 & 19.8 & 19.5 & 19.2 & 18.9 & 18.6 & 18.3 \\
\hline & 20 & 20.2 & 19.9 & 19.7 & 19.4 & 19.1 & 18.8 & 18.5 & 18.2 & 18.0 & 17.7 & 17.4 & 17.1 & 16.8 \\
\hline & 15 & 19.3 & 19.0 & 18.7 & 18.4 & 18.2 & 17.9 & 17.6 & 17.3 & 17.0 & 16.7 & 16.4 & 16.2 & 15.9 \\
\hline & 10 & 18.2 & 17.9 & 17.6 & 17.3 & 17.0 & 16.7 & 16.5 & 16.2 & 15.9 & 15.6 & 15.3 & 15.0 & 14.7 \\
\hline & 5 & 16.5 & 16.2 & 15.9 & 15.6 & 15.3 & 15.0 & 14.8 & 14.5 & 14.2 & 13.9 & 13.6 & 13.3 & 13.0 \\
\hline \multirow{13}{*}{ 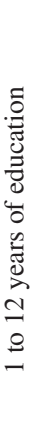 } & 95 & 26.2 & 25.9 & 25.6 & 25.3 & 25.1 & 24.8 & 24.5 & 24.2 & 23.9 & 23.6 & 23.4 & 23.1 & 22.8 \\
\hline & 90 & 24.5 & 24.2 & 23.9 & 23.6 & 23.4 & 23.1 & 22.8 & 22.5 & 22.2 & 21.9 & 21.7 & 21.4 & 21.1 \\
\hline & 85 & 23.4 & 23.1 & 22.8 & 22.5 & 22.2 & 21.9 & 21.7 & 21.4 & 21.1 & 20.8 & 20.5 & 20.2 & 20.0 \\
\hline & 80 & 22.4 & 22.1 & 21.9 & 21.6 & 21.3 & 21.0 & 20.7 & 20.4 & 20.2 & 19.9 & 19.6 & 19.3 & 19.0 \\
\hline & 70 & 20.9 & 20.6 & 20.3 & 20.1 & 19.8 & 19.5 & 19.2 & 18.9 & 18.6 & 18.4 & 18.1 & 17.8 & 17.5 \\
\hline & 60 & 19.6 & 19.4 & 19.1 & 18.8 & 18.5 & 18.2 & 17.9 & 17.7 & 17.4 & 17.1 & 16.8 & 16.5 & 16.2 \\
\hline & 50 & 18.5 & 18.2 & 17.9 & 17.6 & 17.3 & 17.0 & 16.8 & 16.5 & 16.2 & 15.9 & 15.6 & 15.3 & 15.1 \\
\hline & 40 & 17.3 & 17.0 & 16.7 & 16.4 & 16.1 & 15.9 & 15.6 & 15.3 & 15.0 & 14.7 & 14.4 & 14.2 & 13.9 \\
\hline & 30 & 16.0 & 15.7 & 15.4 & 15.2 & 14.9 & 14.6 & 14.3 & 14.0 & 13.7 & 13.5 & 13.2 & 12.9 & 12.6 \\
\hline & 20 & 14.5 & 14.2 & 13.9 & 13.6 & 13.4 & 13.1 & 12.8 & 12.5 & 12.2 & 11.9 & 11.7 & 11.4 & 11.1 \\
\hline & 15 & 13.6 & 13.3 & 13.0 & 12.7 & 12.4 & 12.1 & 11.8 & 11.6 & 11.3 & 11.0 & 10.7 & 10.4 & 10.1 \\
\hline & 10 & 12.4 & 12.1 & 11.9 & 11.6 & 11.3 & 11.0 & 10.7 & 10.4 & 10.1 & 9.9 & 9.6 & 9.3 & 9.0 \\
\hline & 5 & 10.7 & 10.4 & 10.2 & 9.9 & 9.6 & 9.3 & 9.0 & 8.7 & 8.4 & 8.2 & 7.9 & 7.6 & 7.3 \\
\hline
\end{tabular}


Table A40

Normative data for the Animals category stratified by age and education levels for HONDURAS

\begin{tabular}{|c|c|c|c|c|c|c|c|c|c|c|c|c|c|c|}
\hline & \multirow[b]{2}{*}{ Percentile } & \multicolumn{13}{|c|}{ Age (Years) } \\
\hline & & $18-22$ & $23-27$ & $28-32$ & $33-37$ & $38-42$ & $43-47$ & $48-52$ & $53-57$ & $58-62$ & $63-67$ & $68-72$ & $73-77$ & $>77$ \\
\hline \multirow{13}{*}{ 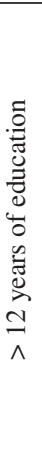 } & 95 & 28.6 & 28.2 & 27.8 & 27.3 & 26.9 & 26.4 & 26.0 & 25.6 & 25.1 & 24.7 & 24.2 & 23.8 & 23.4 \\
\hline & 90 & 27.1 & 26.7 & 26.3 & 25.8 & 25.4 & 24.9 & 24.5 & 24.1 & 23.6 & 23.2 & 22.7 & 22.3 & 21.9 \\
\hline & 85 & 26.1 & 25.7 & 25.3 & 24.8 & 24.4 & 23.9 & 23.5 & 23.1 & 22.6 & 22.2 & 21.7 & 21.3 & 20.9 \\
\hline & 80 & 25.3 & 24.9 & 24.4 & 24.0 & 23.5 & 23.1 & 22.7 & 22.2 & 21.8 & 21.3 & 20.9 & 20.5 & 20.0 \\
\hline & 70 & 24.0 & 23.5 & 23.1 & 22.6 & 22.2 & 21.8 & 21.3 & 20.9 & 20.4 & 20.0 & 19.6 & 19.1 & 18.7 \\
\hline & 60 & 22.8 & 22.4 & 22.0 & 21.5 & 21.1 & 20.6 & 20.2 & 19.8 & 19.3 & 18.9 & 18.4 & 18.0 & 17.5 \\
\hline & 50 & 21.8 & 21.3 & 20.9 & 20.5 & 20.0 & 19.6 & 19.1 & 18.7 & 18.3 & 17.8 & 17.4 & 16.9 & 16.5 \\
\hline & 40 & 20.7 & 20.3 & 19.9 & 19.4 & 19.0 & 18.5 & 18.1 & 17.7 & 17.2 & 16.8 & 16.3 & 15.9 & 15.5 \\
\hline & 30 & 19.6 & 19.2 & 18.7 & 18.3 & 17.9 & 17.4 & 17.0 & 16.5 & 16.1 & 15.6 & 15.2 & 14.8 & 14.3 \\
\hline & 20 & 18.3 & 17.8 & 17.4 & 17.0 & 16.5 & 16.1 & 15.6 & 15.2 & 14.8 & 14.3 & 13.9 & 13.4 & 13.0 \\
\hline & 15 & 17.4 & 17.0 & 16.6 & 16.1 & 15.7 & 15.2 & 14.8 & 14.4 & 13.9 & 13.5 & 13.0 & 12.6 & 12.2 \\
\hline & 10 & 16.4 & 16.0 & 15.6 & 15.1 & 14.7 & 14.2 & 13.8 & 13.4 & 12.9 & 12.5 & 12.0 & 11.6 & 11.1 \\
\hline & 5 & 14.9 & 14.5 & 14.0 & 13.6 & 13.2 & 12.7 & 12.3 & 11.8 & 11.4 & 11.0 & 10.5 & 10.1 & 9.6 \\
\hline \multirow{13}{*}{ 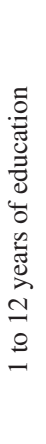 } & 95 & 23.8 & 23.4 & 23.0 & 22.5 & 22.1 & 21.6 & 21.2 & 20.8 & 20.3 & 19.9 & 19.4 & 19.0 & 18.6 \\
\hline & 90 & 22.3 & 21.9 & 21.5 & 21.0 & 20.6 & 20.1 & 19.7 & 19.3 & 18.8 & 18.4 & 17.9 & 17.5 & 17.1 \\
\hline & 85 & 21.3 & 20.9 & 20.5 & 20.0 & 19.6 & 19.1 & 18.7 & 18.3 & 17.8 & 17.4 & 16.9 & 16.5 & 16.1 \\
\hline & 80 & 20.5 & 20.1 & 19.6 & 19.2 & 18.7 & 18.3 & 17.9 & 17.4 & 17.0 & 16.5 & 16.1 & 15.7 & 15.2 \\
\hline & 70 & 19.2 & 18.7 & 18.3 & 17.8 & 17.4 & 17.0 & 16.5 & 16.1 & 15.6 & 15.2 & 14.8 & 14.3 & 13.9 \\
\hline & 60 & 18.0 & 17.6 & 17.1 & 16.7 & 16.3 & 15.8 & 15.4 & 14.9 & 14.5 & 14.1 & 13.6 & 13.2 & 12.7 \\
\hline & 50 & 17.0 & 16.5 & 16.1 & 15.7 & 15.2 & 14.8 & 14.3 & 13.9 & 13.5 & 13.0 & 12.6 & 12.1 & 11.7 \\
\hline & 40 & 15.9 & 15.5 & 15.1 & 14.6 & 14.2 & 13.7 & 13.3 & 12.9 & 12.4 & 12.0 & 11.5 & 11.1 & 10.7 \\
\hline & 30 & 14.8 & 14.4 & 13.9 & 13.5 & 13.0 & 12.6 & 12.2 & 11.7 & 11.3 & 10.8 & 10.4 & 10.0 & 9.5 \\
\hline & 20 & 13.5 & 13.0 & 12.6 & 12.1 & 11.7 & 11.3 & 10.8 & 10.4 & 9.9 & 9.5 & 9.1 & 8.6 & 8.2 \\
\hline & 15 & 12.6 & 12.2 & 11.8 & 11.3 & 10.9 & 10.4 & 10.0 & 9.6 & 9.1 & 8.7 & 8.2 & 7.8 & 7.3 \\
\hline & 10 & 11.6 & 11.2 & 10.7 & 10.3 & 9.9 & 9.4 & 9.0 & 8.5 & 8.1 & 7.7 & 7.2 & 6.8 & 6.3 \\
\hline & 5 & 10.1 & 9.7 & 9.2 & 8.8 & 8.4 & 7.9 & 7.5 & 7.0 & 6.6 & 6.2 & 5.7 & 5.3 & 4.8 \\
\hline
\end{tabular}


Table A41

Normative data for the Animals category stratified by age and education levels for MEXICO

\begin{tabular}{|c|c|c|c|c|c|c|c|c|c|c|c|c|c|c|}
\hline & \multirow[b]{2}{*}{ Percentile } & \multicolumn{13}{|c|}{ Age (Years) } \\
\hline & & $18-22$ & $23-27$ & $28-32$ & $33-37$ & $38-42$ & $43-47$ & $48-52$ & $53-57$ & $58-62$ & $63-67$ & $68-72$ & $73-77$ & $>77$ \\
\hline \multirow{13}{*}{ 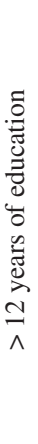 } & 95 & 29.5 & 29.1 & 28.6 & 28.2 & 27.8 & 27.3 & 26.9 & 26.5 & 26.0 & 25.6 & 25.1 & 24.7 & 24.3 \\
\hline & 90 & 27.8 & 27.4 & 27.0 & 26.5 & 26.1 & 25.6 & 25.2 & 24.8 & 24.3 & 23.9 & 23.5 & 23.0 & 22.6 \\
\hline & 85 & 26.7 & 26.3 & 25.8 & 25.4 & 25.0 & 24.5 & 24.1 & 23.7 & 23.2 & 22.8 & 22.3 & 21.9 & 21.5 \\
\hline & 80 & 25.8 & 25.3 & 24.9 & 24.5 & 24.0 & 23.6 & 23.2 & 22.7 & 22.3 & 21.8 & 21.4 & 21.0 & 20.5 \\
\hline & 70 & 24.3 & 23.8 & 23.4 & 23.0 & 22.5 & 22.1 & 21.7 & 21.2 & 20.8 & 20.3 & 19.9 & 19.5 & 19.0 \\
\hline & 60 & 23.0 & 22.6 & 22.1 & 21.7 & 21.3 & 20.8 & 20.4 & 20.0 & 19.5 & 19.1 & 18.6 & 18.2 & 17.8 \\
\hline & 50 & 21.8 & 21.4 & 21.0 & 20.5 & 20.1 & 19.7 & 19.2 & 18.8 & 18.4 & 17.9 & 17.5 & 17.0 & 16.6 \\
\hline & 40 & 20.7 & 20.2 & 19.8 & 19.4 & 18.9 & 18.5 & 18.1 & 17.6 & 17.2 & 16.7 & 16.3 & 15.9 & 15.4 \\
\hline & 30 & 19.4 & 19.0 & 18.5 & 18.1 & 17.7 & 17.2 & 16.8 & 16.4 & 15.9 & 15.5 & 15.0 & 14.6 & 14.2 \\
\hline & 20 & 17.9 & 17.5 & 17.0 & 16.6 & 16.2 & 15.7 & 15.3 & 14.9 & 14.4 & 14.0 & 13.6 & 13.1 & 12.7 \\
\hline & 15 & 17.0 & 16.6 & 16.1 & 15.7 & 15.2 & 14.8 & 14.4 & 13.9 & 13.5 & 13.1 & 12.6 & 12.2 & 11.7 \\
\hline & 10 & 15.9 & 15.4 & 15.0 & 14.6 & 14.1 & 13.7 & 13.2 & 12.8 & 12.4 & 11.9 & 11.5 & 11.1 & 10.6 \\
\hline & 5 & 14.2 & 13.7 & 13.3 & 12.9 & 12.4 & 12.0 & 11.6 & 11.1 & 10.7 & 10.3 & 9.8 & 9.4 & 8.9 \\
\hline \multirow{13}{*}{ 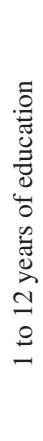 } & 95 & 27.5 & 27.0 & 26.6 & 26.2 & 25.7 & 25.3 & 24.8 & 24.4 & 24.0 & 23.5 & 23.1 & 22.7 & 22.2 \\
\hline & 90 & 25.8 & 25.3 & 24.9 & 24.5 & 24.0 & 23.6 & 23.2 & 22.7 & 22.3 & 21.9 & 21.4 & 21.0 & 20.5 \\
\hline & 85 & 24.7 & 24.2 & 23.8 & 23.4 & 22.9 & 22.5 & 22.0 & 21.6 & 21.2 & 20.7 & 20.3 & 19.9 & 19.4 \\
\hline & 80 & 23.7 & 23.3 & 22.9 & 22.4 & 22.0 & 21.5 & 21.1 & 20.7 & 20.2 & 19.8 & 19.4 & 18.9 & 18.5 \\
\hline & 70 & 22.2 & 21.8 & 21.4 & 20.9 & 20.5 & 20.1 & 19.6 & 19.2 & 18.7 & 18.3 & 17.9 & 17.4 & 17.0 \\
\hline & 60 & 21.0 & 20.5 & 20.1 & 19.7 & 19.2 & 18.8 & 18.4 & 17.9 & 17.5 & 17.0 & 16.6 & 16.2 & 15.7 \\
\hline & 50 & 19.8 & 19.4 & 18.9 & 18.5 & 18.1 & 17.6 & 17.2 & 16.7 & 16.3 & 15.9 & 15.4 & 15.0 & 14.6 \\
\hline & 40 & 18.6 & 18.2 & 17.8 & 17.3 & 16.9 & 16.5 & 16.0 & 15.6 & 15.1 & 14.7 & 14.3 & 13.8 & 13.4 \\
\hline & 30 & 17.4 & 16.9 & 16.5 & 16.1 & 15.6 & 15.2 & 14.8 & 14.3 & 13.9 & 13.4 & 13.0 & 12.6 & 12.1 \\
\hline & 20 & 15.9 & 15.4 & 15.0 & 14.6 & 14.1 & 13.7 & 13.3 & 12.8 & 12.4 & 11.9 & 11.5 & 11.1 & 10.6 \\
\hline & 15 & 14.9 & 14.5 & 14.1 & 13.6 & 13.2 & 12.8 & 12.3 & 11.9 & 11.4 & 11.0 & 10.6 & 10.1 & 9.7 \\
\hline & 10 & 13.8 & 13.4 & 12.9 & 12.5 & 12.1 & 11.6 & 11.2 & 10.8 & 10.3 & 9.9 & 9.5 & 9.0 & 8.6 \\
\hline & 5 & 12.1 & 11.7 & 11.3 & 10.8 & 10.4 & 10.0 & 9.5 & 9.1 & 8.6 & 8.2 & 7.8 & 7.3 & 6.9 \\
\hline
\end{tabular}


Table A42

Normative data for the Animals category stratified by age and education levels for PARAGUAY

\begin{tabular}{|c|c|c|c|c|c|c|c|c|c|c|c|c|c|c|}
\hline & \multirow[b]{2}{*}{ Percentile } & \multicolumn{13}{|c|}{ Age (Years) } \\
\hline & & $18-22$ & $23-27$ & $28-32$ & $33-37$ & $38-42$ & $43-47$ & $48-52$ & $53-57$ & $58-62$ & $63-67$ & $68-72$ & $73-77$ & $>77$ \\
\hline \multirow{13}{*}{ 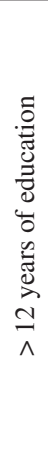 } & 95 & 22.2 & 21.9 & 21.6 & 21.3 & 21.0 & 20.7 & 20.4 & 20.1 & 19.8 & 19.5 & 19.2 & 18.9 & 18.6 \\
\hline & 90 & 21.3 & 21.0 & 20.7 & 20.4 & 20.1 & 19.7 & 19.4 & 19.1 & 18.8 & 18.5 & 18.2 & 17.9 & 17.6 \\
\hline & 85 & 20.6 & 20.3 & 20.0 & 19.7 & 19.4 & 19.1 & 18.8 & 18.5 & 18.2 & 17.9 & 17.6 & 17.3 & 17.0 \\
\hline & 80 & 20.1 & 19.8 & 19.5 & 19.2 & 18.9 & 18.6 & 18.3 & 18.0 & 17.7 & 17.4 & 17.1 & 16.8 & 16.5 \\
\hline & 70 & 19.3 & 19.0 & 18.7 & 18.4 & 18.1 & 17.8 & 17.5 & 17.1 & 16.8 & 16.5 & 16.2 & 15.9 & 15.6 \\
\hline & 60 & 18.6 & 18.3 & 18.0 & 17.7 & 17.4 & 17.0 & 16.7 & 16.4 & 16.1 & 15.8 & 15.5 & 15.2 & 14.9 \\
\hline & 50 & 17.9 & 17.6 & 17.3 & 17.0 & 16.7 & 16.4 & 16.1 & 15.8 & 15.5 & 15.2 & 14.9 & 14.6 & 14.3 \\
\hline & 40 & 17.3 & 17.0 & 16.7 & 16.3 & 16.0 & 15.7 & 15.4 & 15.1 & 14.8 & 14.5 & 14.2 & 13.9 & 13.6 \\
\hline & 30 & 16.6 & 16.2 & 15.9 & 15.6 & 15.3 & 15.0 & 14.7 & 14.4 & 14.1 & 13.8 & 13.5 & 13.2 & 12.9 \\
\hline & 20 & 15.7 & 15.4 & 15.1 & 14.8 & 14.5 & 14.2 & 13.9 & 13.6 & 13.3 & 13.0 & 12.7 & 12.4 & 12.1 \\
\hline & 15 & 15.2 & 14.9 & 14.6 & 14.3 & 14.0 & 13.7 & 13.4 & 13.1 & 12.7 & 12.4 & 12.1 & 11.8 & 11.5 \\
\hline & 10 & 14.6 & 14.3 & 13.9 & 13.6 & 13.3 & 13.0 & 12.7 & 12.4 & 12.1 & 11.8 & 11.5 & 11.2 & 10.9 \\
\hline & 5 & 13.6 & 13.3 & 13.0 & 12.7 & 12.4 & 12.1 & 11.8 & 11.5 & 11.2 & 10.9 & 10.6 & 10.3 & 10.0 \\
\hline \multirow{13}{*}{ 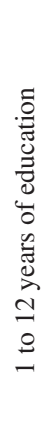 } & 95 & 17.6 & 17.3 & 17.0 & 16.7 & 16.4 & 16.1 & 15.8 & 15.5 & 15.2 & 14.9 & 14.6 & 14.3 & 14.0 \\
\hline & 90 & 16.7 & 16.4 & 16.1 & 15.8 & 15.5 & 15.2 & 14.9 & 14.6 & 14.2 & 13.9 & 13.6 & 13.3 & 13.0 \\
\hline & 85 & 16.1 & 15.8 & 15.4 & 15.1 & 14.8 & 14.5 & 14.2 & 13.9 & 13.6 & 13.3 & 13.0 & 12.7 & 12.4 \\
\hline & 80 & 15.5 & 15.2 & 14.9 & 14.6 & 14.3 & 14.0 & 13.7 & 13.4 & 13.1 & 12.8 & 12.5 & 12.2 & 11.9 \\
\hline & 70 & 14.7 & 14.4 & 14.1 & 13.8 & 13.5 & 13.2 & 12.9 & 12.6 & 12.3 & 11.9 & 11.6 & 11.3 & 11.0 \\
\hline & 60 & 14.0 & 13.7 & 13.4 & 13.1 & 12.8 & 12.5 & 12.2 & 11.8 & 11.5 & 11.2 & 10.9 & 10.6 & 10.3 \\
\hline & 50 & 13.3 & 13.0 & 12.7 & 12.4 & 12.1 & 11.8 & 11.5 & 11.2 & 10.9 & 10.6 & 10.3 & 10.0 & 9.7 \\
\hline & 40 & 12.7 & 12.4 & 12.1 & 11.8 & 11.5 & 11.1 & 10.8 & 10.5 & 10.2 & 9.9 & 9.6 & 9.3 & 9.0 \\
\hline & 30 & 12.0 & 11.7 & 11.4 & 11.0 & 10.7 & 10.4 & 10.1 & 9.8 & 9.5 & 9.2 & 8.9 & 8.6 & 8.3 \\
\hline & 20 & 11.1 & 10.8 & 10.5 & 10.2 & 9.9 & 9.6 & 9.3 & 9.0 & 8.7 & 8.4 & 8.1 & 7.8 & 7.5 \\
\hline & 15 & 10.6 & 10.3 & 10.0 & 9.7 & 9.4 & 9.1 & 8.8 & 8.5 & 8.2 & 7.9 & 7.6 & 7.2 & 6.9 \\
\hline & 10 & 10.0 & 9.7 & 9.4 & 9.1 & 8.8 & 8.4 & 8.1 & 7.8 & 7.5 & 7.2 & 6.9 & 6.6 & 6.3 \\
\hline & 5 & 9.0 & 8.7 & 8.4 & 8.1 & 7.8 & 7.5 & 7.2 & 6.9 & 6.6 & 6.3 & 6.0 & 5.7 & 5.4 \\
\hline
\end{tabular}


Table A43

Normative data for the Animals category stratified by age and education levels for PERU

\begin{tabular}{|c|c|c|c|c|c|c|c|c|c|c|c|c|c|c|}
\hline & \multirow[b]{2}{*}{ Percentile } & \multicolumn{13}{|c|}{ Age (Years) } \\
\hline & & $18-22$ & $23-27$ & $28-32$ & $33-37$ & $38-42$ & $43-47$ & $48-52$ & $53-57$ & $58-62$ & $63-67$ & $68-72$ & $73-77$ & $>77$ \\
\hline \multirow{13}{*}{ 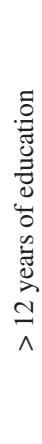 } & 95 & 29.5 & 29.2 & 28.8 & 28.5 & 28.1 & 27.7 & 27.4 & 27.0 & 26.7 & 26.3 & 26.0 & 25.6 & 25.3 \\
\hline & 90 & 27.9 & 27.5 & 27.2 & 26.8 & 26.5 & 26.1 & 25.7 & 25.4 & 25.0 & 24.7 & 24.3 & 24.0 & 23.6 \\
\hline & 85 & 26.8 & 26.4 & 26.1 & 25.7 & 25.4 & 25.0 & 24.6 & 24.3 & 23.9 & 23.6 & 23.2 & 22.9 & 22.5 \\
\hline & 80 & 25.9 & 25.5 & 25.1 & 24.8 & 24.4 & 24.1 & 23.7 & 23.4 & 23.0 & 22.7 & 22.3 & 22.0 & 21.6 \\
\hline & 70 & 24.4 & 24.0 & 23.7 & 23.3 & 23.0 & 22.6 & 22.3 & 21.9 & 21.6 & 21.2 & 20.8 & 20.5 & 20.1 \\
\hline & 60 & 23.2 & 22.8 & 22.4 & 22.1 & 21.7 & 21.4 & 21.0 & 20.7 & 20.3 & 20.0 & 19.6 & 19.3 & 18.9 \\
\hline & 50 & 22.0 & 21.7 & 21.3 & 20.9 & 20.6 & 20.2 & 19.9 & 19.5 & 19.2 & 18.8 & 18.5 & 18.1 & 17.8 \\
\hline & 40 & 20.9 & 20.5 & 20.2 & 19.8 & 19.4 & 19.1 & 18.7 & 18.4 & 18.0 & 17.7 & 17.3 & 17.0 & 16.6 \\
\hline & 30 & 19.6 & 19.3 & 18.9 & 18.6 & 18.2 & 17.9 & 17.5 & 17.1 & 16.8 & 16.4 & 16.1 & 15.7 & 15.4 \\
\hline & 20 & 18.2 & 17.8 & 17.5 & 17.1 & 16.7 & 16.4 & 16.0 & 15.7 & 15.3 & 15.0 & 14.6 & 14.3 & 13.9 \\
\hline & 15 & 17.2 & 16.9 & 16.5 & 16.2 & 15.8 & 15.5 & 15.1 & 14.8 & 14.4 & 14.1 & 13.7 & 13.4 & 13.0 \\
\hline & 10 & 16.1 & 15.8 & 15.4 & 15.1 & 14.7 & 14.4 & 14.0 & 13.7 & 13.3 & 13.0 & 12.6 & 12.3 & 11.9 \\
\hline & 5 & 14.5 & 14.1 & 13.8 & 13.4 & 13.1 & 12.7 & 12.4 & 12.0 & 11.7 & 11.3 & 11.0 & 10.6 & 10.2 \\
\hline \multirow{13}{*}{ 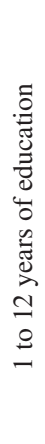 } & 95 & 25.8 & 25.5 & 25.1 & 24.8 & 24.4 & 24.1 & 23.7 & 23.4 & 23.0 & 22.6 & 22.3 & 21.9 & 21.6 \\
\hline & 90 & 24.2 & 23.8 & 23.5 & 23.1 & 22.8 & 22.4 & 22.1 & 21.7 & 21.4 & 21.0 & 20.6 & 20.3 & 19.9 \\
\hline & 85 & 23.1 & 22.7 & 22.4 & 22.0 & 21.7 & 21.3 & 21.0 & 20.6 & 20.3 & 19.9 & 19.5 & 19.2 & 18.8 \\
\hline & 80 & 22.2 & 21.8 & 21.5 & 21.1 & 20.8 & 20.4 & 20.0 & 19.7 & 19.3 & 19.0 & 18.6 & 18.3 & 17.9 \\
\hline & 70 & 20.7 & 20.4 & 20.0 & 19.6 & 19.3 & 18.9 & 18.6 & 18.2 & 17.9 & 17.5 & 17.2 & 16.8 & 16.5 \\
\hline & 60 & 19.5 & 19.1 & 18.8 & 18.4 & 18.1 & 17.7 & 17.3 & 17.0 & 16.6 & 16.3 & 15.9 & 15.6 & 15.2 \\
\hline & 50 & 18.3 & 18.0 & 17.6 & 17.3 & 16.9 & 16.6 & 16.2 & 15.8 & 15.5 & 15.1 & 14.8 & 14.4 & 14.1 \\
\hline & 40 & 17.2 & 16.8 & 16.5 & 16.1 & 15.8 & 15.4 & 15.1 & 14.7 & 14.3 & 14.0 & 13.6 & 13.3 & 12.9 \\
\hline & 30 & 15.9 & 15.6 & 15.2 & 14.9 & 14.5 & 14.2 & 13.8 & 13.5 & 13.1 & 12.8 & 12.4 & 12.0 & 11.7 \\
\hline & 20 & 14.5 & 14.1 & 13.8 & 13.4 & 13.1 & 12.7 & 12.4 & 12.0 & 11.6 & 11.3 & 10.9 & 10.6 & 10.2 \\
\hline & 15 & 13.6 & 13.2 & 12.9 & 12.5 & 12.1 & 11.8 & 11.4 & 11.1 & 10.7 & 10.4 & 10.0 & 9.7 & 9.3 \\
\hline & 10 & 12.5 & 12.1 & 11.8 & 11.4 & 11.0 & 10.7 & 10.3 & 10.0 & 9.6 & 9.3 & 8.9 & 8.6 & 8.2 \\
\hline & 5 & 10.8 & 10.5 & 10.1 & 9.8 & 9.4 & 9.0 & 8.7 & 8.3 & 8.0 & 7.6 & 7.3 & 6.9 & 6.6 \\
\hline
\end{tabular}


Table A44

Normative data for the Animals category stratified by age and education levels for PUERTO RICO

\begin{tabular}{|c|c|c|c|c|c|c|c|c|c|c|c|c|c|c|}
\hline & \multirow[b]{2}{*}{ Percentile } & \multicolumn{13}{|c|}{ Age (Years) } \\
\hline & & $18-22$ & $23-27$ & $28-32$ & $33-37$ & $38-42$ & $43-47$ & $48-52$ & $53-57$ & $58-62$ & $63-67$ & $68-72$ & $73-77$ & $>77$ \\
\hline \multirow{13}{*}{ 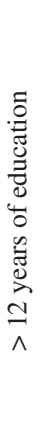 } & 95 & 27.9 & 27.3 & 26.7 & 26.1 & 25.5 & 24.9 & 24.3 & 23.6 & 23.0 & 22.4 & 21.8 & 21.2 & 20.6 \\
\hline & 90 & 26.3 & 25.7 & 25.0 & 24.4 & 23.8 & 23.2 & 22.6 & 22.0 & 21.4 & 20.8 & 20.2 & 19.6 & 19.0 \\
\hline & 85 & 25.2 & 24.6 & 23.9 & 23.3 & 22.7 & 22.1 & 21.5 & 20.9 & 20.3 & 19.7 & 19.1 & 18.5 & 17.9 \\
\hline & 80 & 24.3 & 23.6 & 23.0 & 22.4 & 21.8 & 21.2 & 20.6 & 20.0 & 19.4 & 18.8 & 18.2 & 17.6 & 17.0 \\
\hline & 70 & 22.8 & 22.2 & 21.6 & 21.0 & 20.4 & 19.7 & 19.1 & 18.5 & 17.9 & 17.3 & 16.7 & 16.1 & 15.5 \\
\hline & 60 & 21.6 & 20.9 & 20.3 & 19.7 & 19.1 & 18.5 & 17.9 & 17.3 & 16.7 & 16.1 & 15.5 & 14.9 & 14.3 \\
\hline & 50 & 20.4 & 19.8 & 19.2 & 18.6 & 18.0 & 17.4 & 16.8 & 16.2 & 15.5 & 14.9 & 14.3 & 13.7 & 13.1 \\
\hline & 40 & 19.3 & 18.7 & 18.1 & 17.4 & 16.8 & 16.2 & 15.6 & 15.0 & 14.4 & 13.8 & 13.2 & 12.6 & 12.0 \\
\hline & 30 & 18.0 & 17.4 & 16.8 & 16.2 & 15.6 & 15.0 & 14.4 & 13.8 & 13.2 & 12.6 & 12.0 & 11.3 & 10.7 \\
\hline & 20 & 16.6 & 16.0 & 15.4 & 14.7 & 14.1 & 13.5 & 12.9 & 12.3 & 11.7 & 11.1 & 10.5 & 9.9 & 9.3 \\
\hline & 15 & 15.7 & 15.0 & 14.4 & 13.8 & 13.2 & 12.6 & 12.0 & 11.4 & 10.8 & 10.2 & 9.6 & 9.0 & 8.4 \\
\hline & 10 & 14.6 & 14.0 & 13.3 & 12.7 & 12.1 & 11.5 & 10.9 & 10.3 & 9.7 & 9.1 & 8.5 & 7.9 & 7.3 \\
\hline & 5 & 12.9 & 12.3 & 11.7 & 11.1 & 10.5 & 9.9 & 9.3 & 8.7 & 8.0 & 7.4 & 6.8 & 6.2 & 5.6 \\
\hline \multirow{13}{*}{ 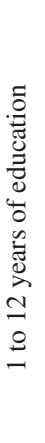 } & 95 & 26.7 & 26.1 & 25.5 & 24.9 & 24.3 & 23.7 & 23.1 & 22.5 & 21.8 & 21.2 & 20.6 & 20.0 & 19.4 \\
\hline & 90 & 25.1 & 24.5 & 23.9 & 23.2 & 22.6 & 22.0 & 21.4 & 20.8 & 20.2 & 19.6 & 19.0 & 18.4 & 17.8 \\
\hline & 85 & 24.0 & 23.4 & 22.8 & 22.1 & 21.5 & 20.9 & 20.3 & 19.7 & 19.1 & 18.5 & 17.9 & 17.3 & 16.7 \\
\hline & 80 & 23.1 & 22.4 & 21.8 & 21.2 & 20.6 & 20.0 & 19.4 & 18.8 & 18.2 & 17.6 & 17.0 & 16.4 & 15.8 \\
\hline & 70 & 21.6 & 21.0 & 20.4 & 19.8 & 19.2 & 18.6 & 17.9 & 17.3 & 16.7 & 16.1 & 15.5 & 14.9 & 14.3 \\
\hline & 60 & 20.4 & 19.8 & 19.1 & 18.5 & 17.9 & 17.3 & 16.7 & 16.1 & 15.5 & 14.9 & 14.3 & 13.7 & 13.1 \\
\hline & 50 & 19.2 & 18.6 & 18.0 & 17.4 & 16.8 & 16.2 & 15.6 & 15.0 & 14.3 & 13.7 & 13.1 & 12.5 & 11.9 \\
\hline & 40 & 18.1 & 17.5 & 16.9 & 16.2 & 15.6 & 15.0 & 14.4 & 13.8 & 13.2 & 12.6 & 12.0 & 11.4 & 10.8 \\
\hline & 30 & 16.8 & 16.2 & 15.6 & 15.0 & 14.4 & 13.8 & 13.2 & 12.6 & 12.0 & 11.4 & 10.8 & 10.1 & 9.5 \\
\hline & 20 & 15.4 & 14.8 & 14.2 & 13.6 & 12.9 & 12.3 & 11.7 & 11.1 & 10.5 & 9.9 & 9.3 & 8.7 & 8.1 \\
\hline & 15 & 14.5 & 13.9 & 13.2 & 12.6 & 12.0 & 11.4 & 10.8 & 10.2 & 9.6 & 9.0 & 8.4 & 7.8 & 7.2 \\
\hline & 10 & 13.4 & 12.8 & 12.1 & 11.5 & 10.9 & 10.3 & 9.7 & 9.1 & 8.5 & 7.9 & 7.3 & 6.7 & 6.1 \\
\hline & 5 & 11.7 & 11.1 & 10.5 & 9.9 & 9.3 & 8.7 & 8.1 & 7.5 & 6.9 & 6.2 & 5.6 & 5.0 & 4.4 \\
\hline
\end{tabular}

